\title{
Allenes and Transition Metals: A Diverging Approach to Heterocycles
}

\author{
Kay M. Brummond and Branko Mitasev \\ Department of Chemistry, University of Pittsburgh, Pittsburgh, PA 15260
}

Supporting Information

\section{Part 2}

${ }^{1} \mathrm{H}$ NMR and ${ }^{13} \mathrm{C}$ NMR spectral data for all compounds............page s47 
门㠃

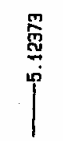

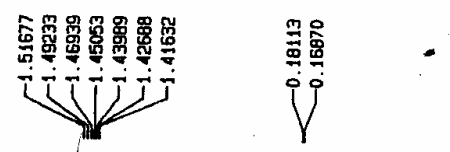<smiles></smiles>
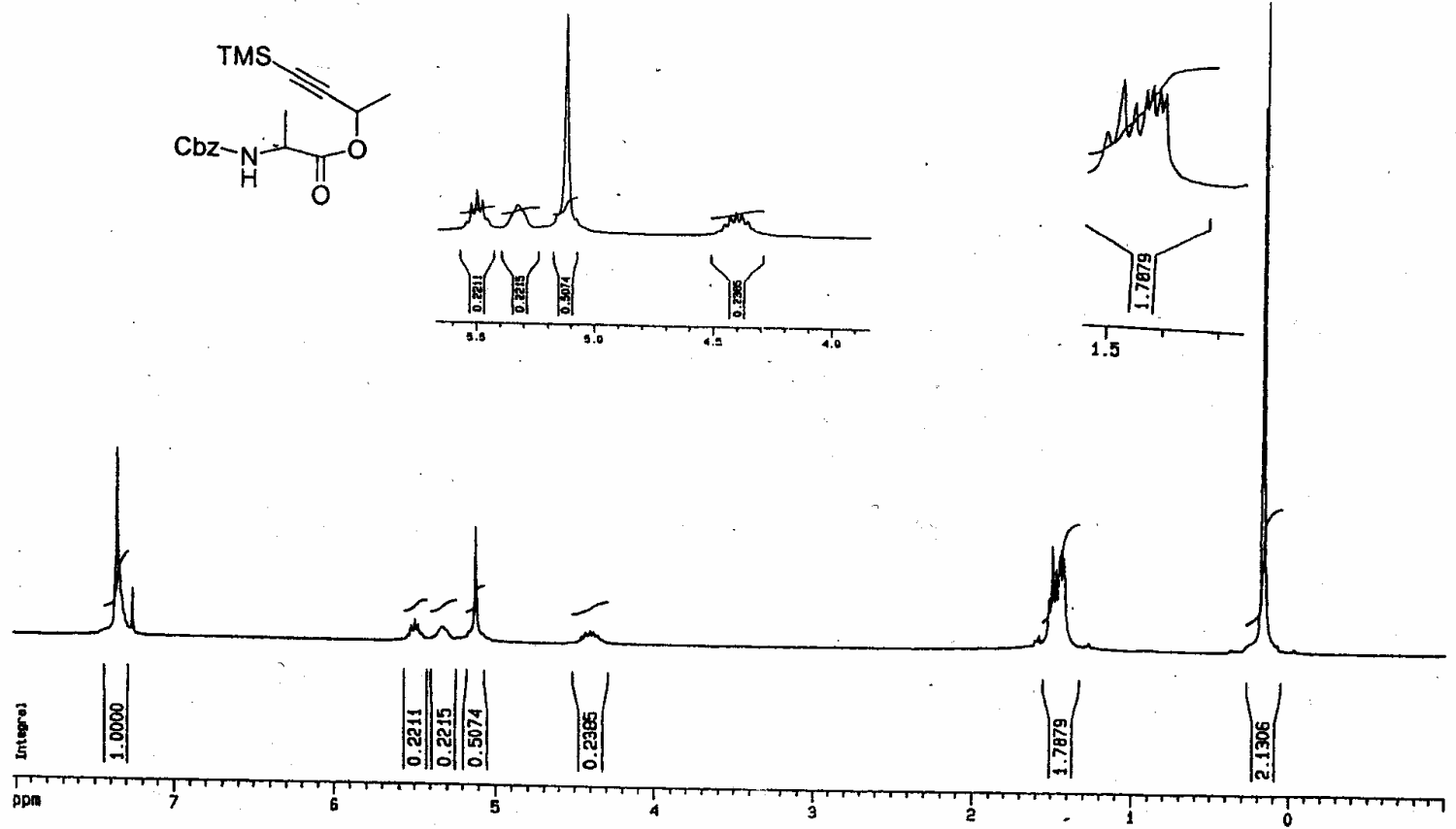

통

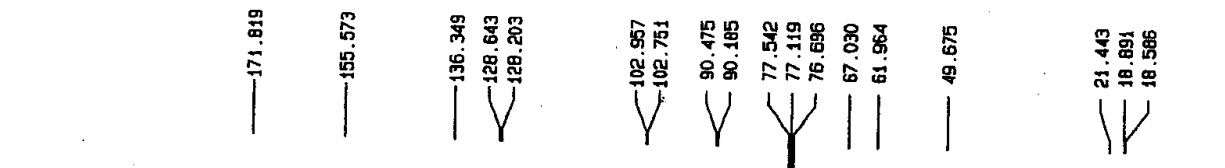<smiles>CC(C#CS(C)(=O)=O)NC(C)C(=O)OC(C)C(=O)OCc1ccccc1</smiles>

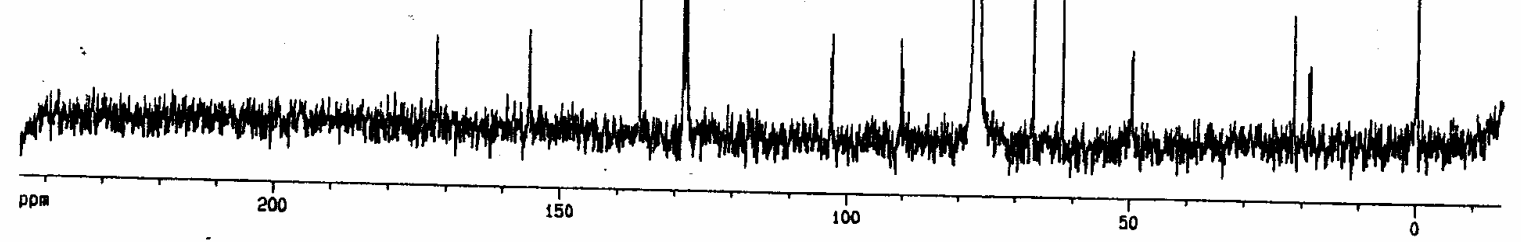




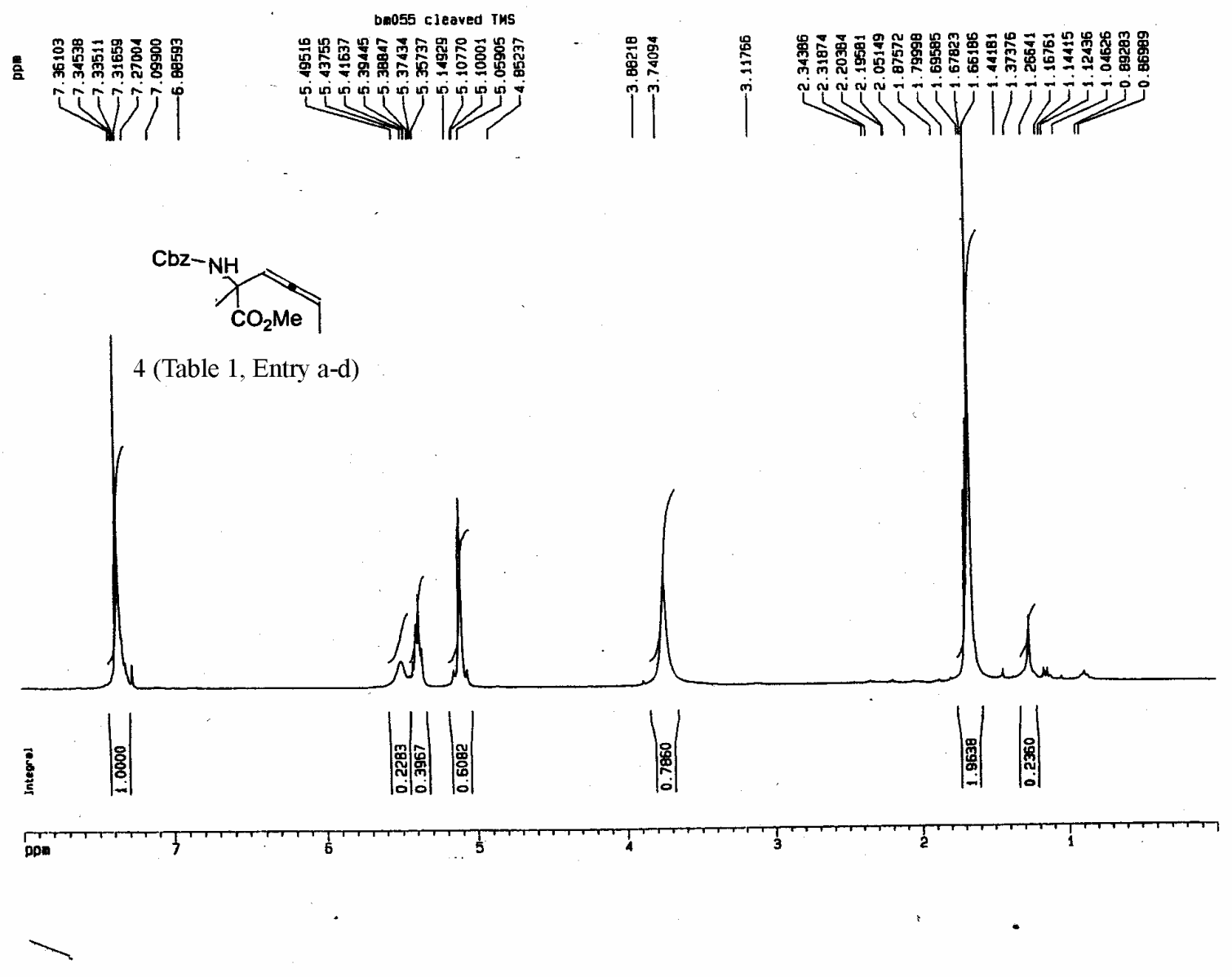

a

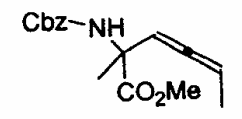



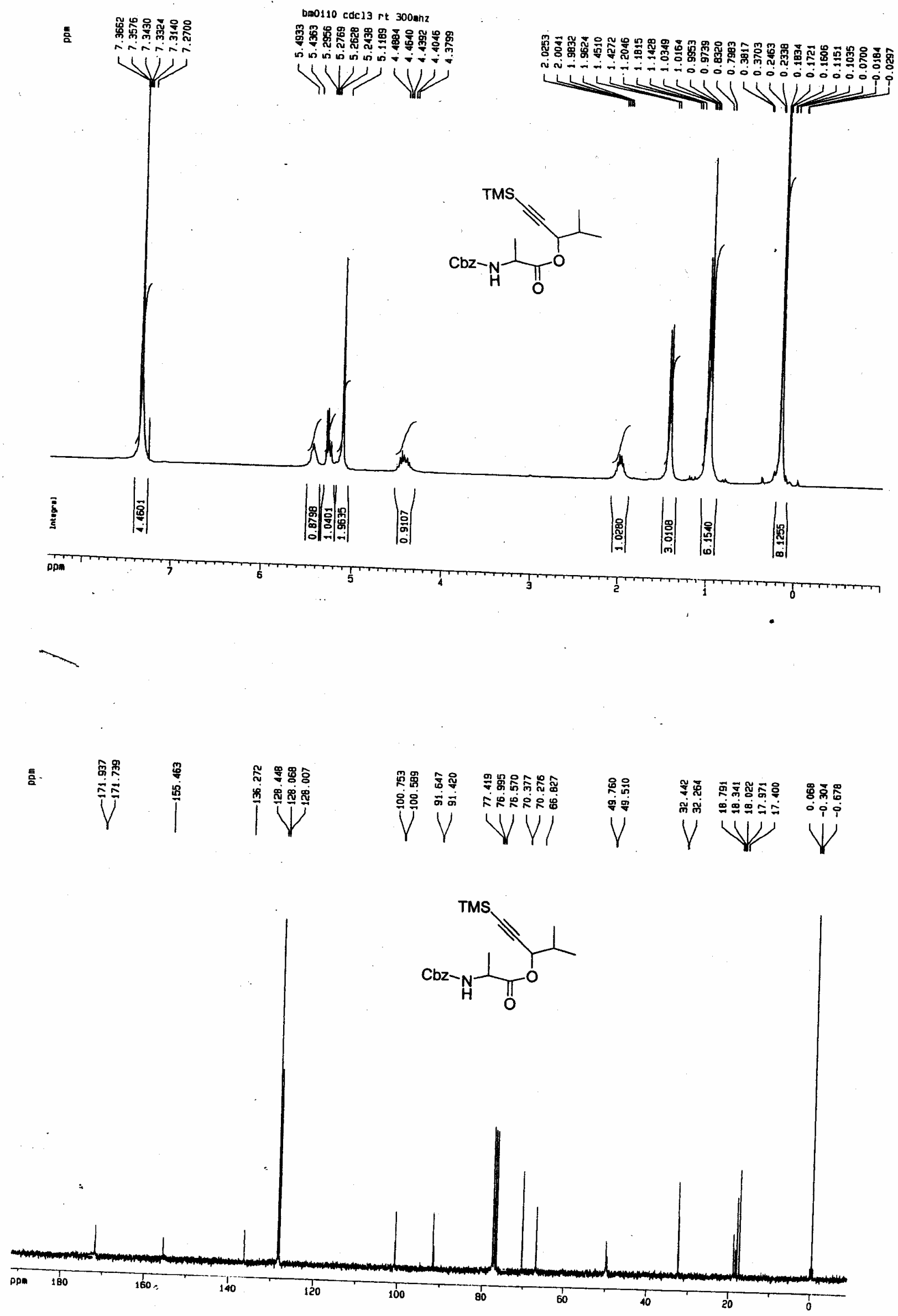


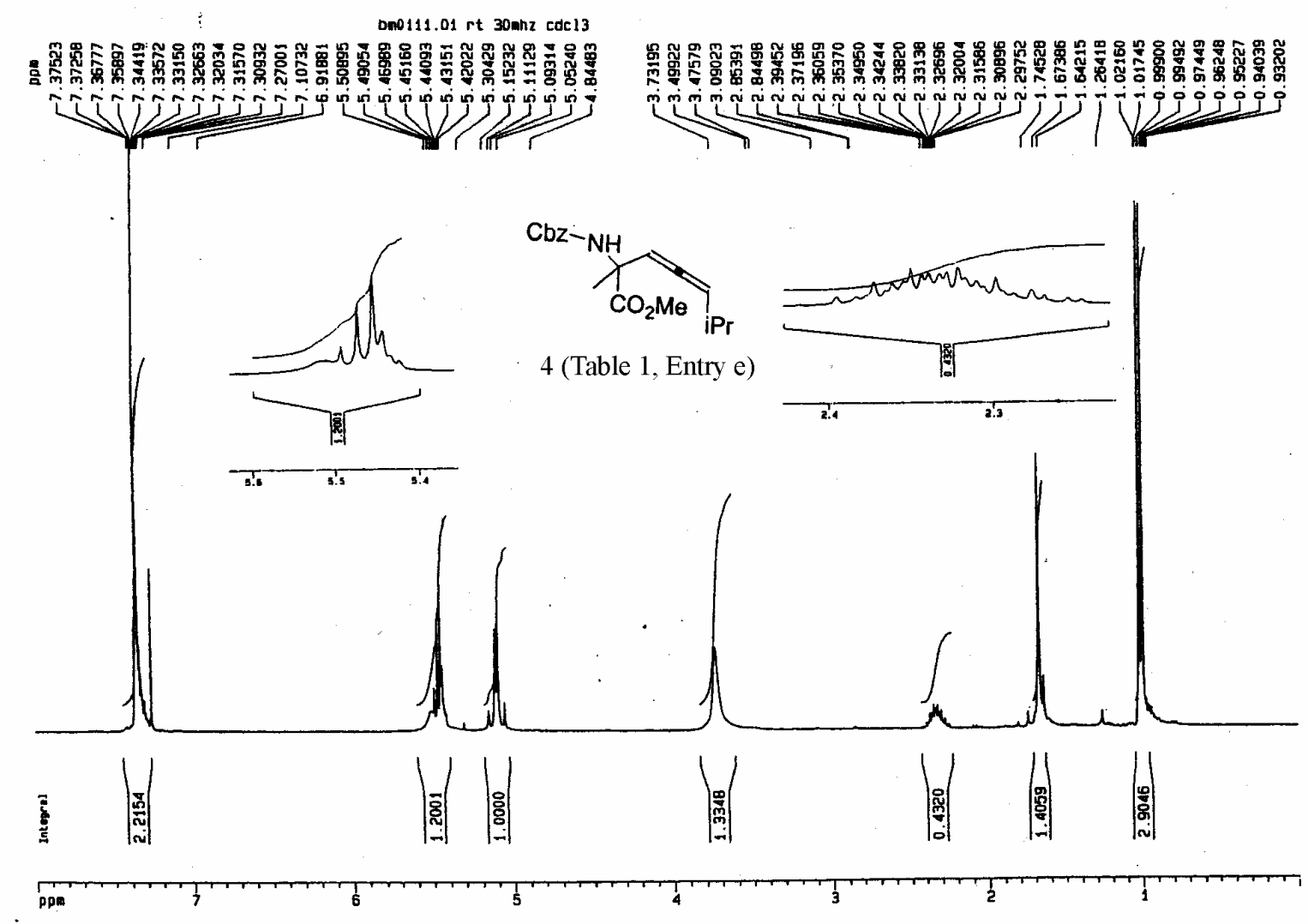

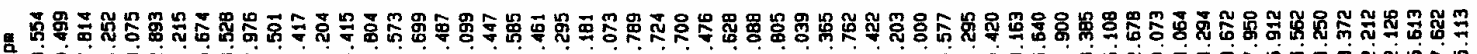

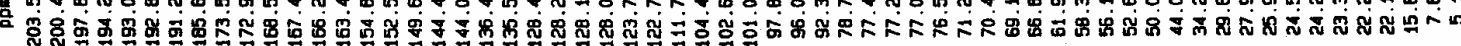

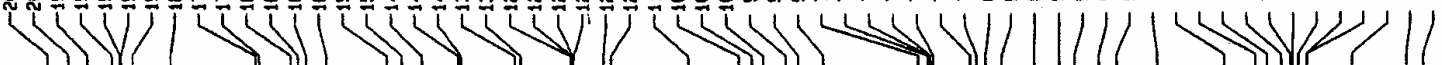
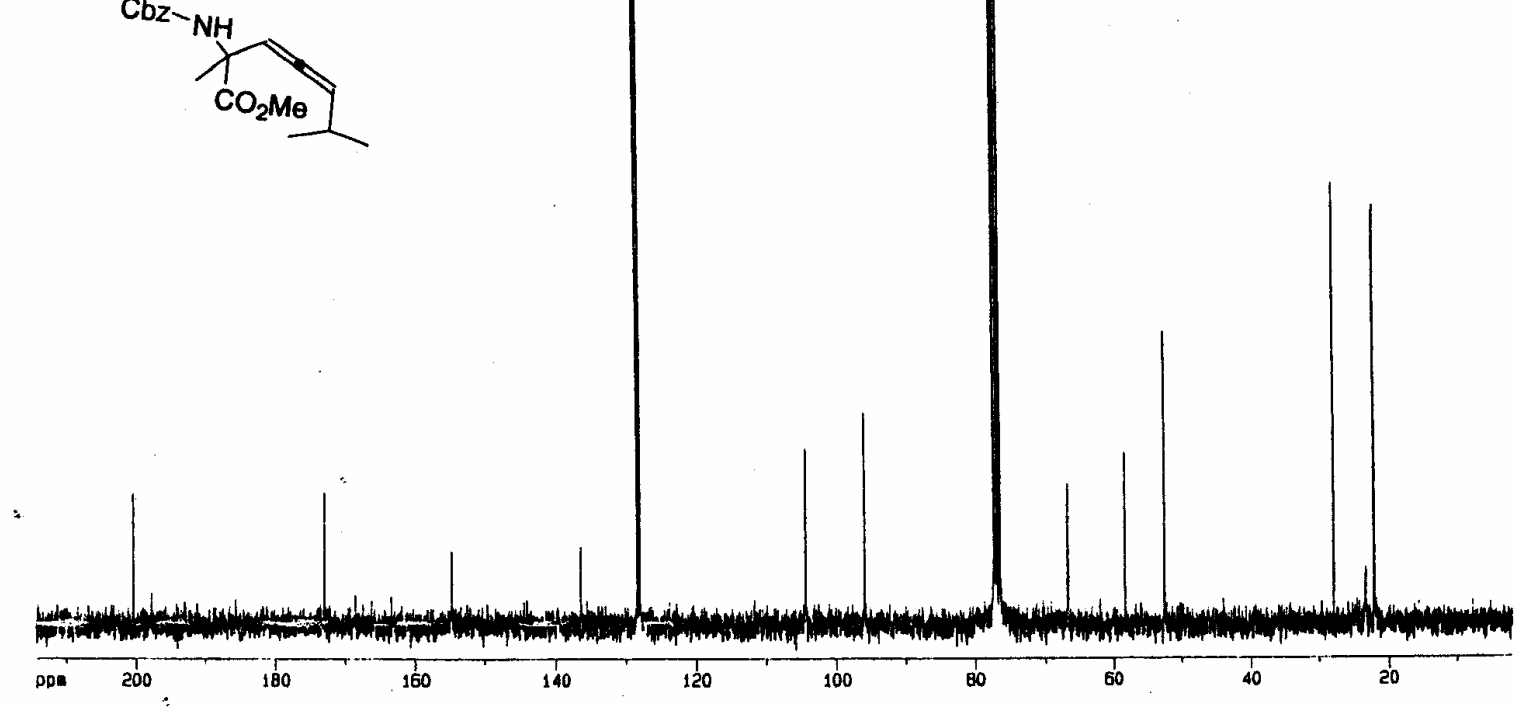
Da0601.01 [01.06] cdc13 rt 300 MH/2
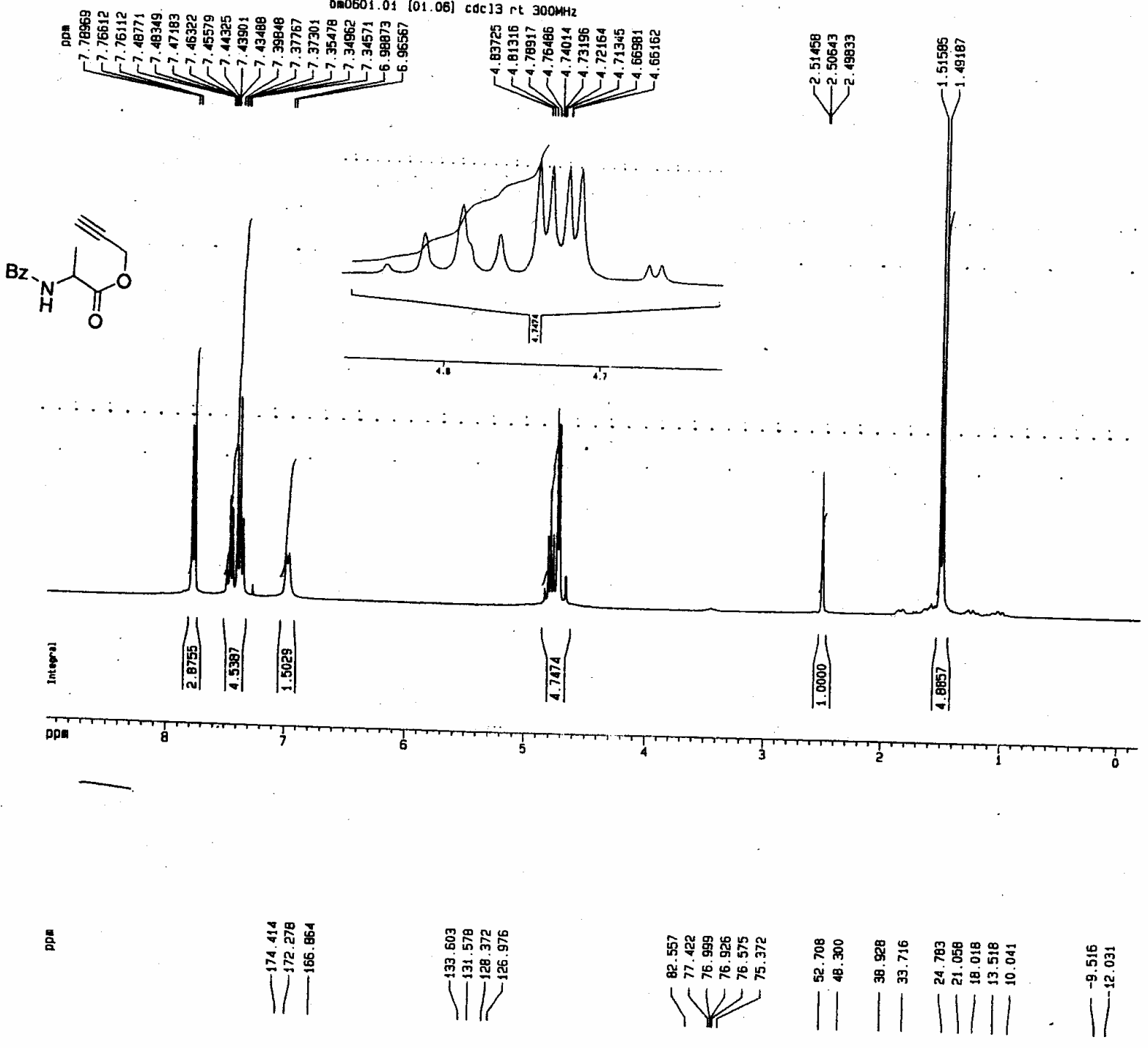<smiles>C#CCOC(=O)C(C)NC(=O)c1ccccc1</smiles>

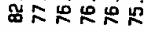

$1 W$

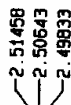

ن 

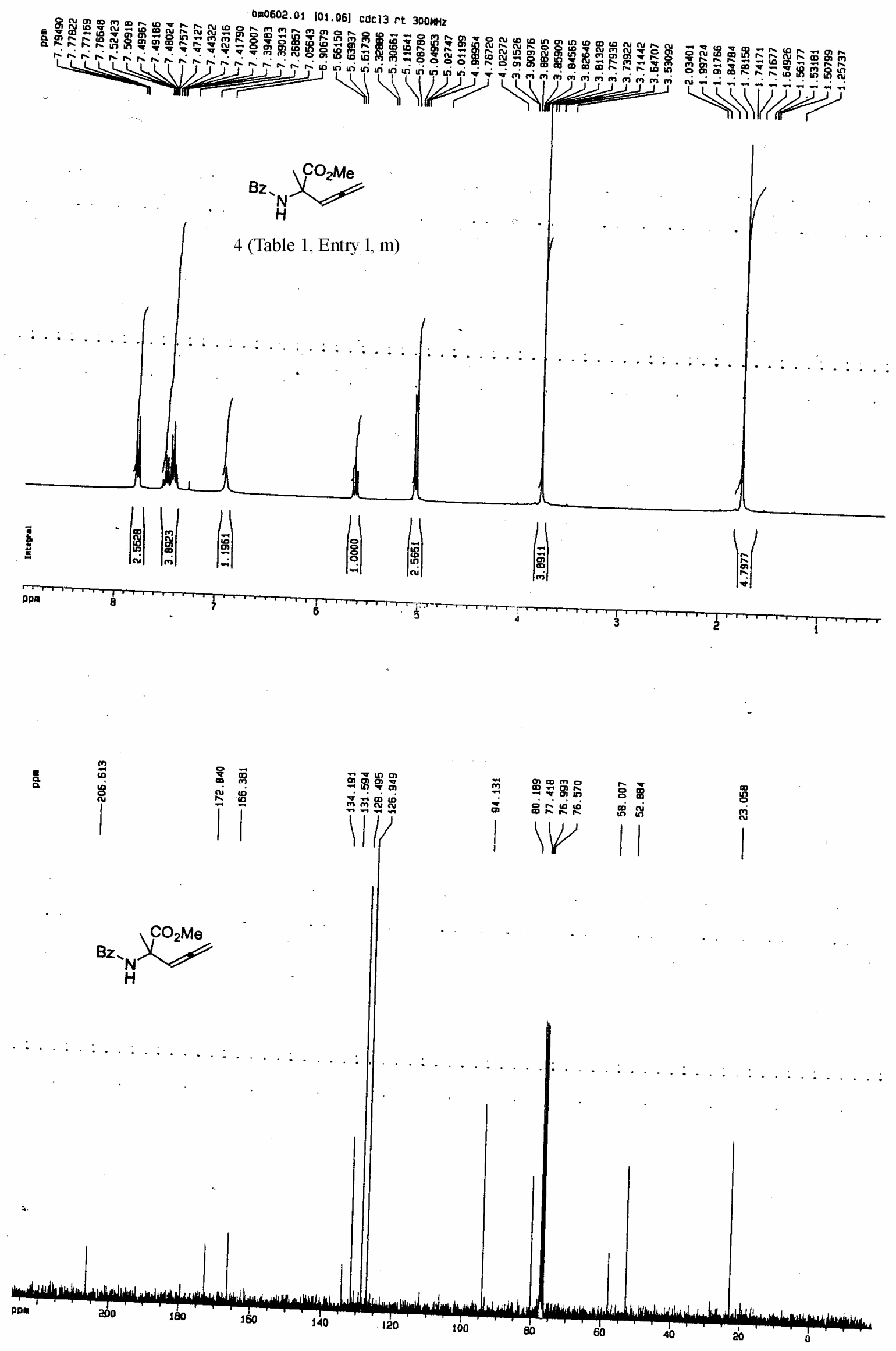

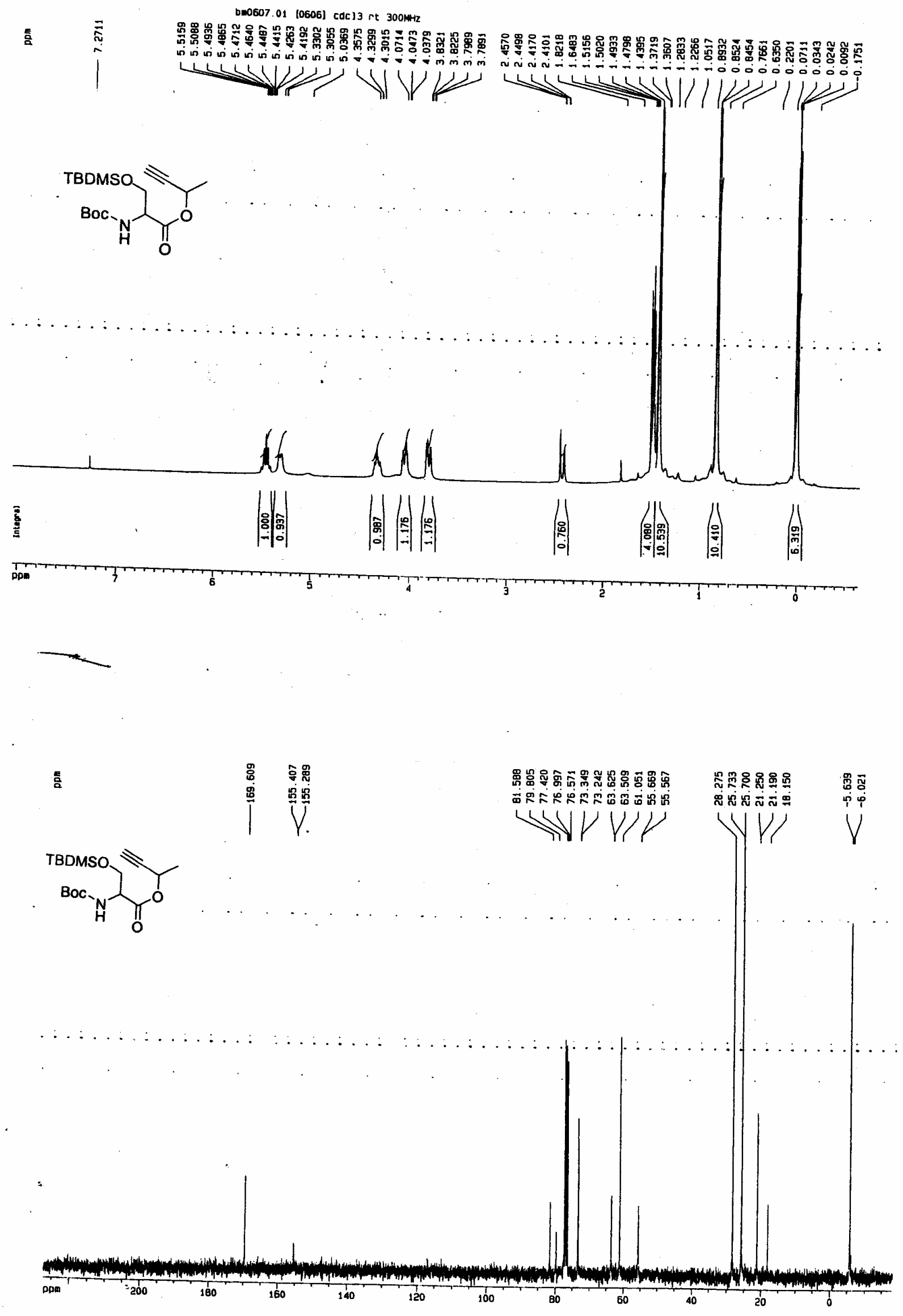
bm0531.01 [26/0g] codc13 rt 300MHZ
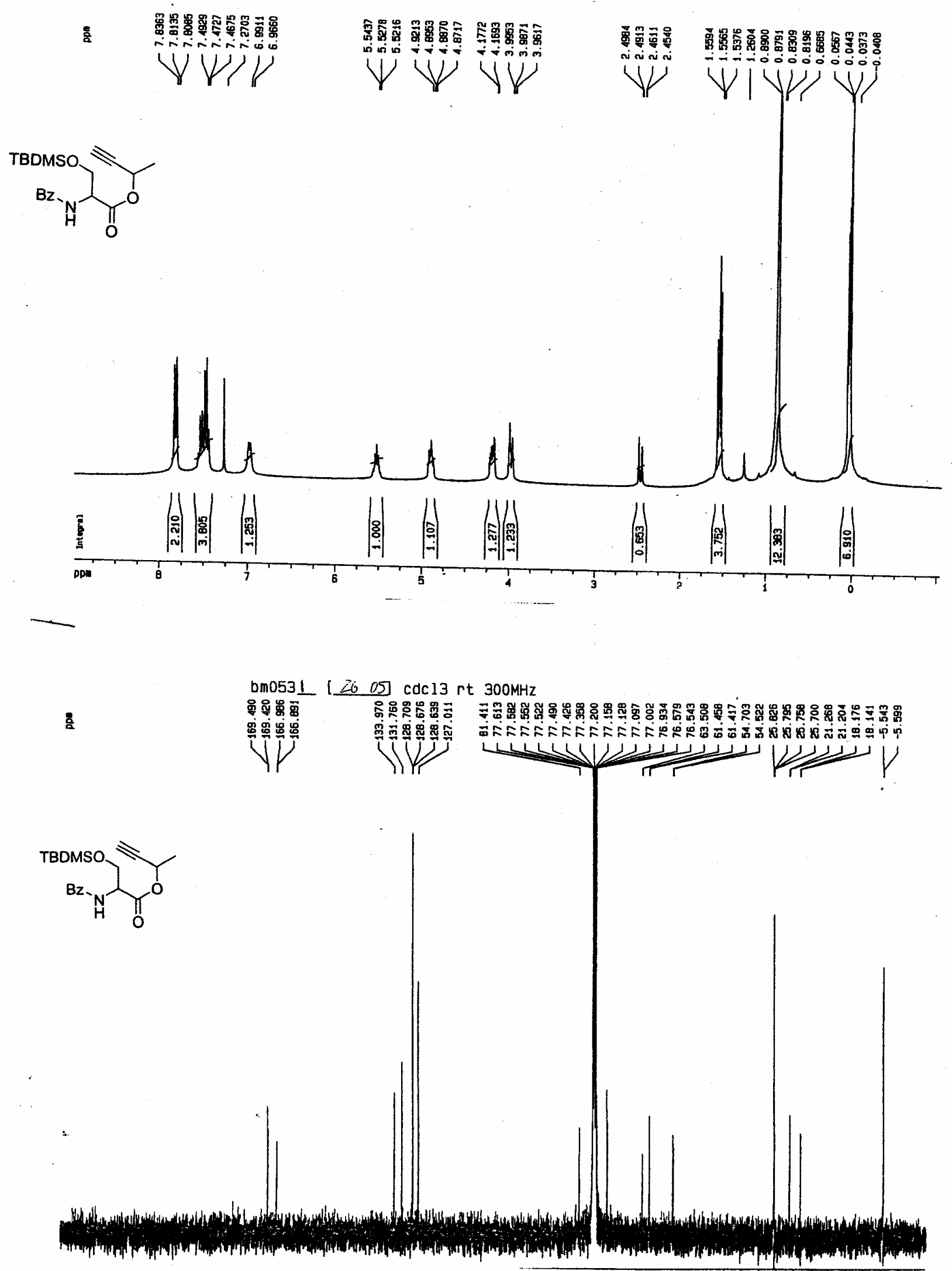
bm0532.01 127 a J cdc13 rt $300 \mathrm{MHz}$

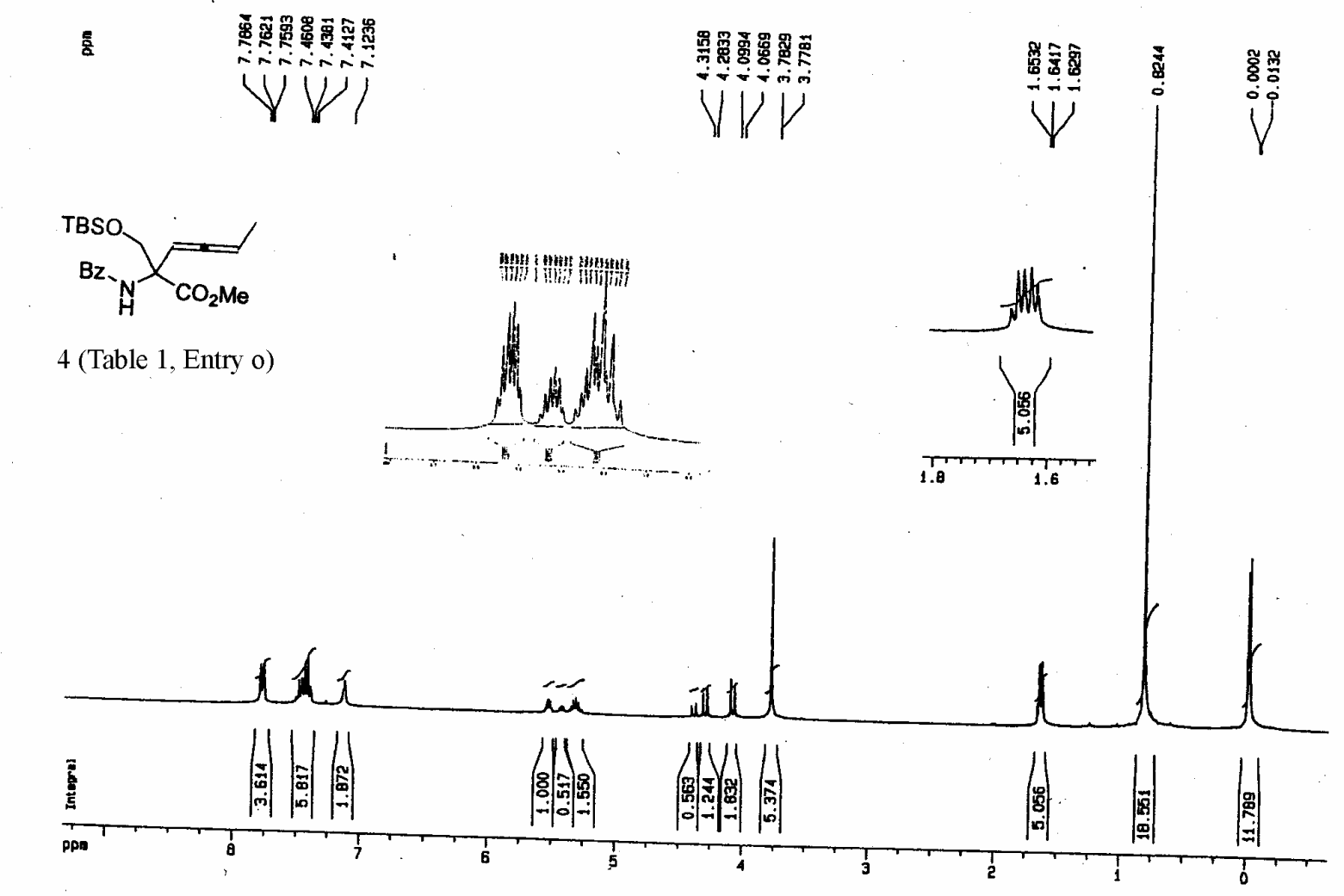

言<smiles>CC=C=CC(COC(C)(C)C)(NC(=O)c1ccccc1)C(=O)OC</smiles>

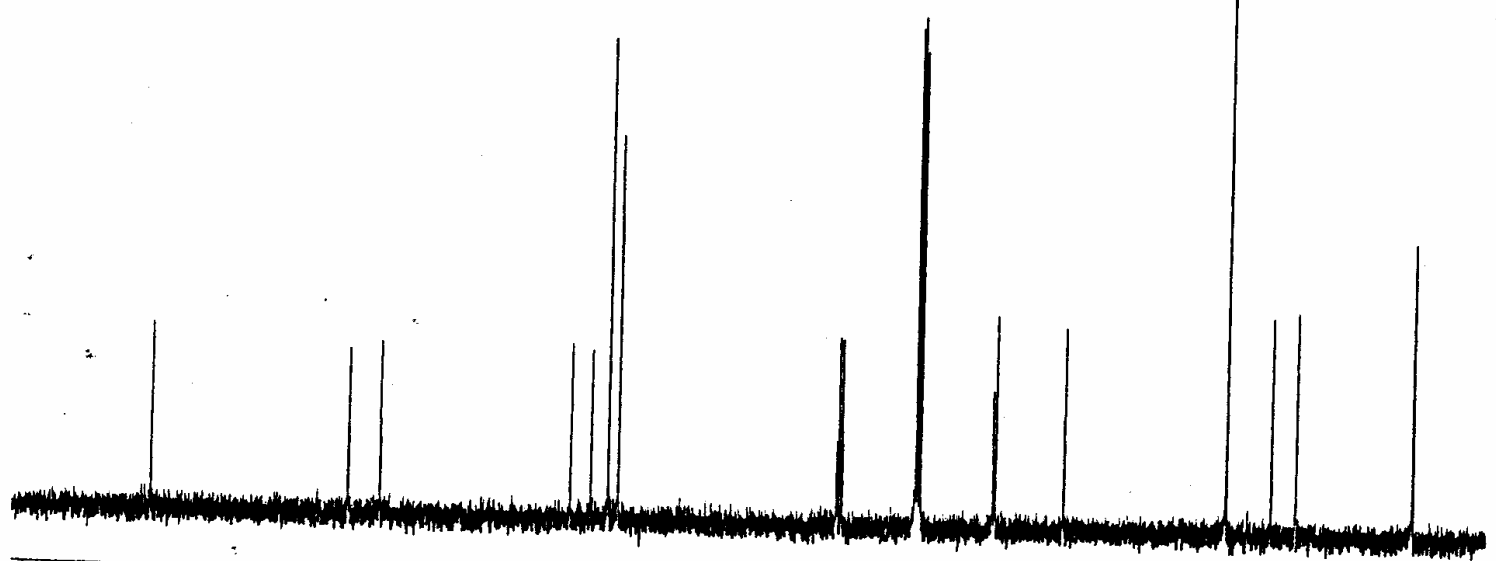



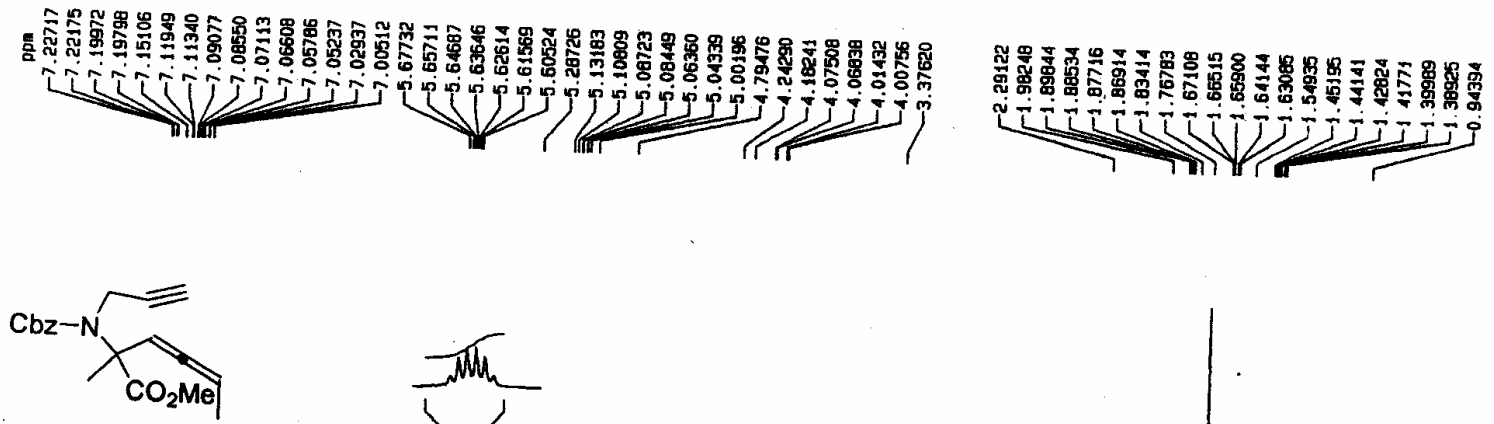

(6, Table 1, Entry a)
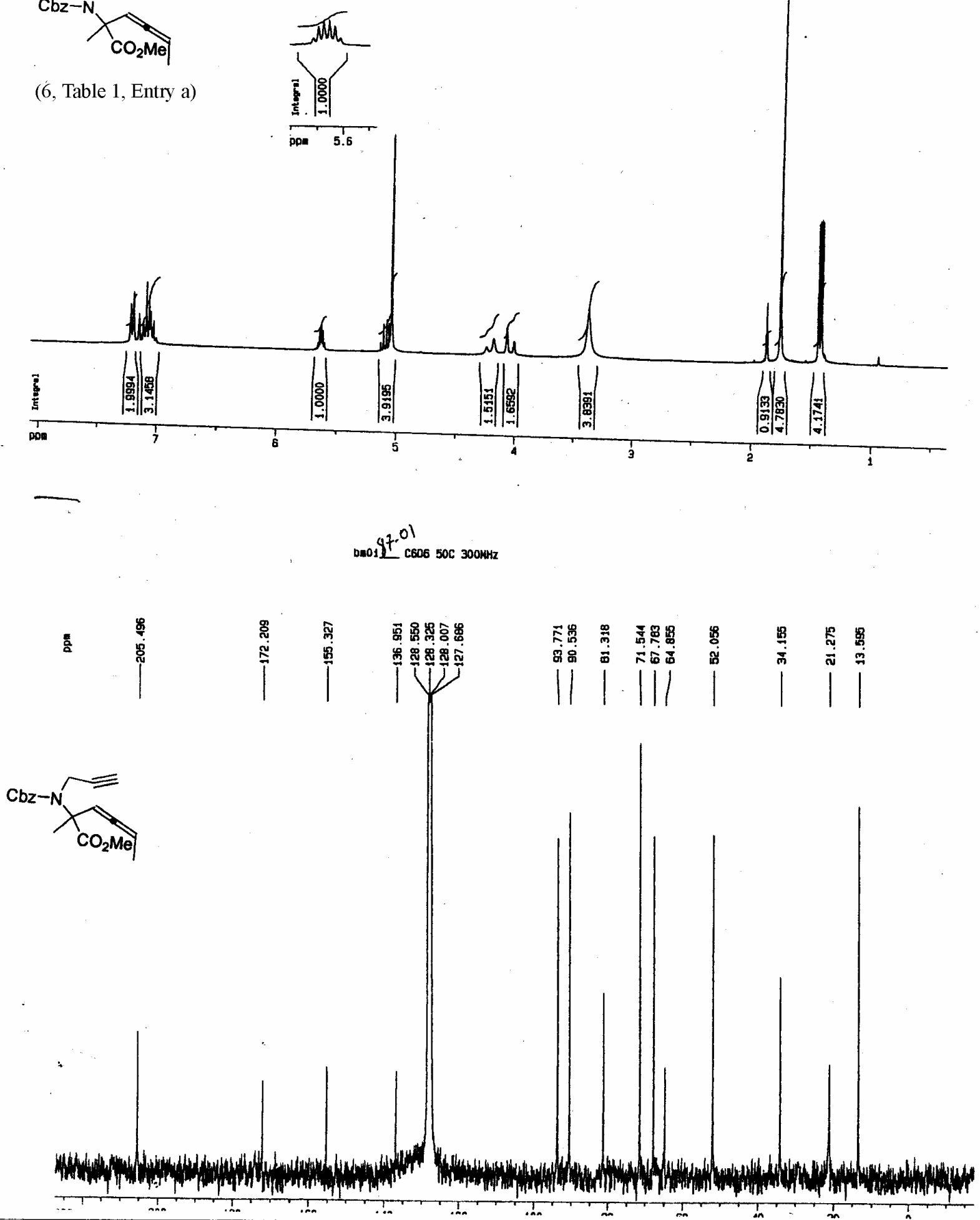

:

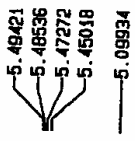
บำ


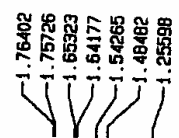

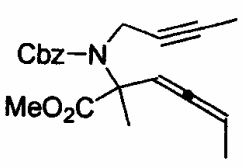

6, Table 1, Entry b
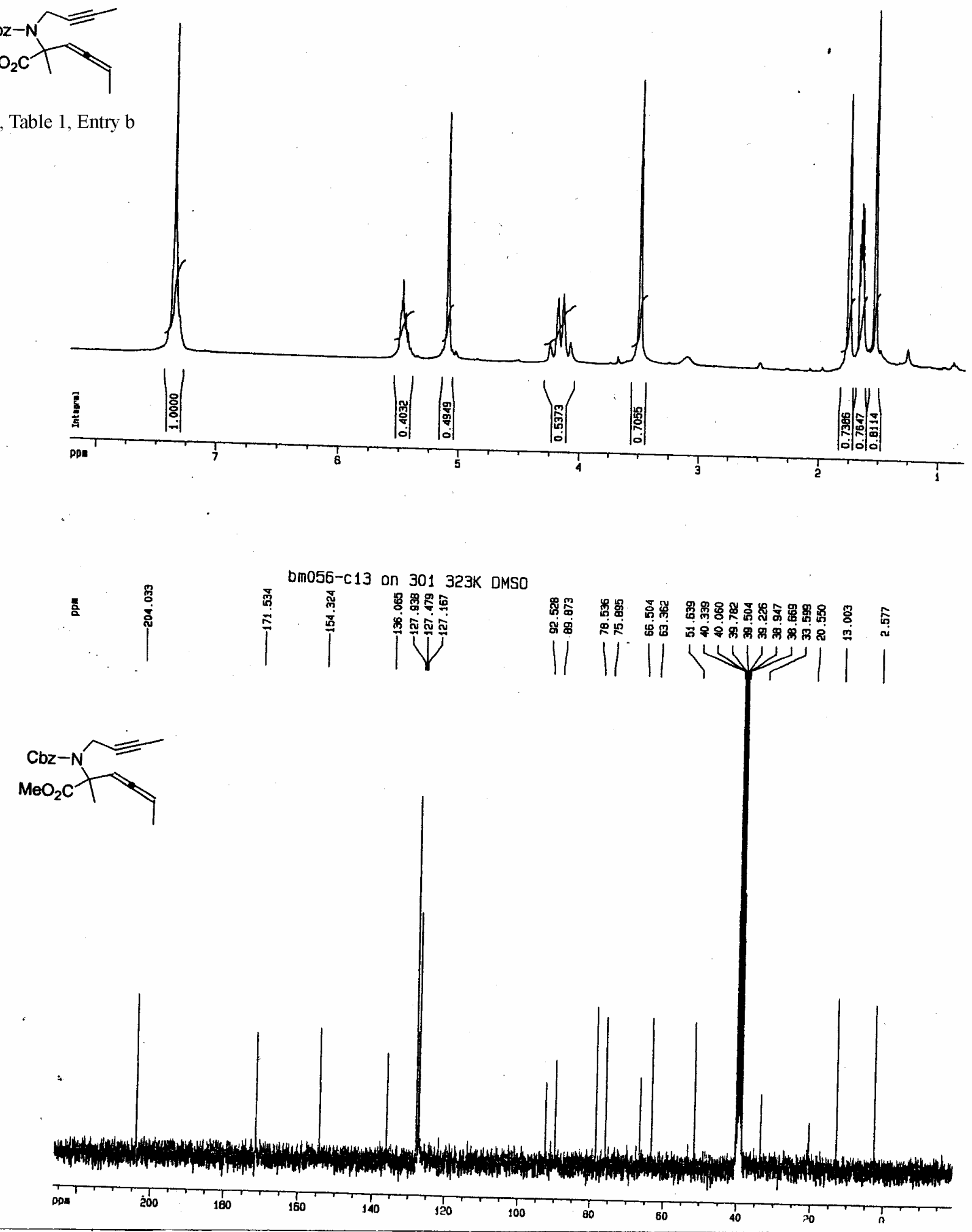
bm0137.01 cdc 13 310K 300MHz

บิบ
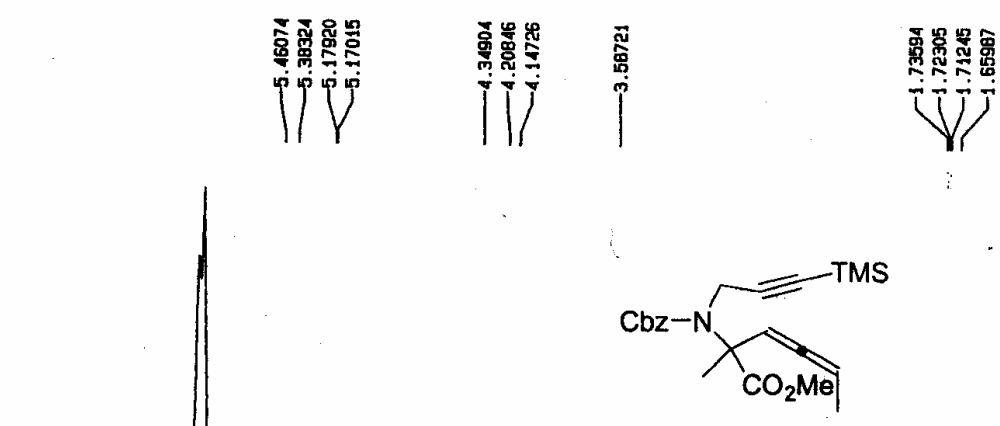

6, Table 1, Entry c
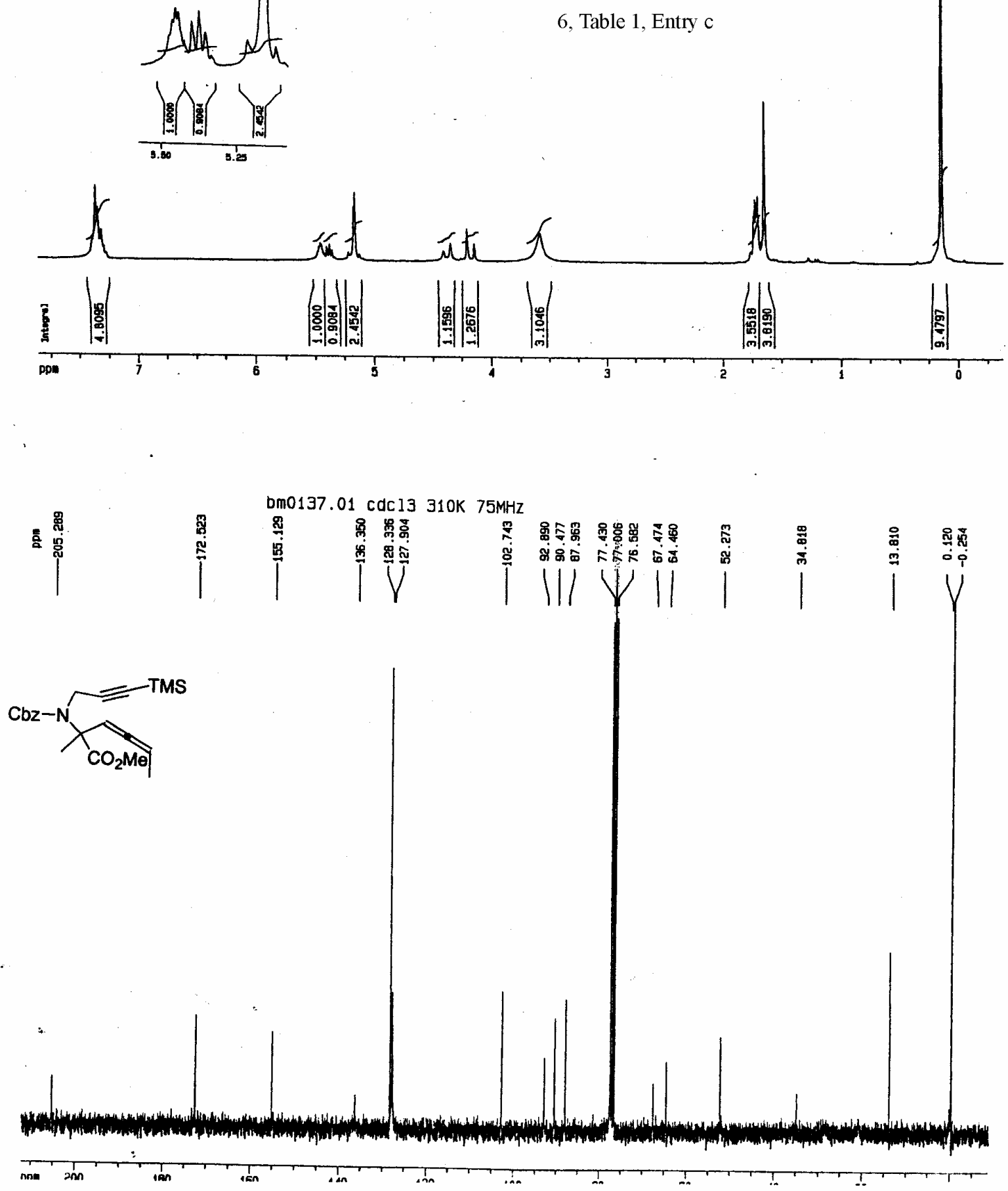

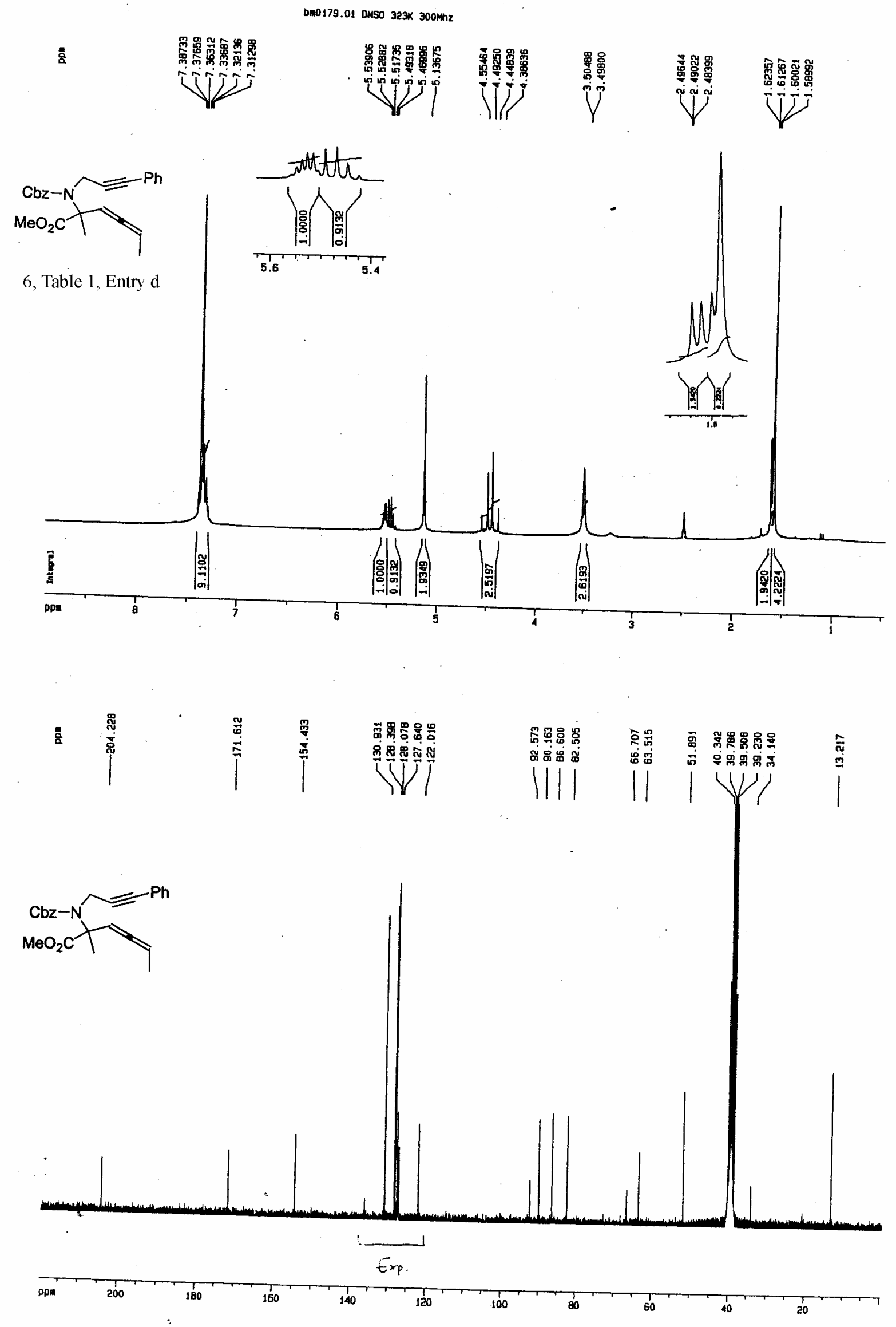
bm0113. 323K 3200Mnz DMSO
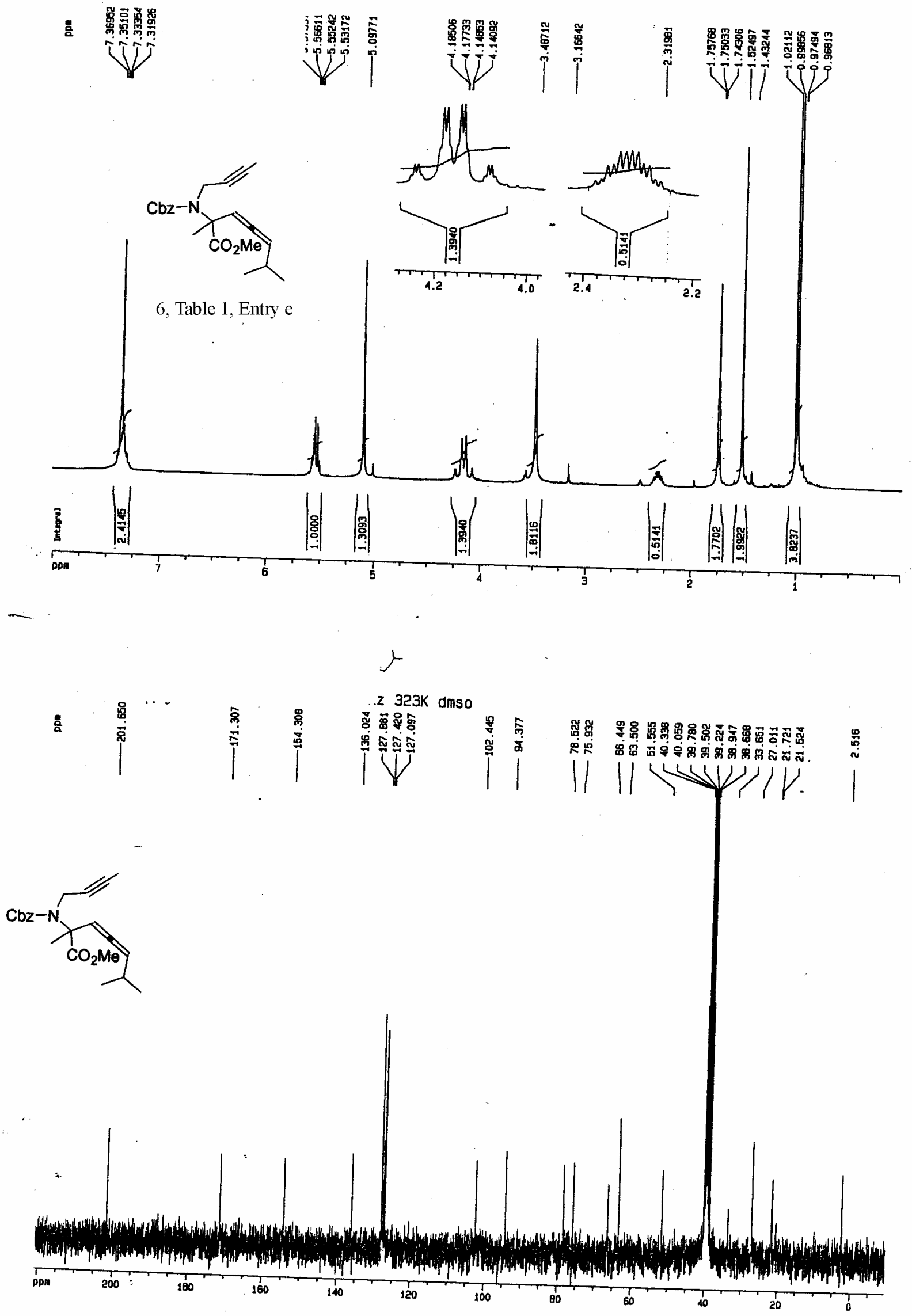


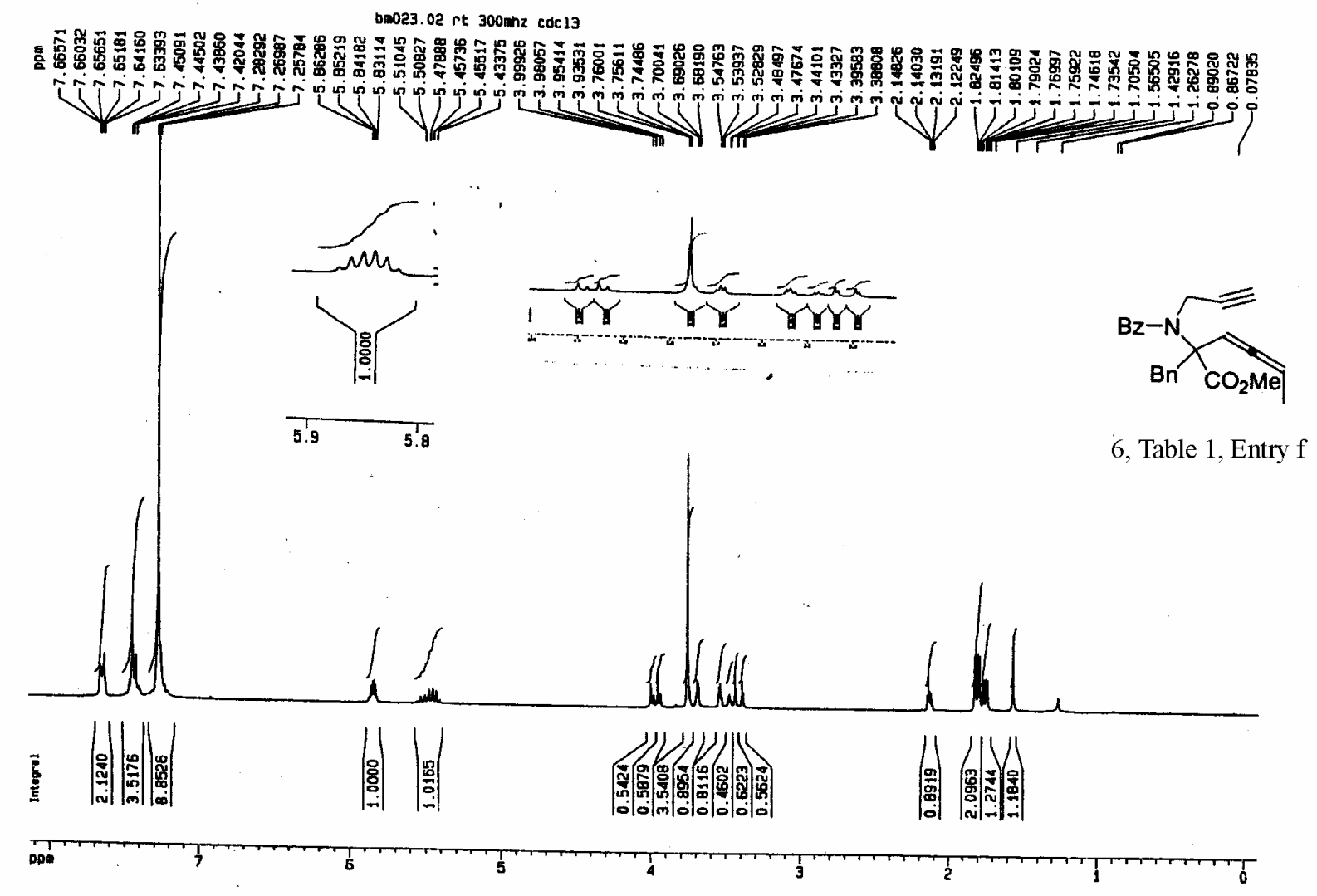

bno23.01 $\cos 33 r t 75 n h z$

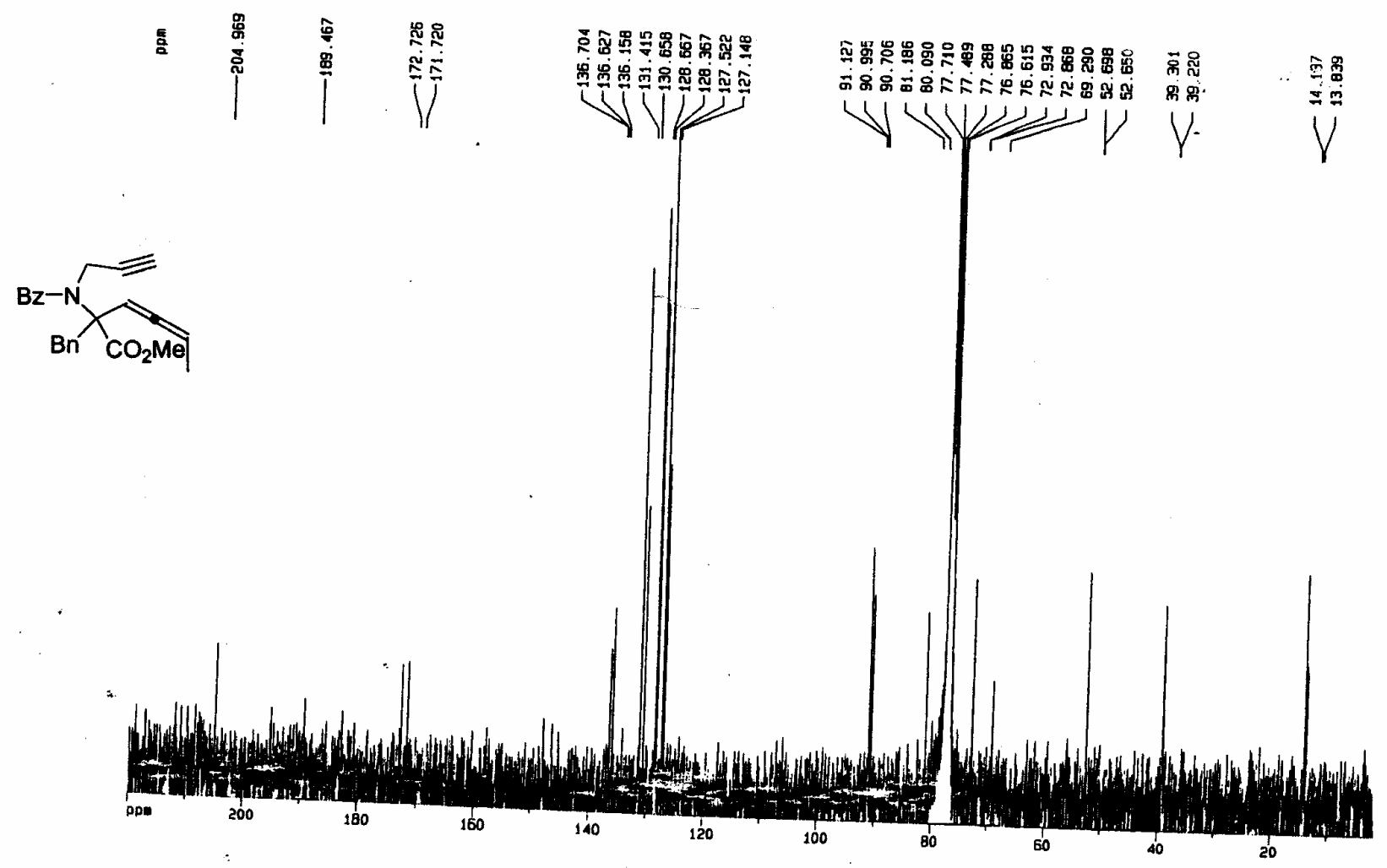


bm030.1 $\mathrm{CDCl}_{3}, \mathrm{rt} 300 \mathrm{mH} / 2$
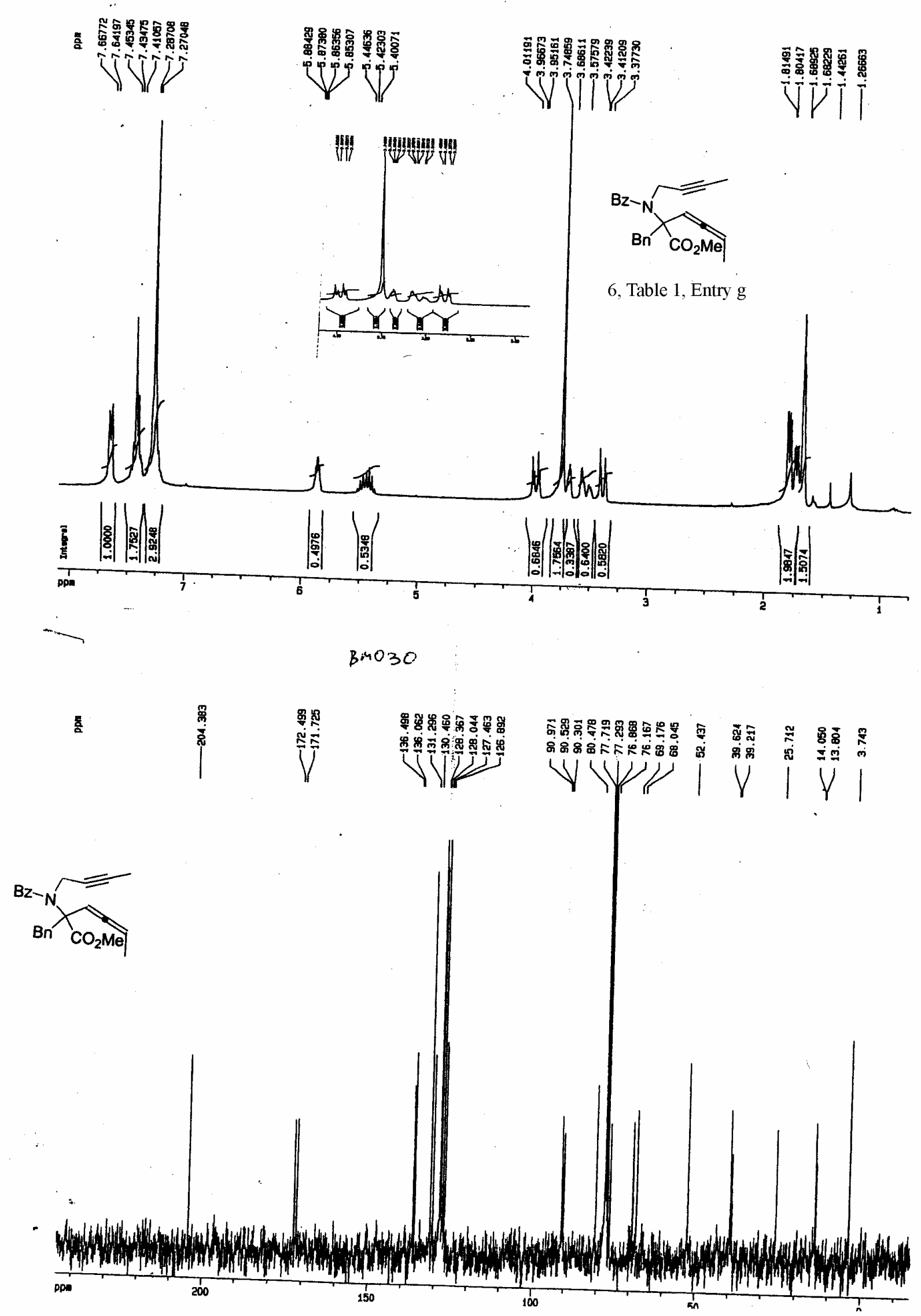

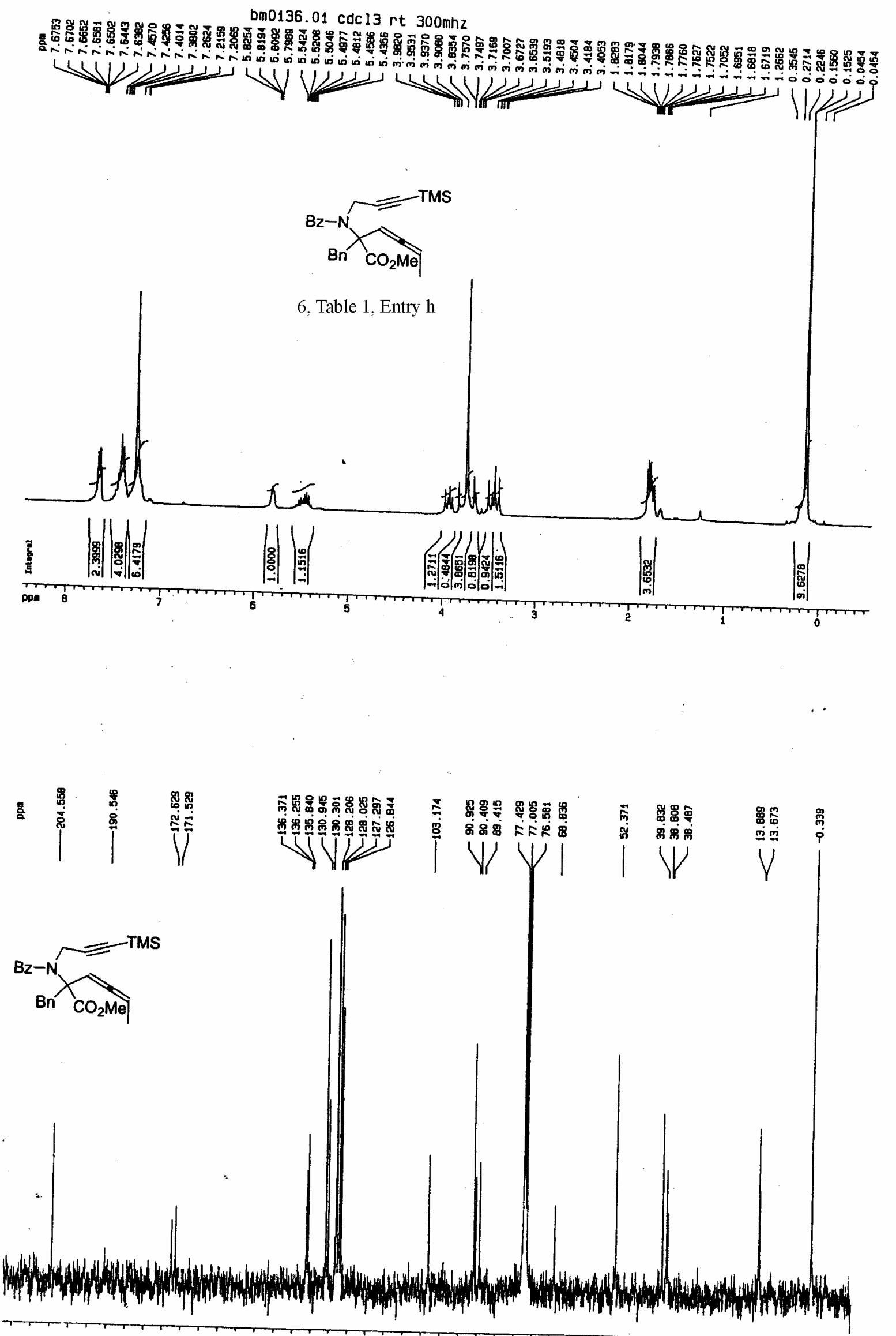
bm0103 coc $13 \mathrm{rt} 300 \mathrm{mnz}$

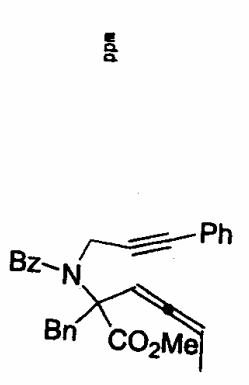

6, Table 1, Entry i
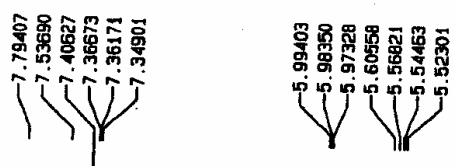

पर

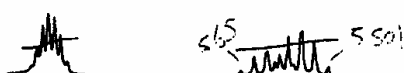
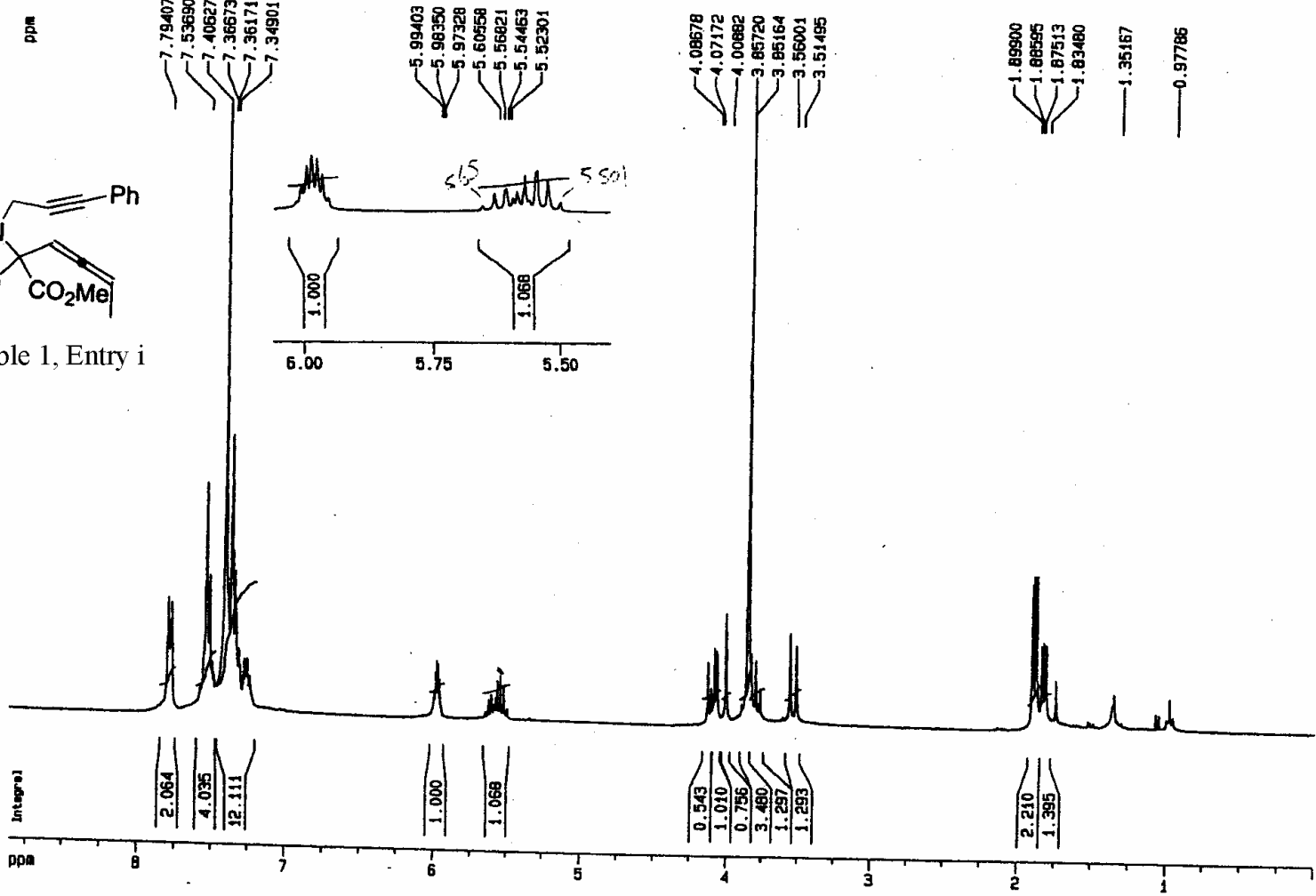

言

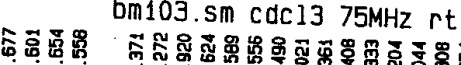

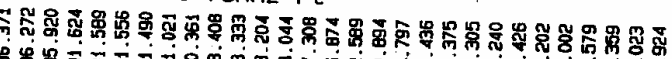

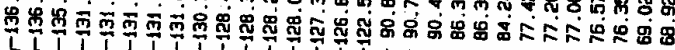

ขึำ

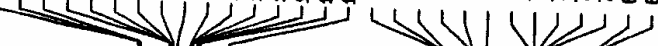

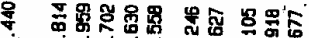

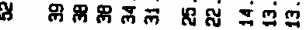

$Y\|\| Y$<smiles>CCC(C)C(Cc1ccccc1)(Cc1ccccc1)N(CC#Cc1ccccc1)C(=O)c1ccccc1</smiles>

$11 \%$
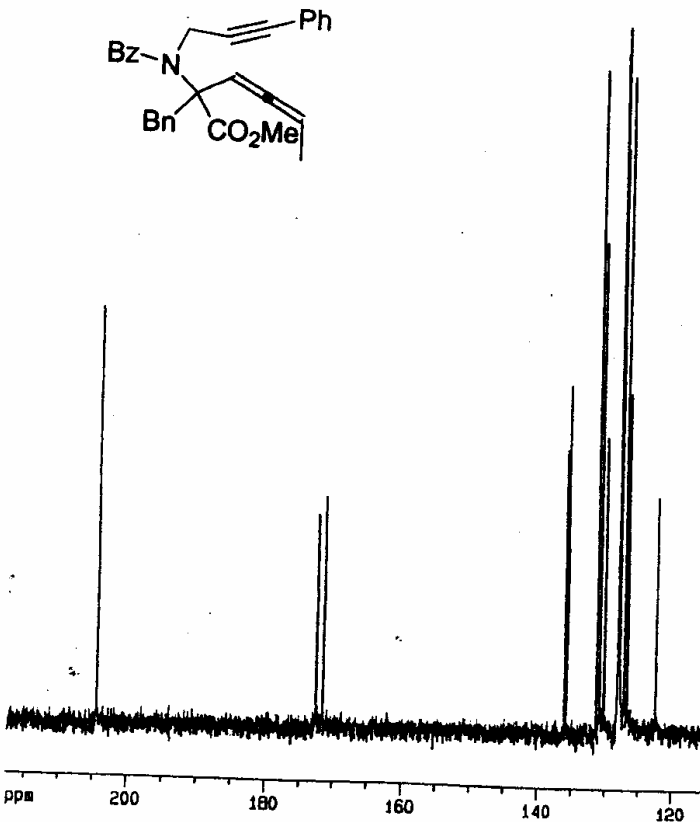

140
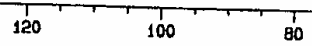

60

40

20 


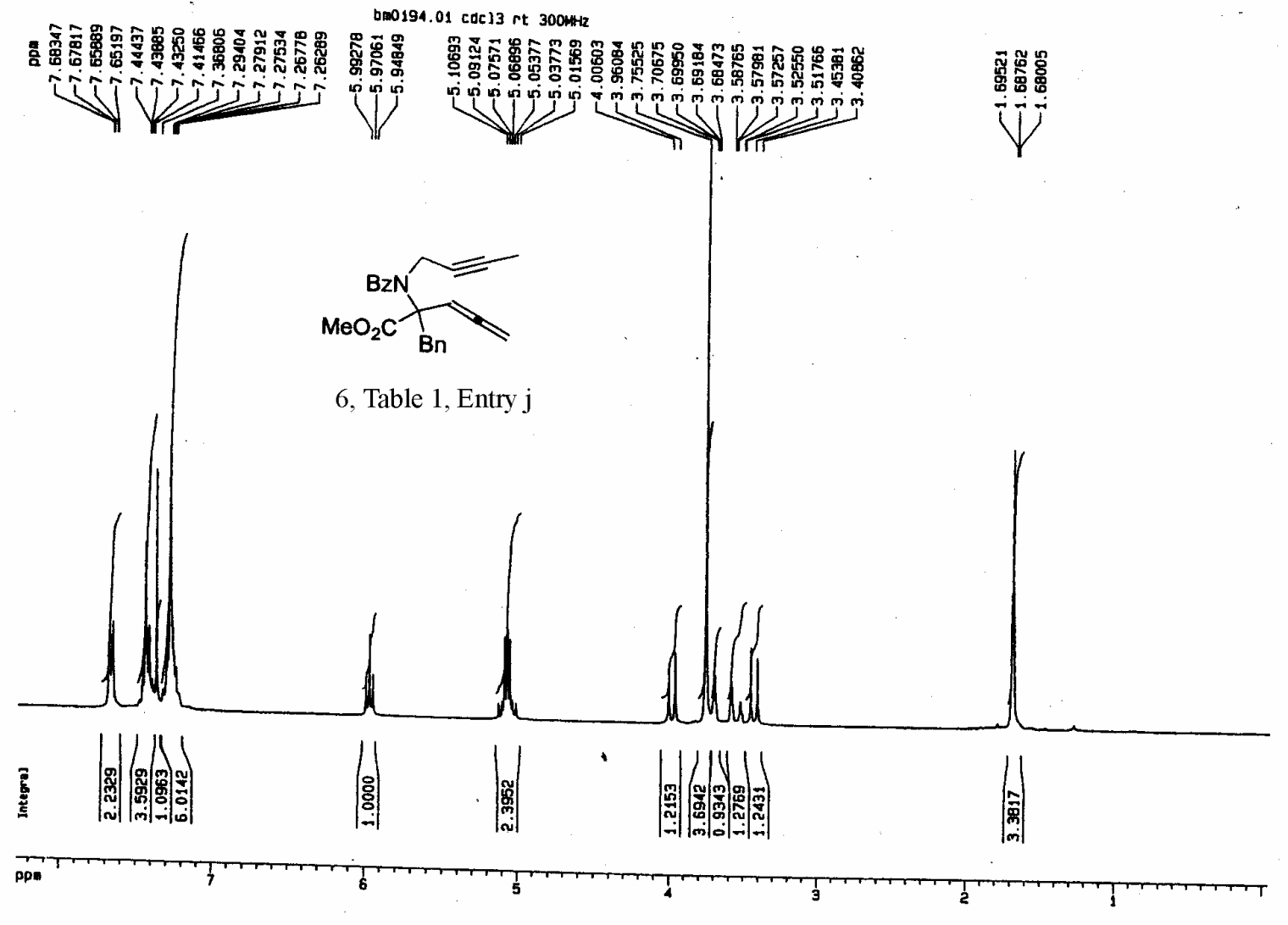

ba0194.02 coc13 rt 75whz

|

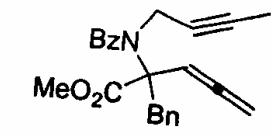




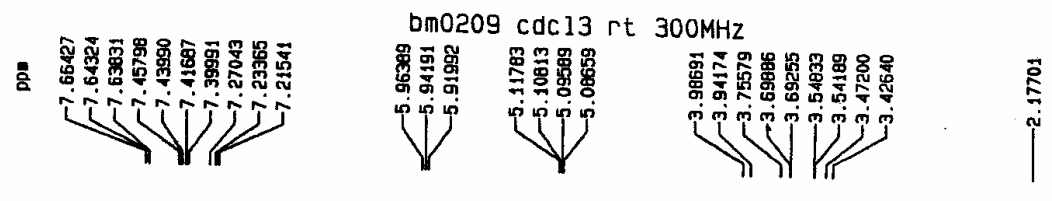

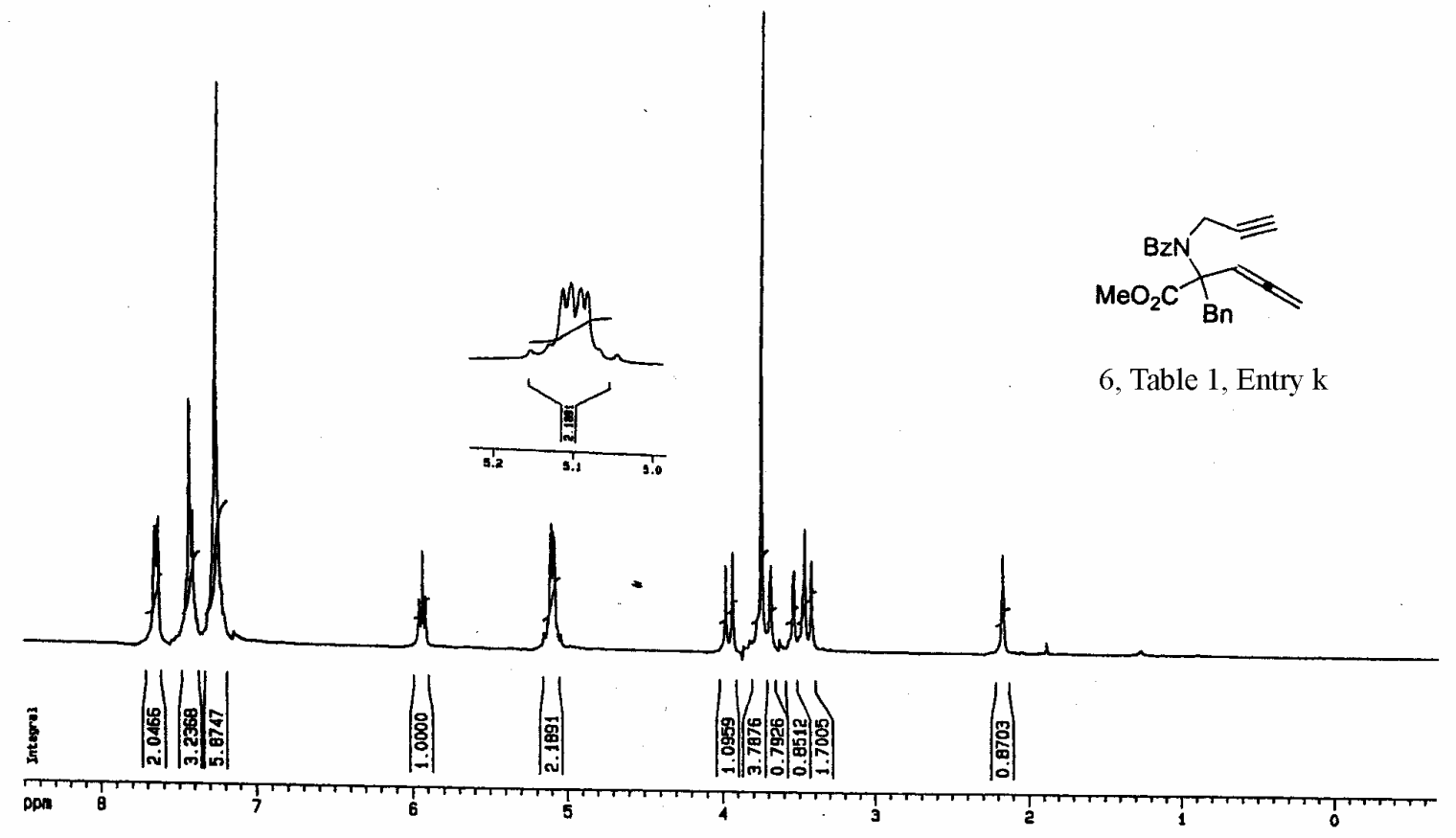

势

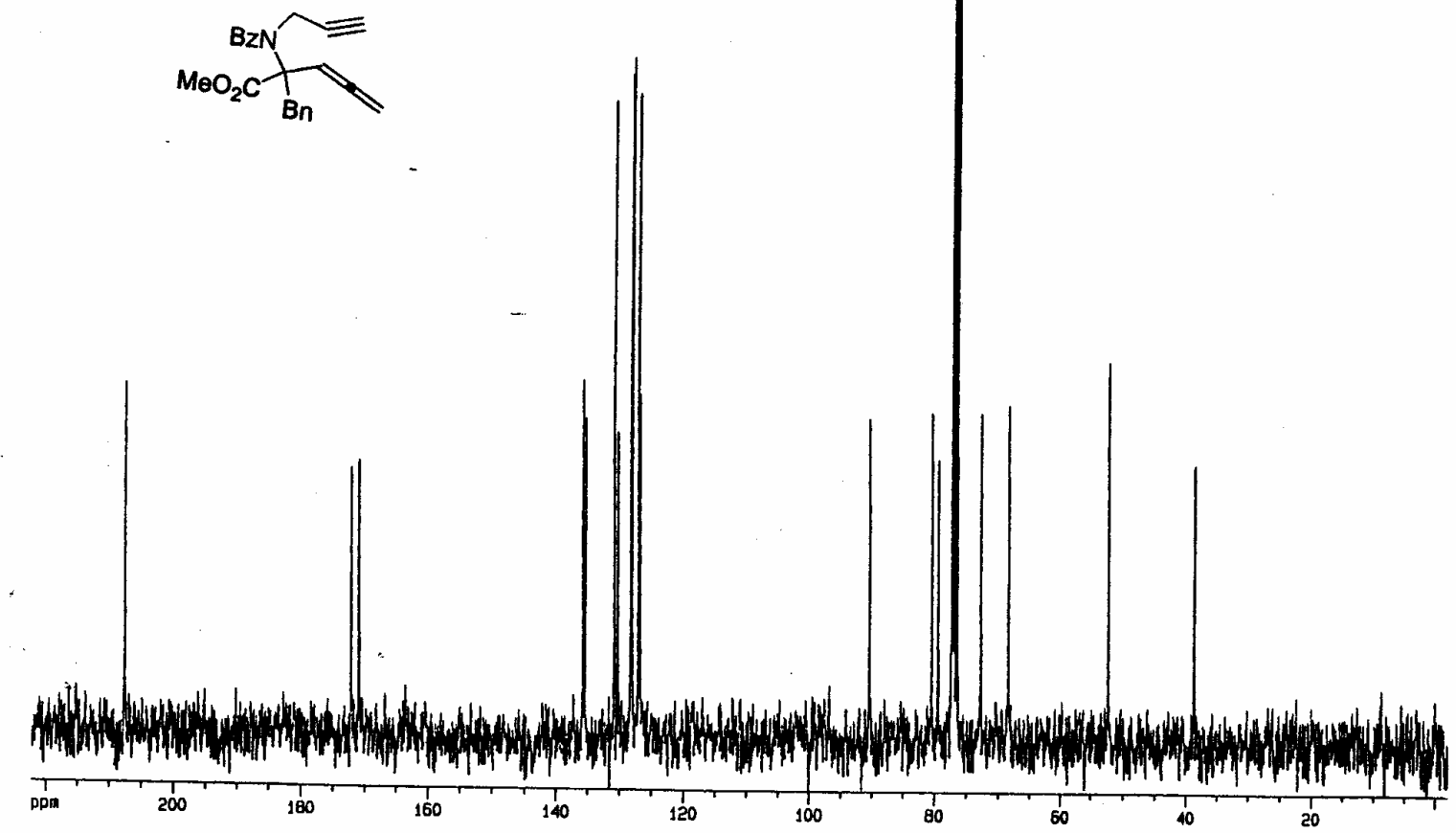




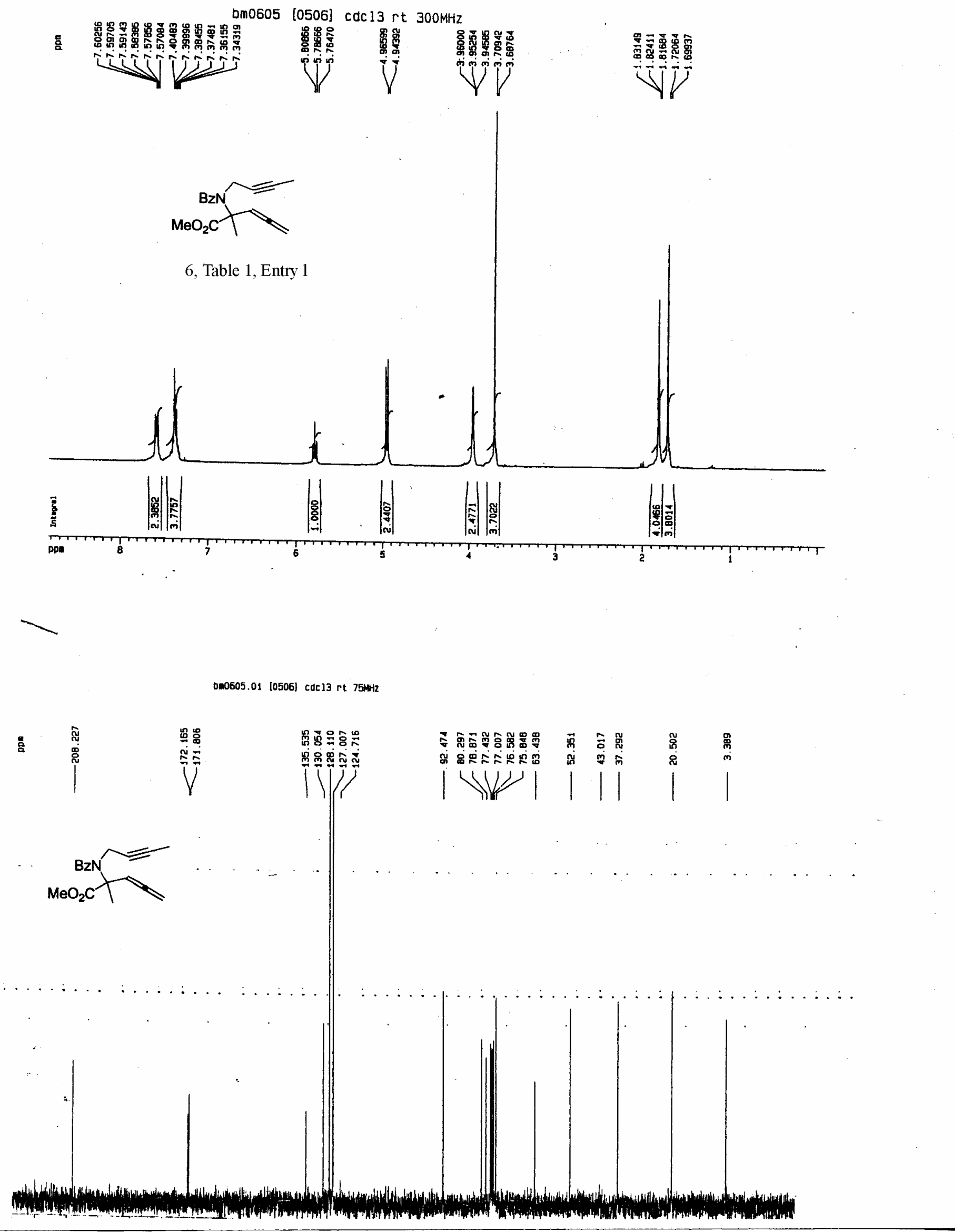



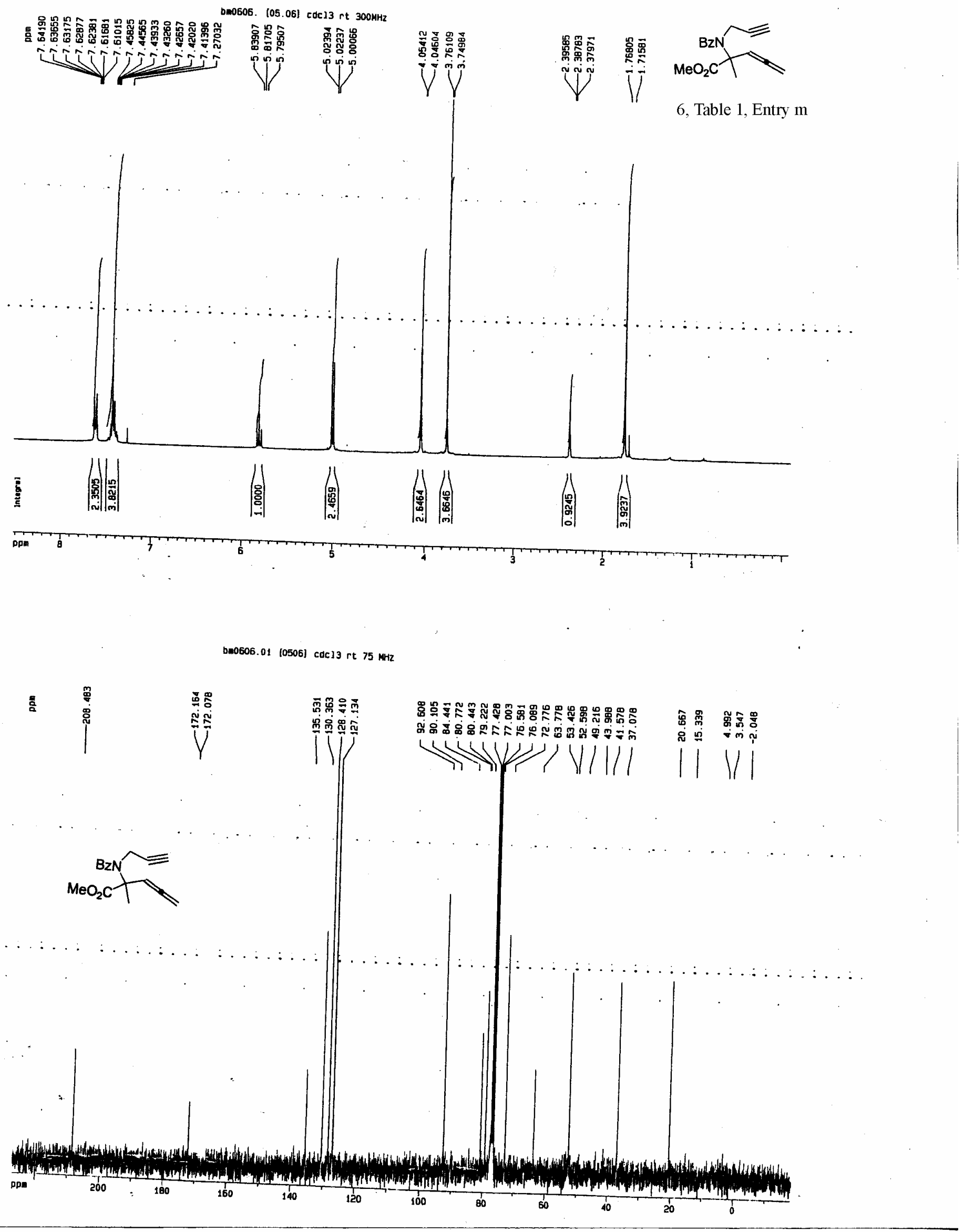

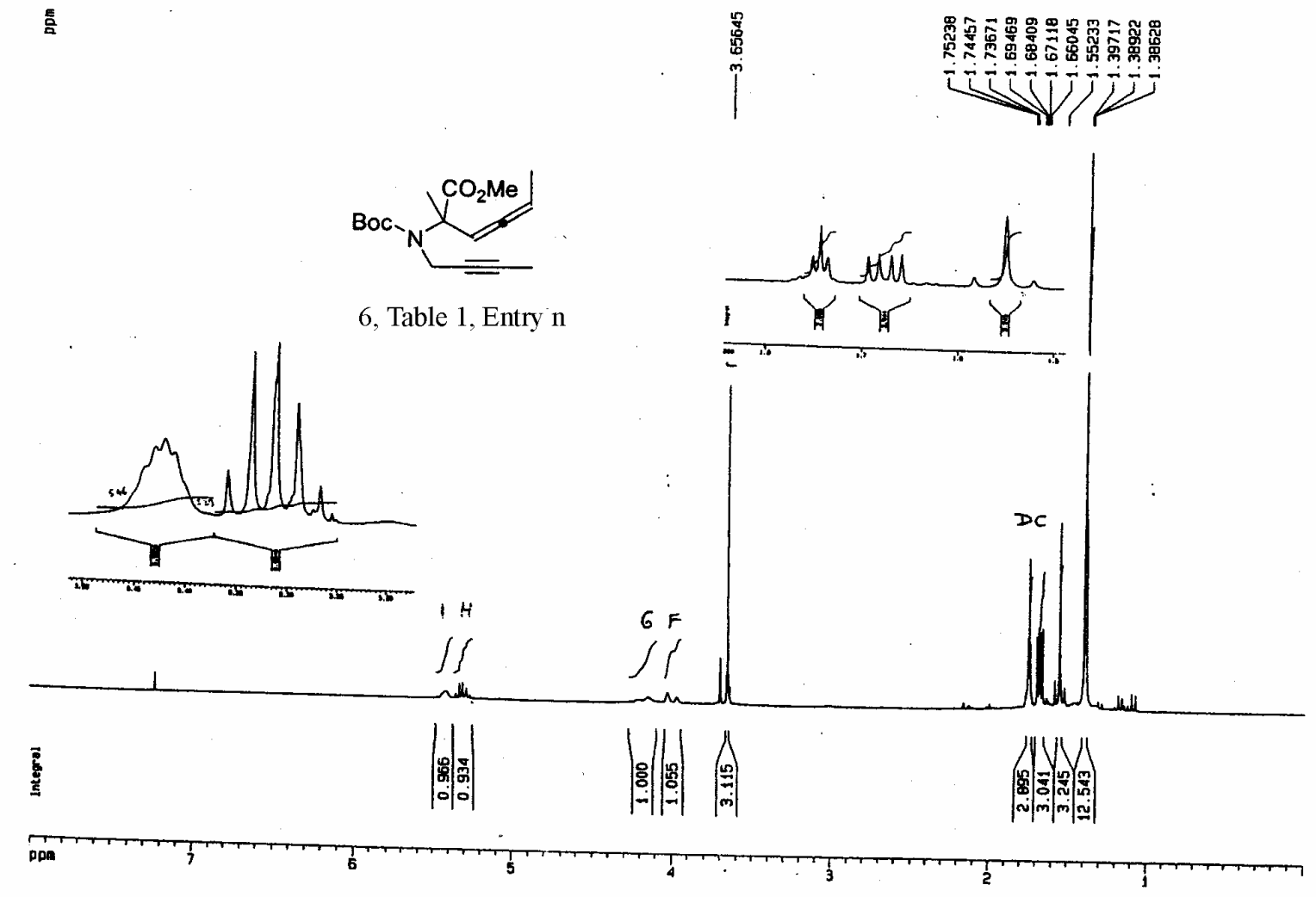

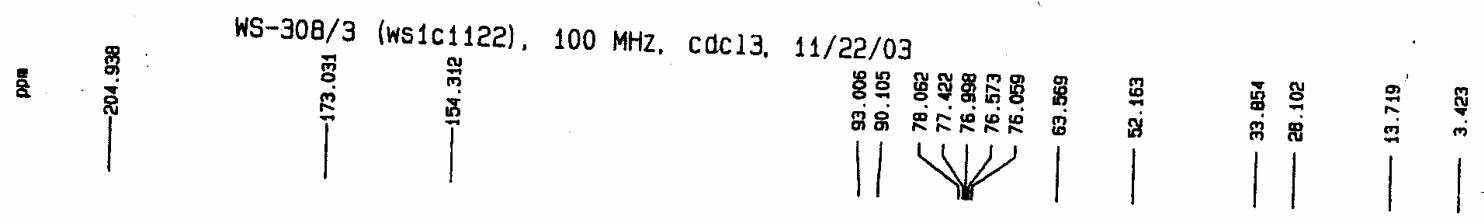
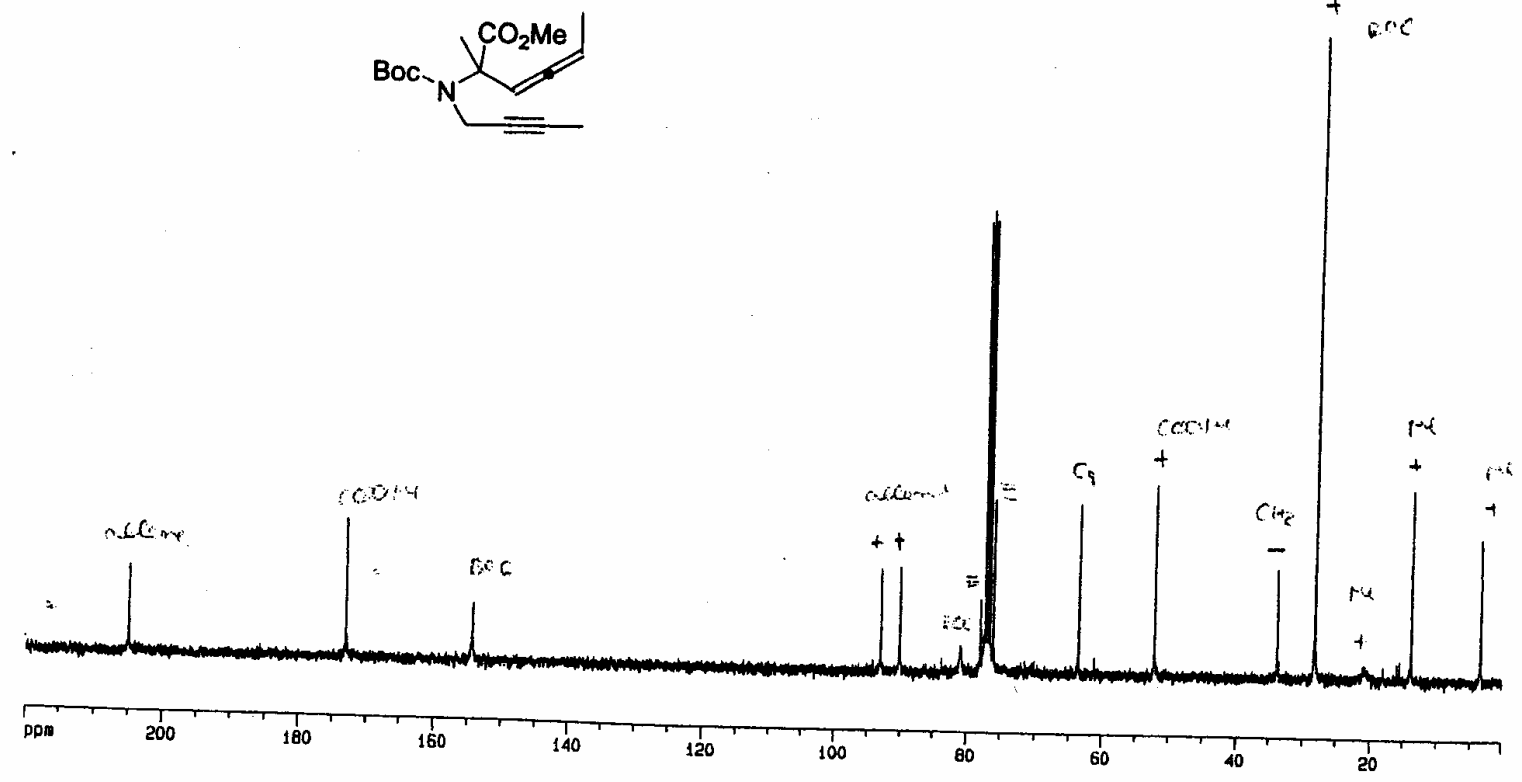
<smiles>CC#CCN(CCOC)C(COC)(CC(=O)O)C(=O)OCc1ccccc1</smiles>

6, Table 1, Entry o
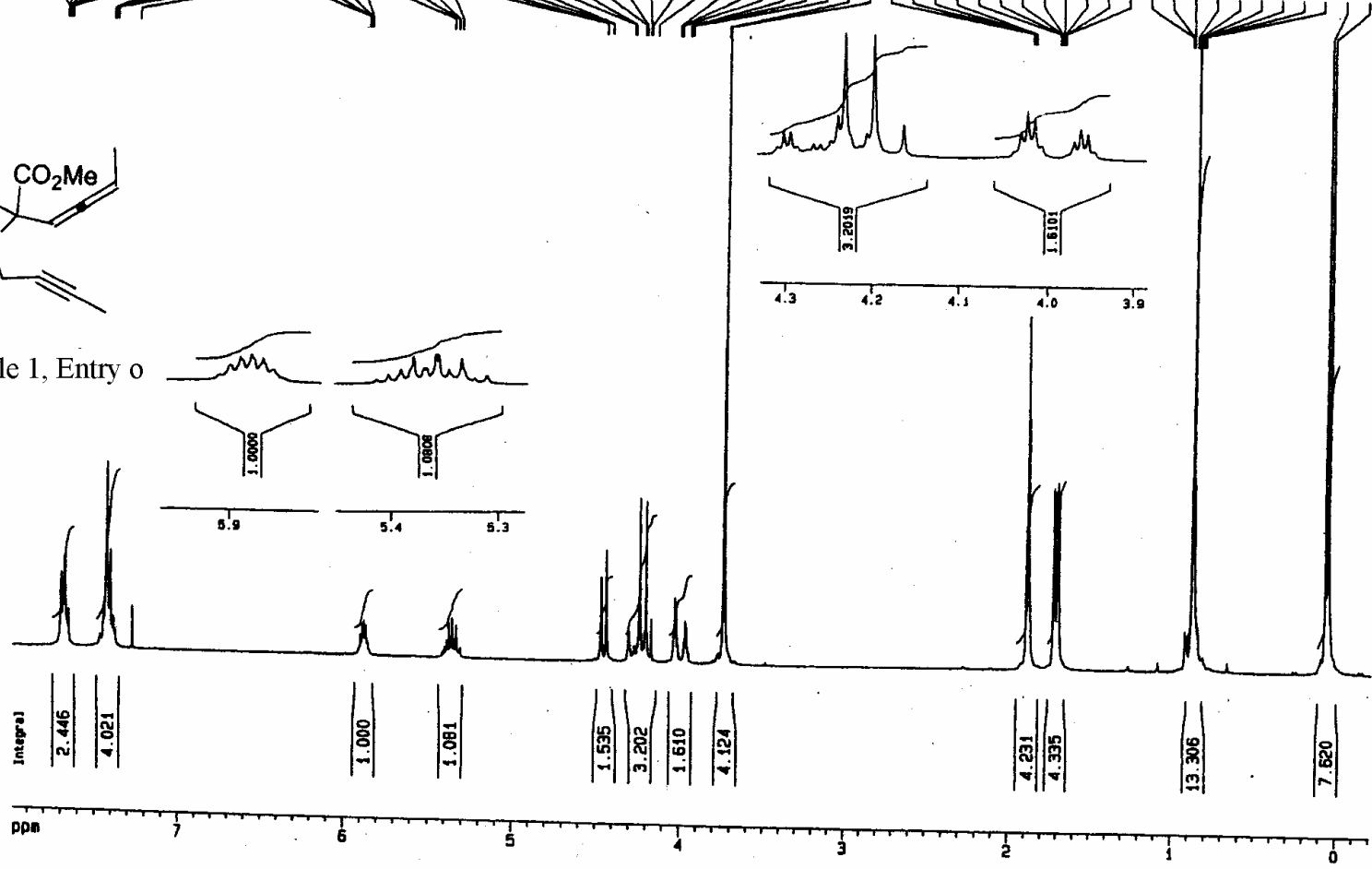

be0148.02 cocj3 rt 754Hz

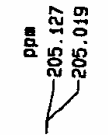

苋是总

ำำ

TBSO<smiles>CC#CCN(CC(C)(C)C)C(COC(=O)c1ccccc1)(CC(C)C)C(=O)OCC</smiles>

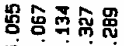

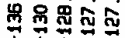

Ti

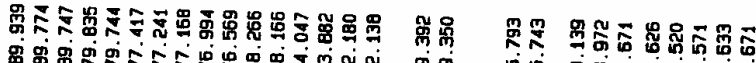

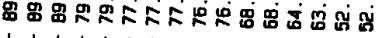

WHP

Y

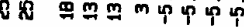

$Y \mid V \backslash Y Y$

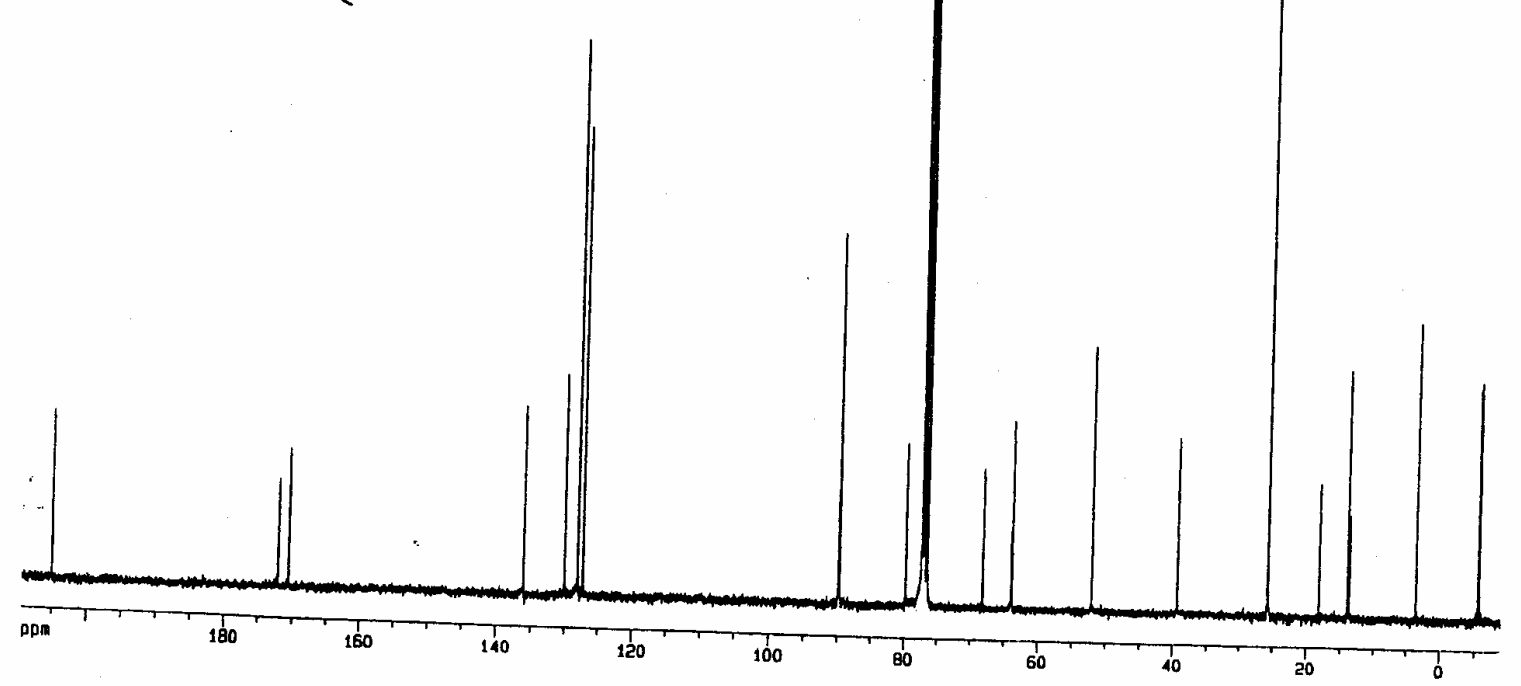


bm0188 323k amso 300Mnz
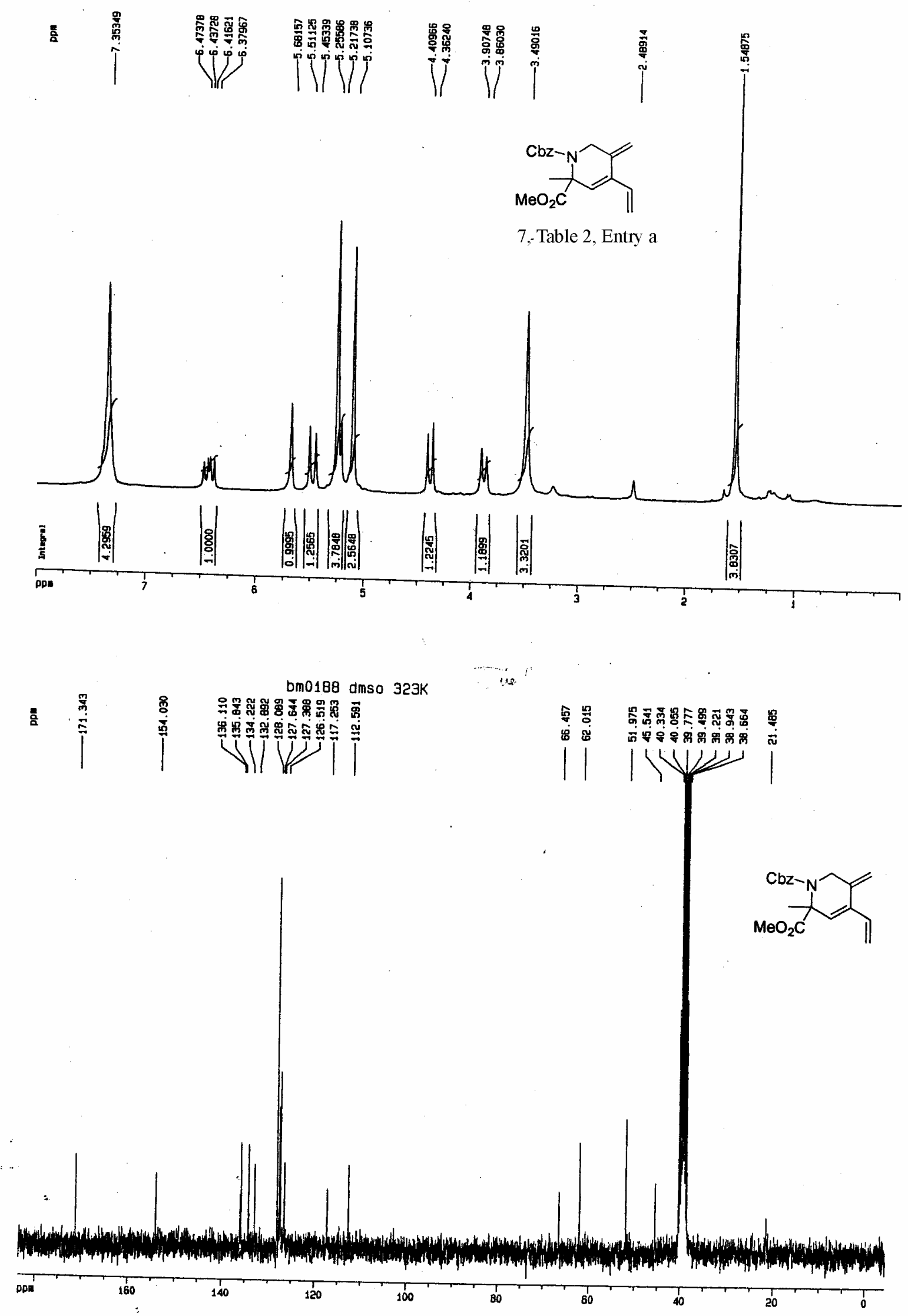
bm057 323K on 301 DMSO
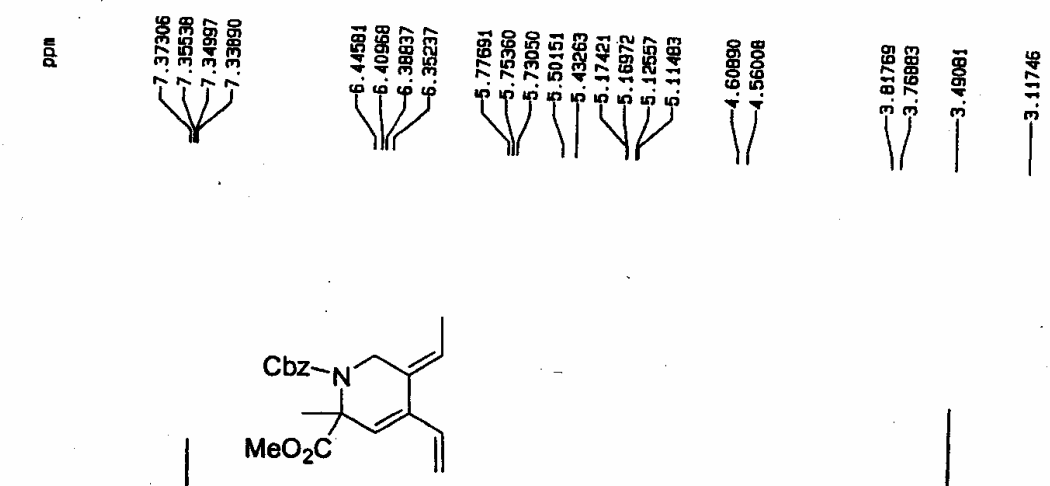

7, Table 2, Entry b
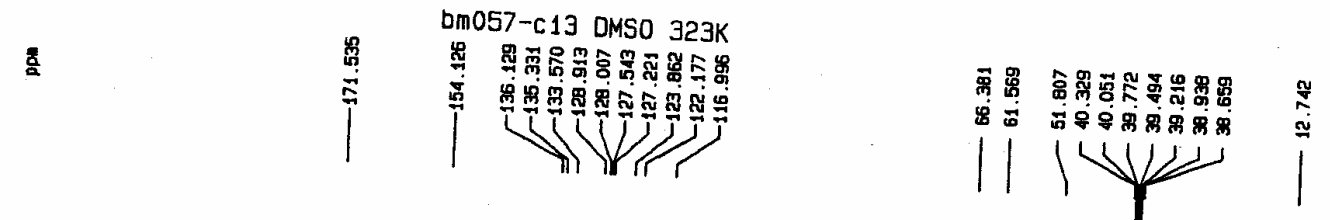<smiles>C=CC1=CC(C)(C(C)(C)C)N(C(=O)O)CC1=CC</smiles>

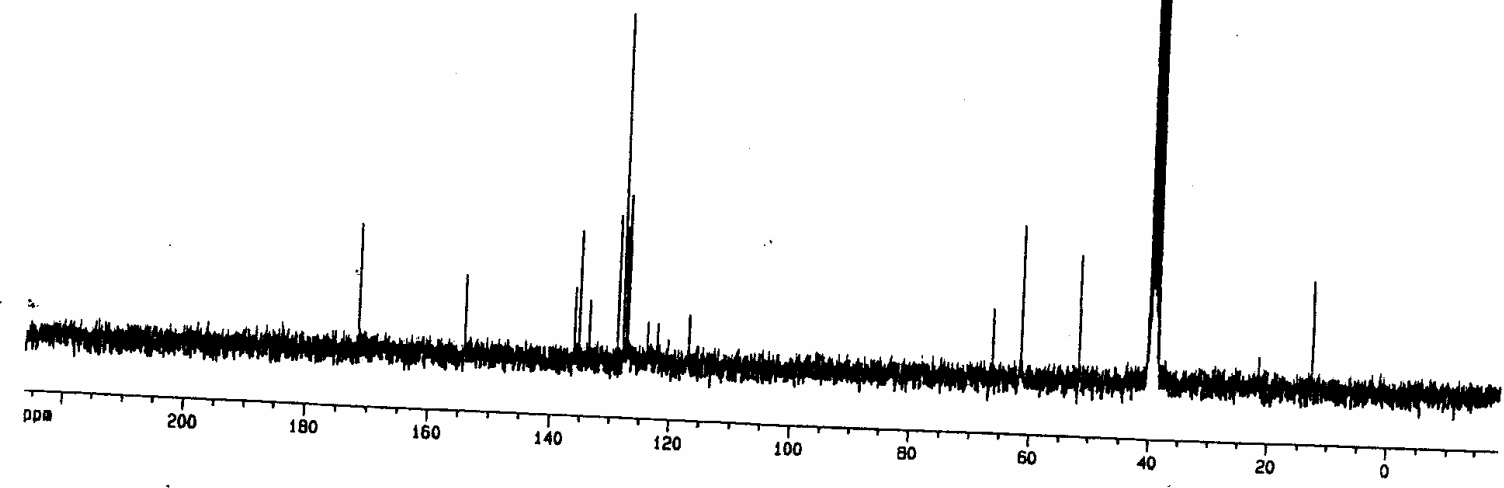


bm0141 323K dmso 300MHz
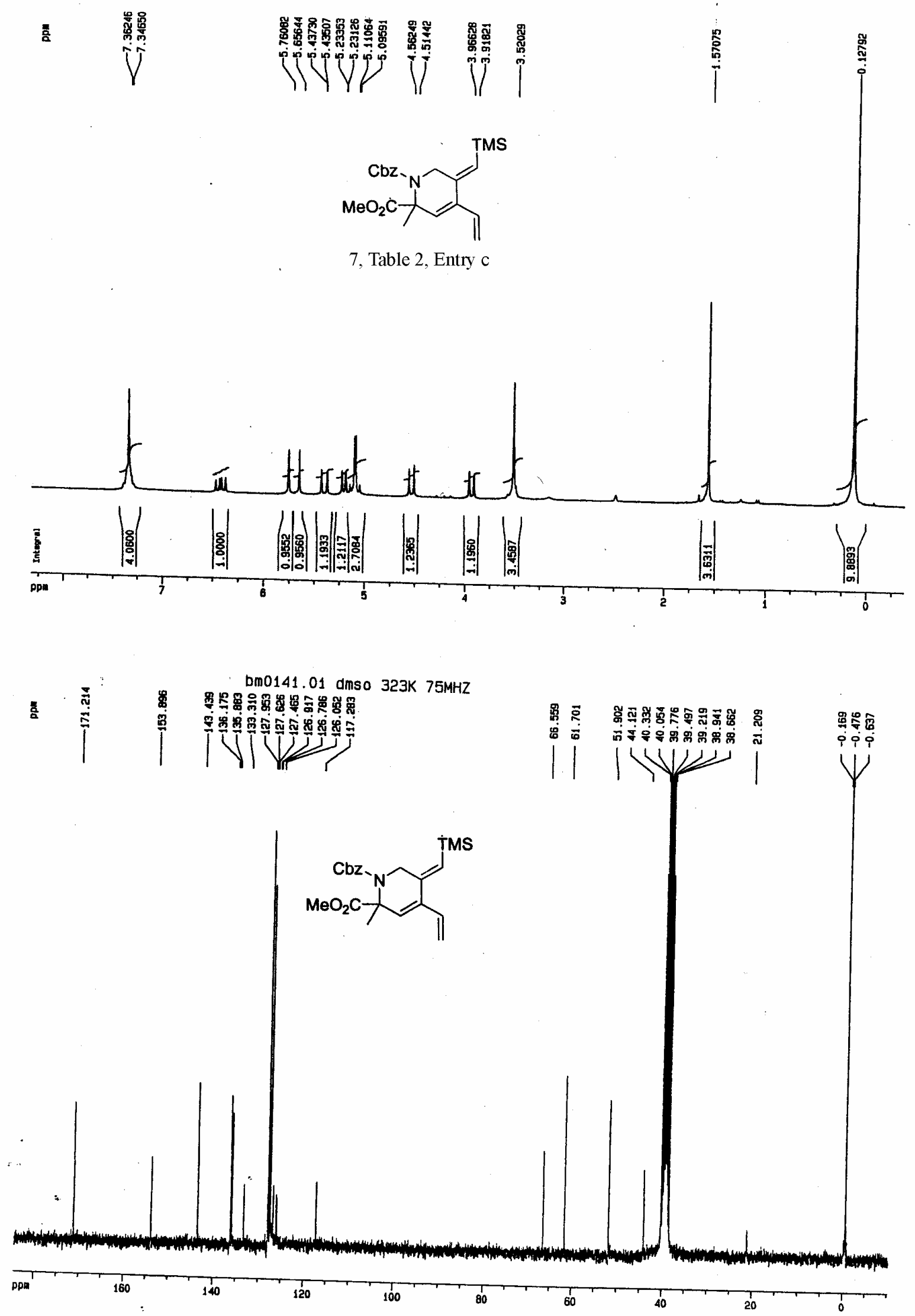
bm0181.01 dmso 323K 300MHz
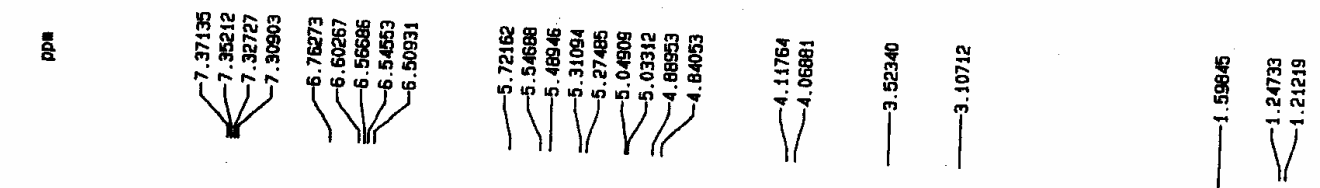<smiles>C=CC1=CC(C)(C(C)=O)N(C(=O)OCc2ccccc2)CC1=Cc1ccccc1</smiles>

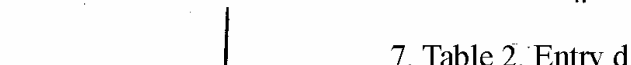

7, Table 2, Entry d

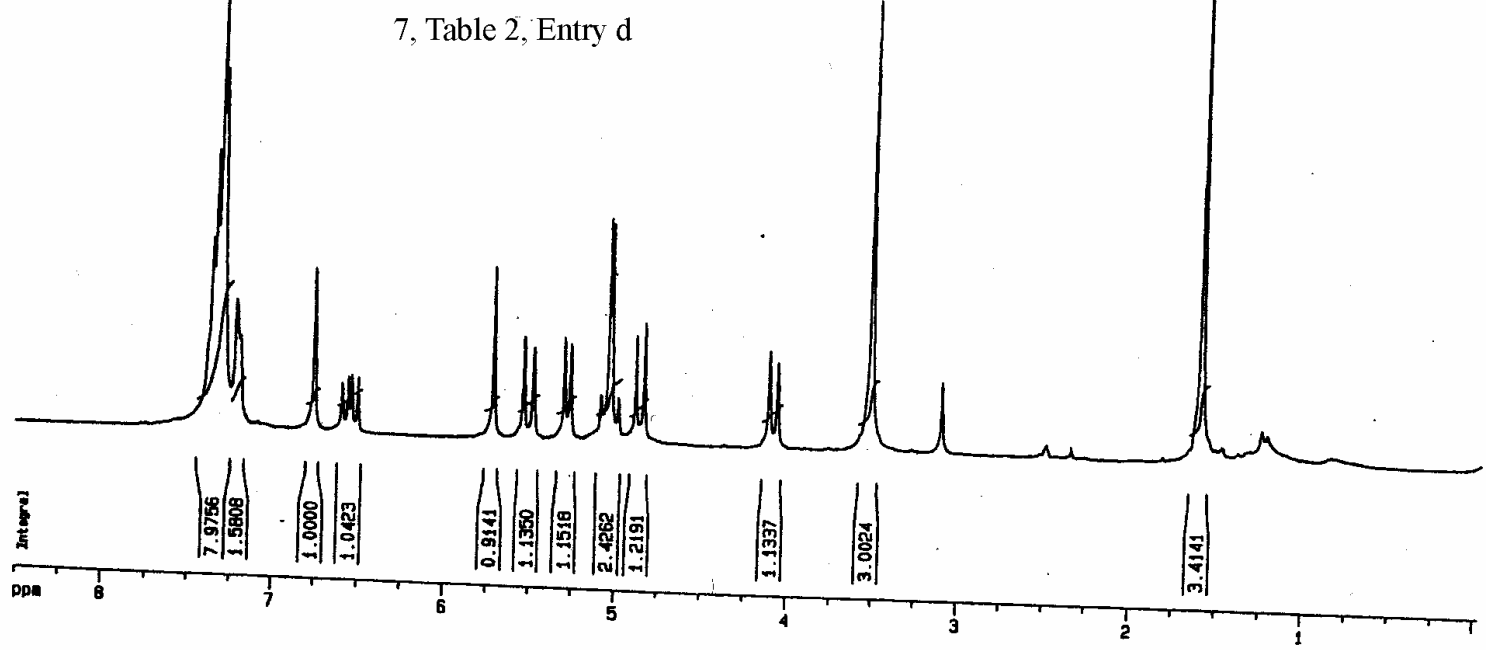

:
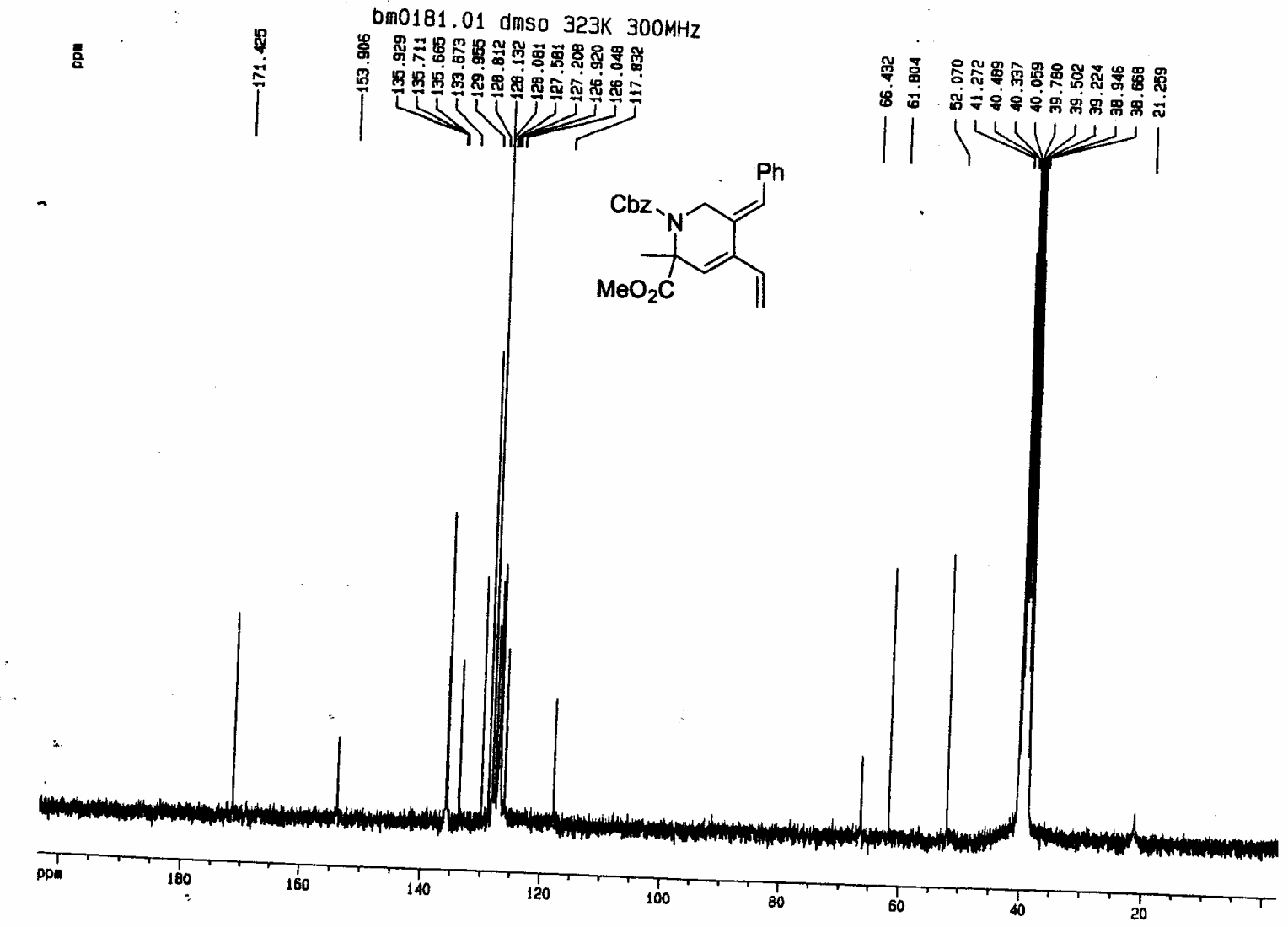

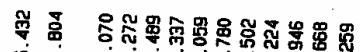

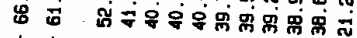

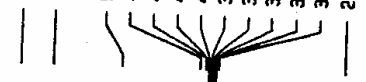




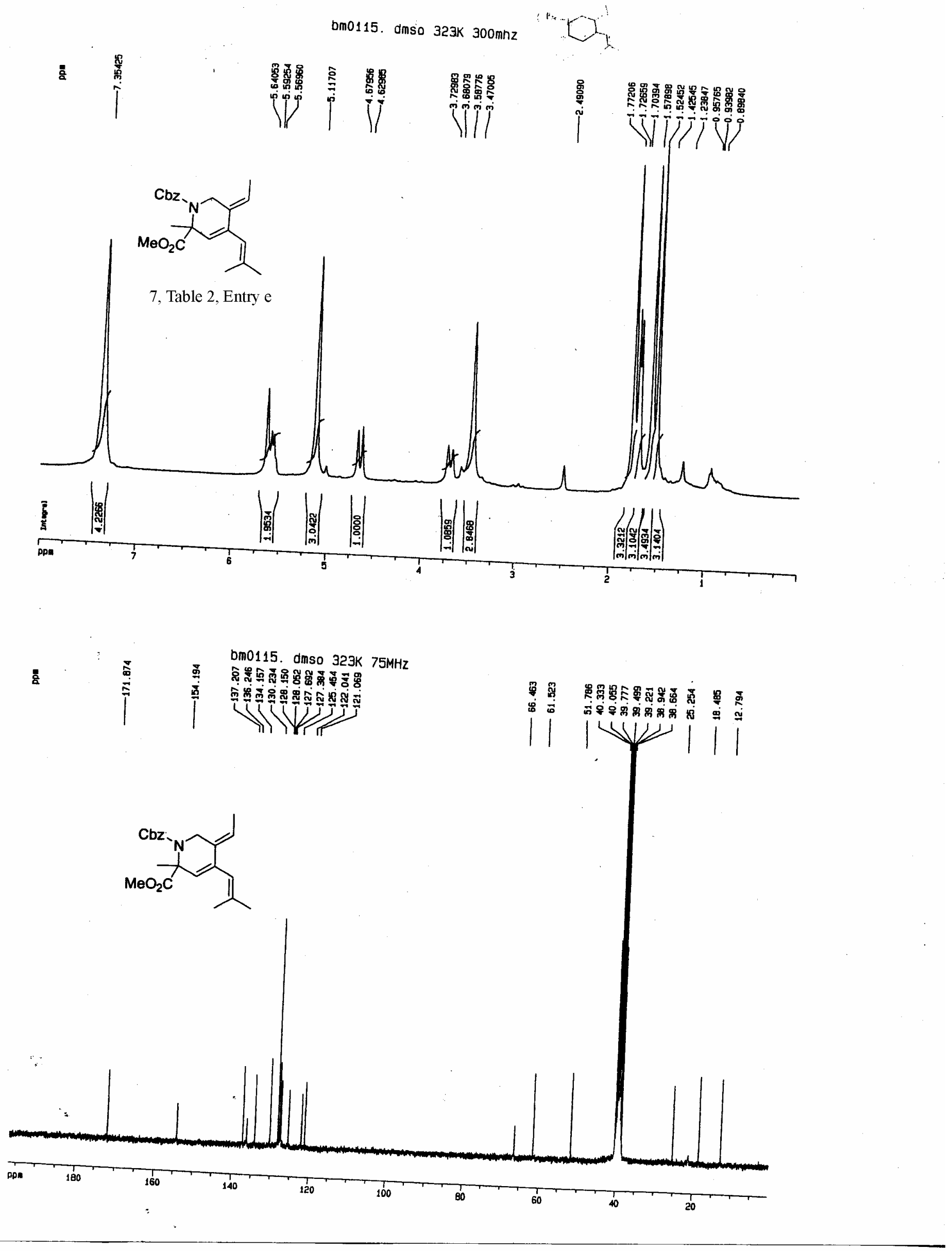




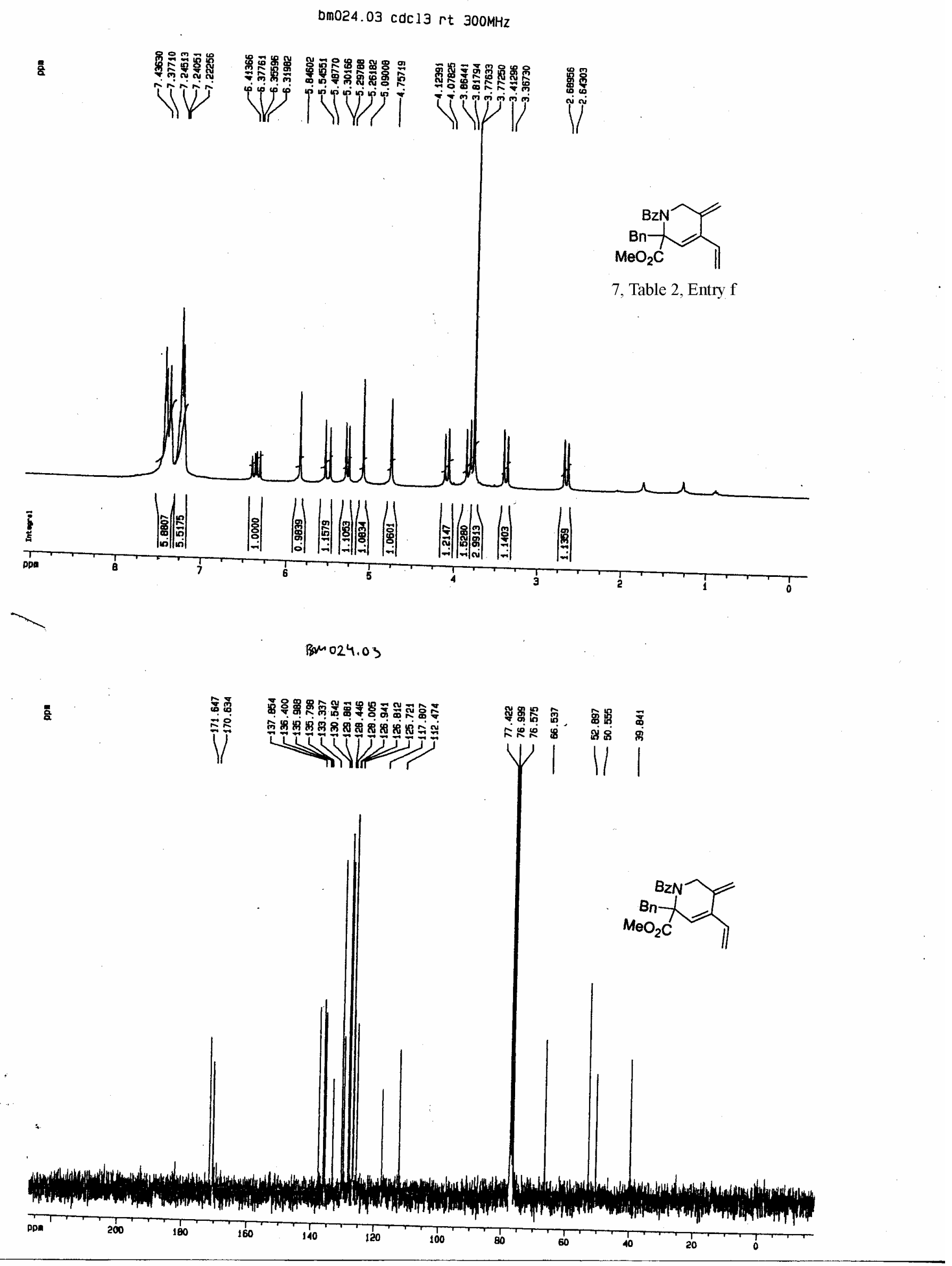




\section{a}

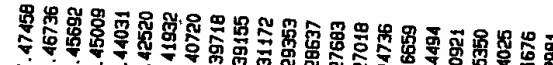

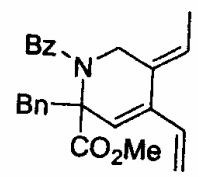

7, Table 2, Entry g

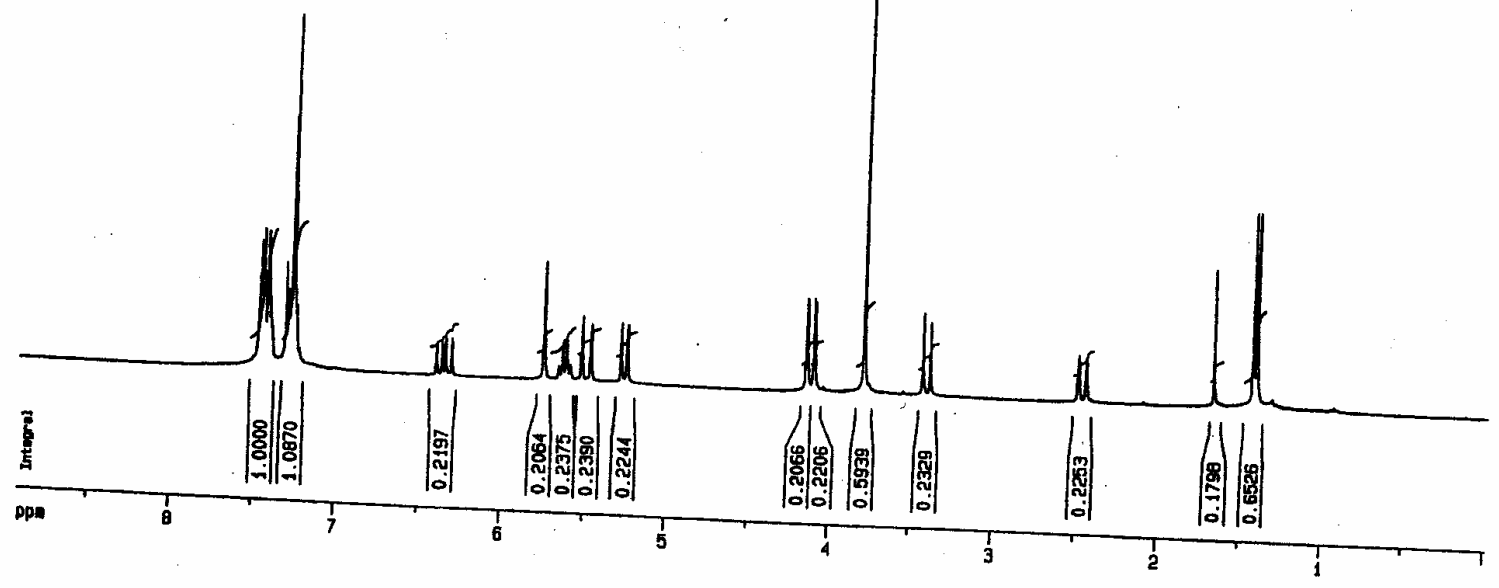

bMo31 c13
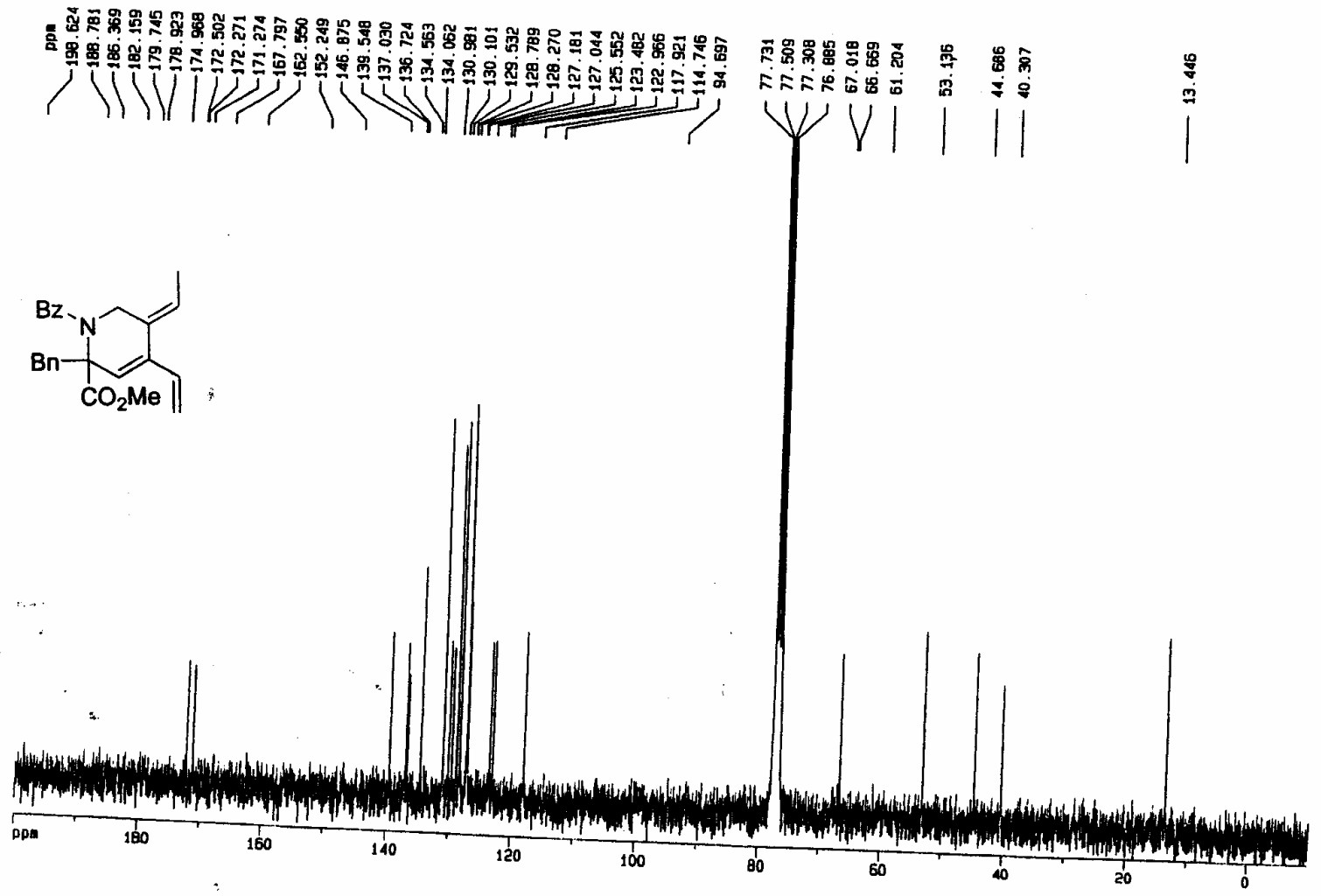
ban0138.01 cdc13 rt 300ahz

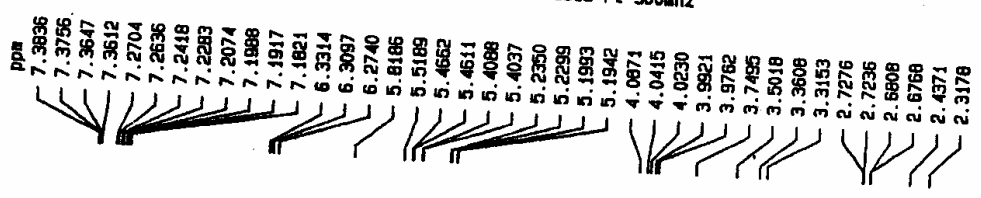

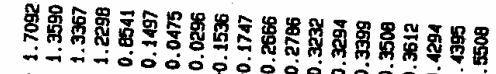<smiles>C=CC1=CC(Cc2ccccc2)(CC(C)(C)C)N(C(=O)c2ccccc2)CC1=CC</smiles>

7, Table 2, Entry h

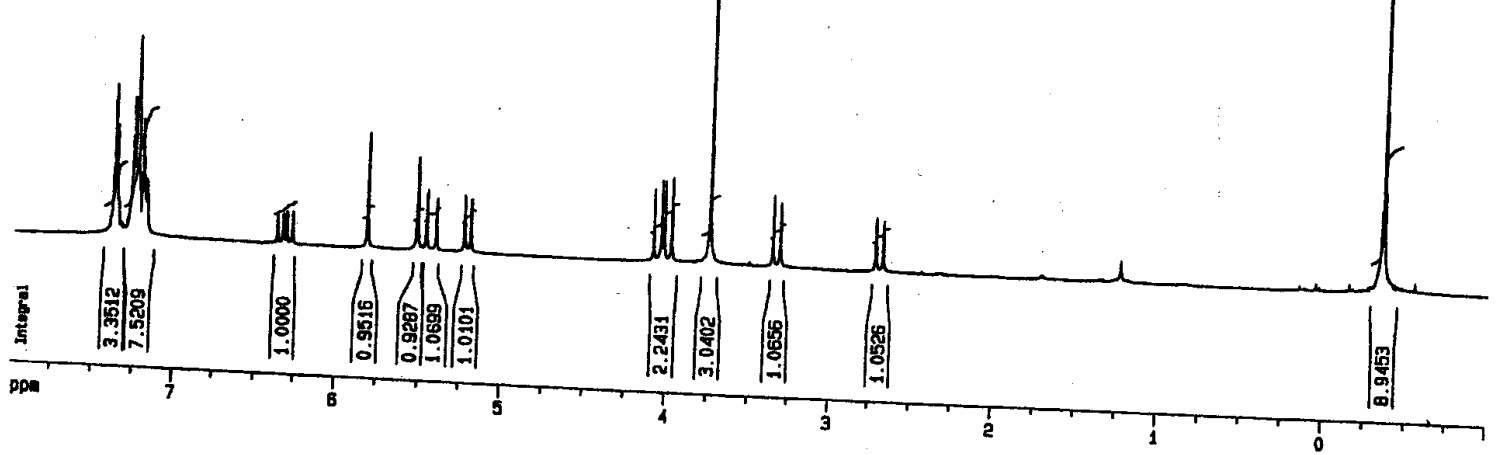

ba0130.01 c13 cdc13 rt 75MHz

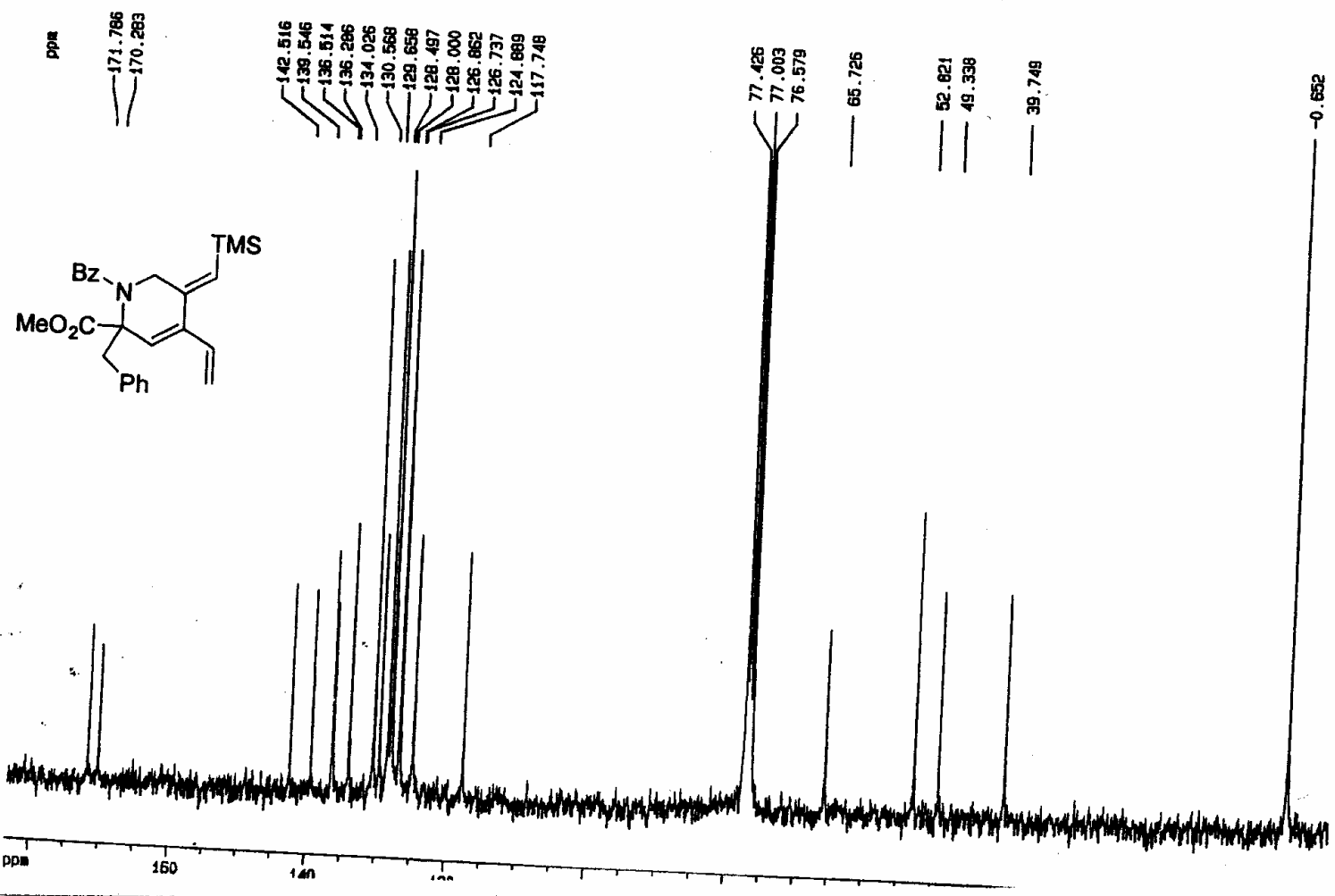




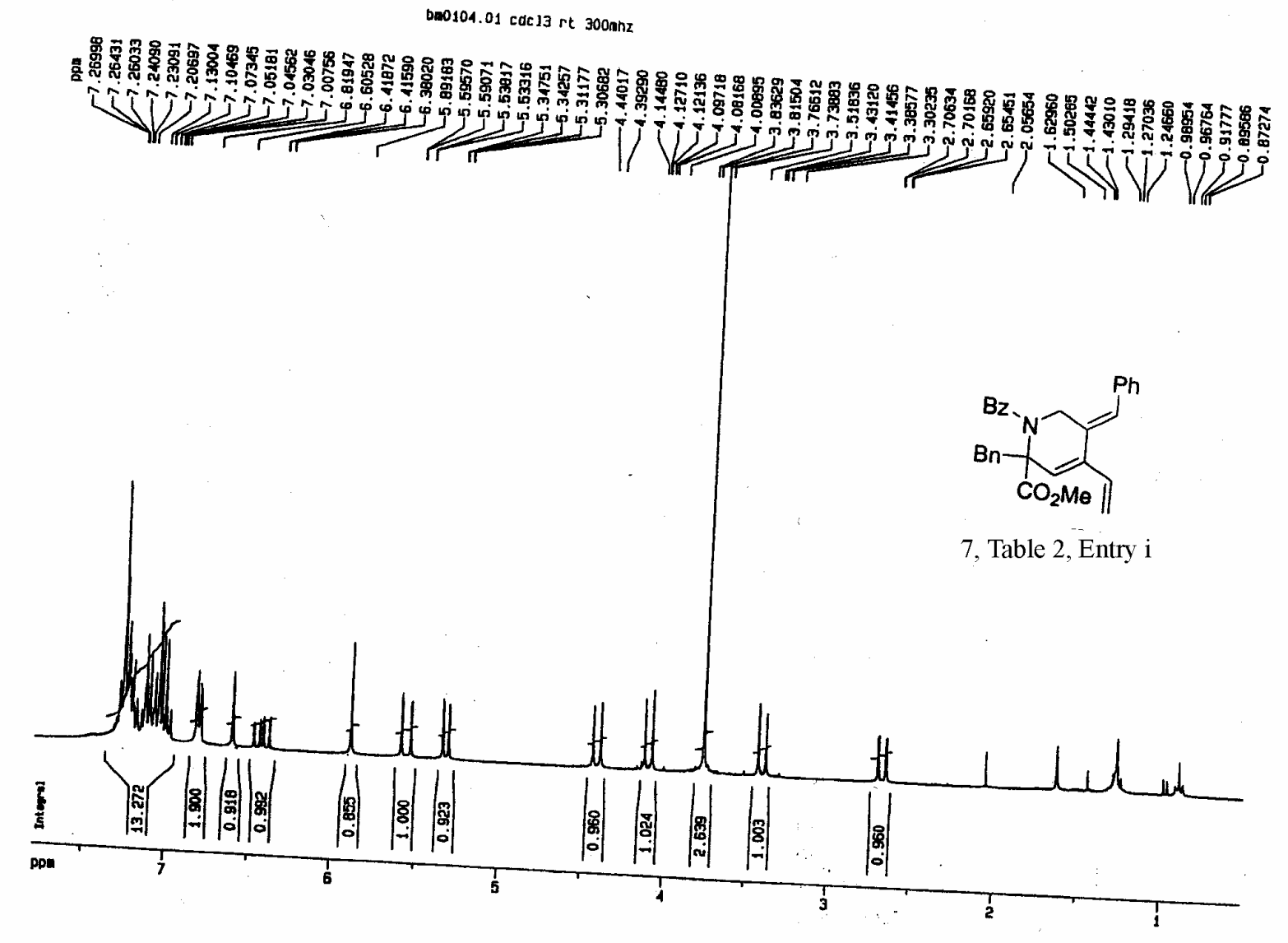

be0104.01 rt 300ninz cac13

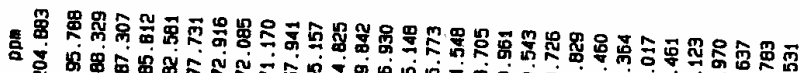

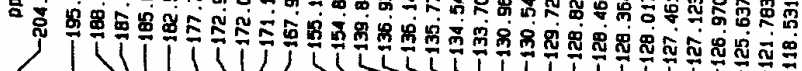

13110

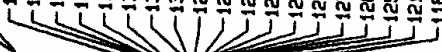

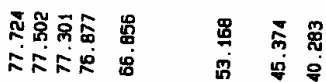

U

11

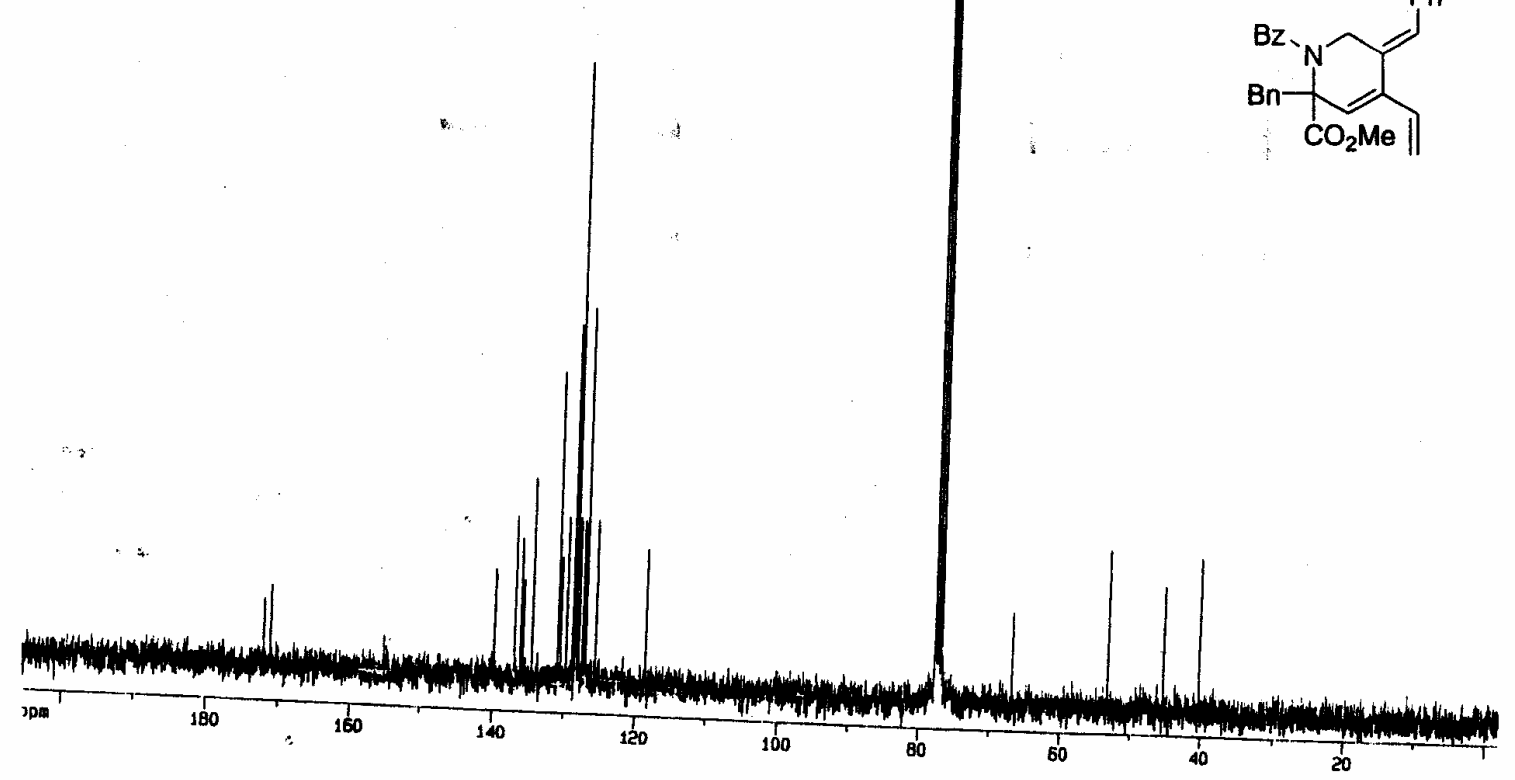



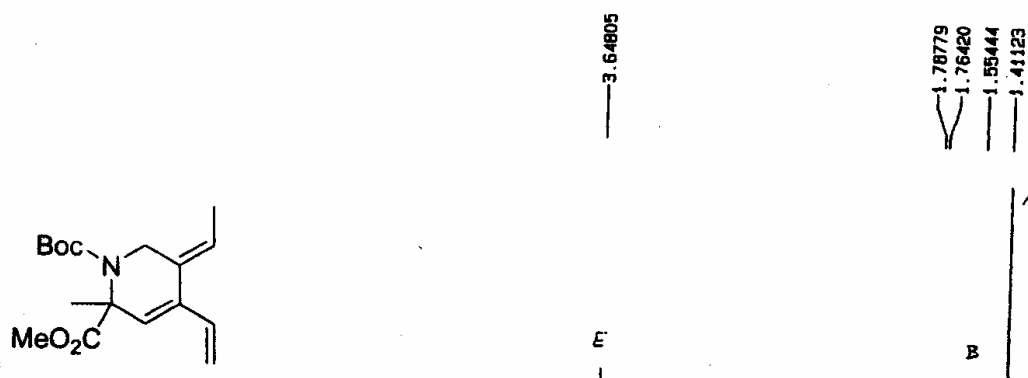

7, Table 2, Entry n
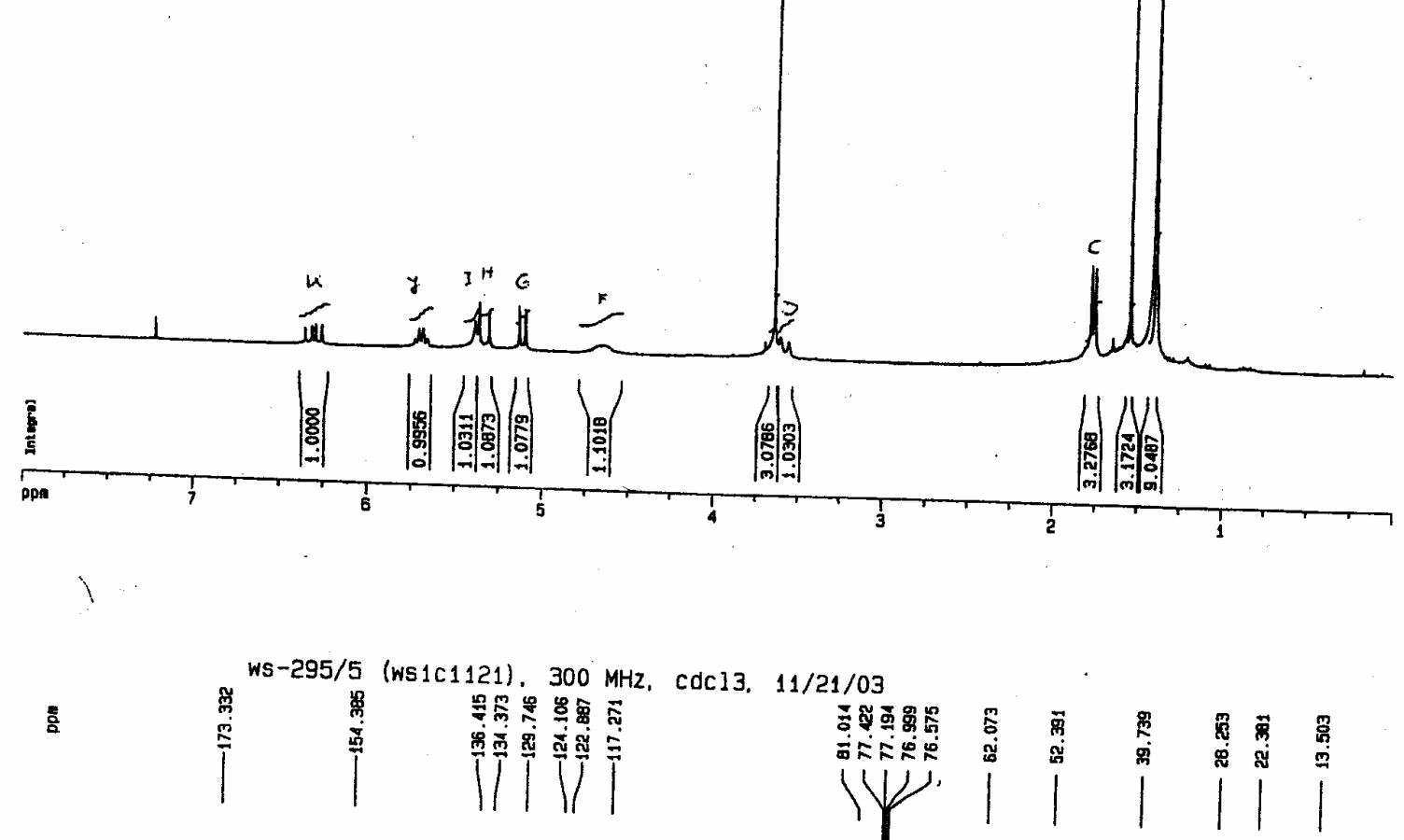<smiles>C=CC1=CC(C)(C(C)(C)C)N(C(=O)OC(C)(C)C)CC1=CC</smiles>

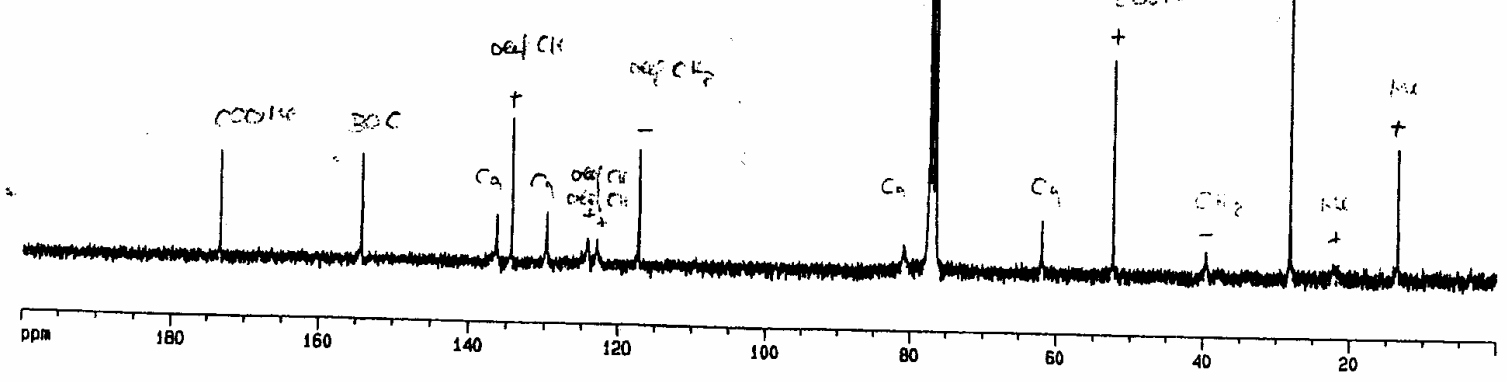


bm0149.01 cdcl3 rt 300mhz
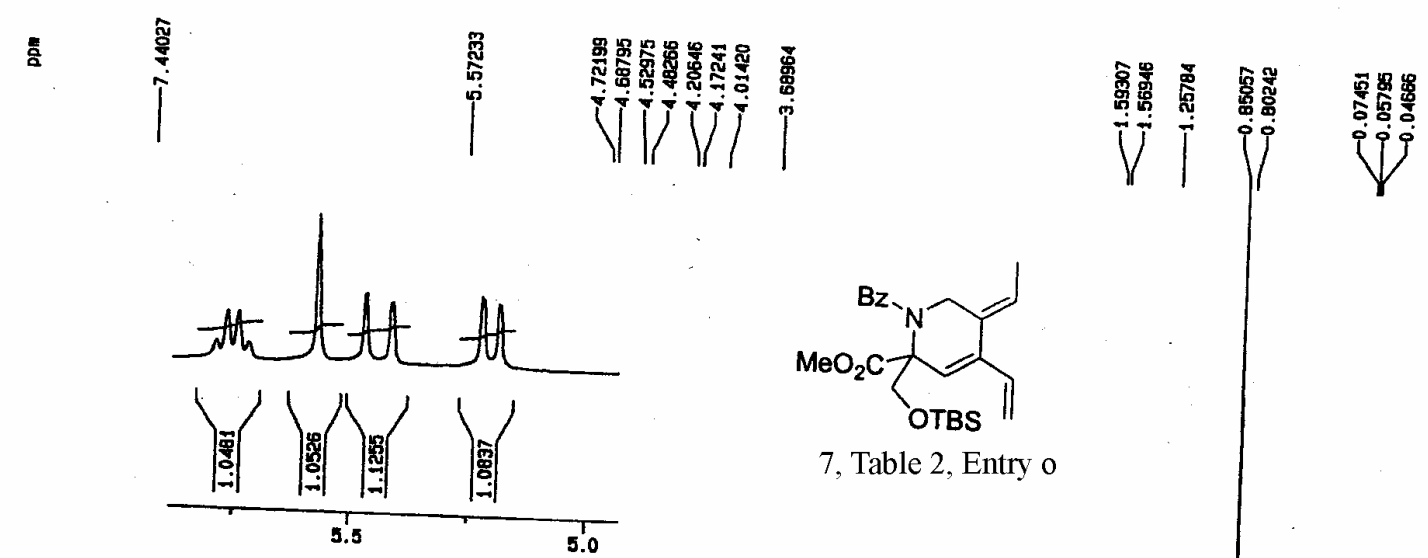

7, Table 2, Entry o
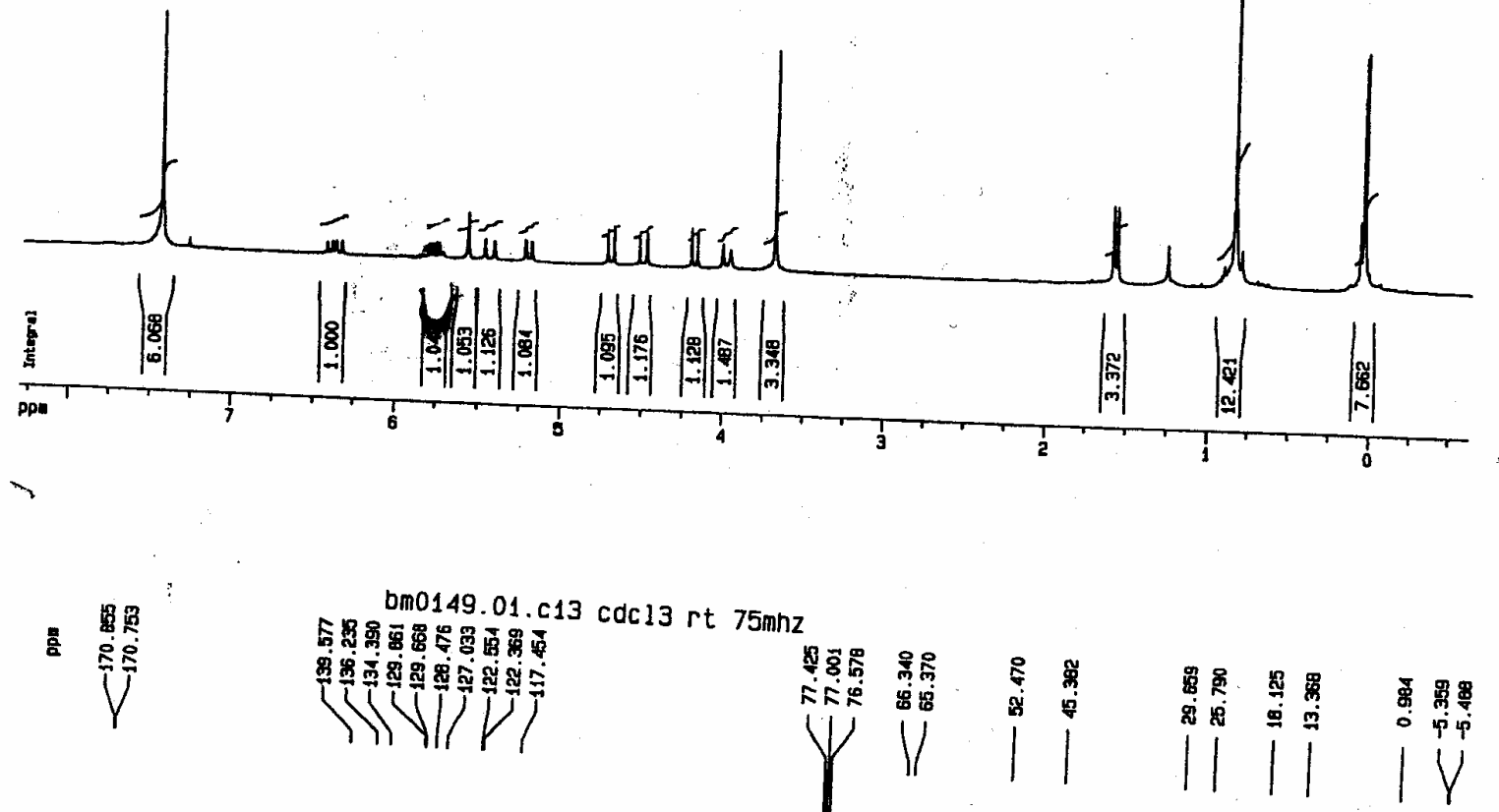<smiles>[B]OCC1(C(C)=O)C=C(C=C)C(=CC)CN1C(C)=O</smiles>

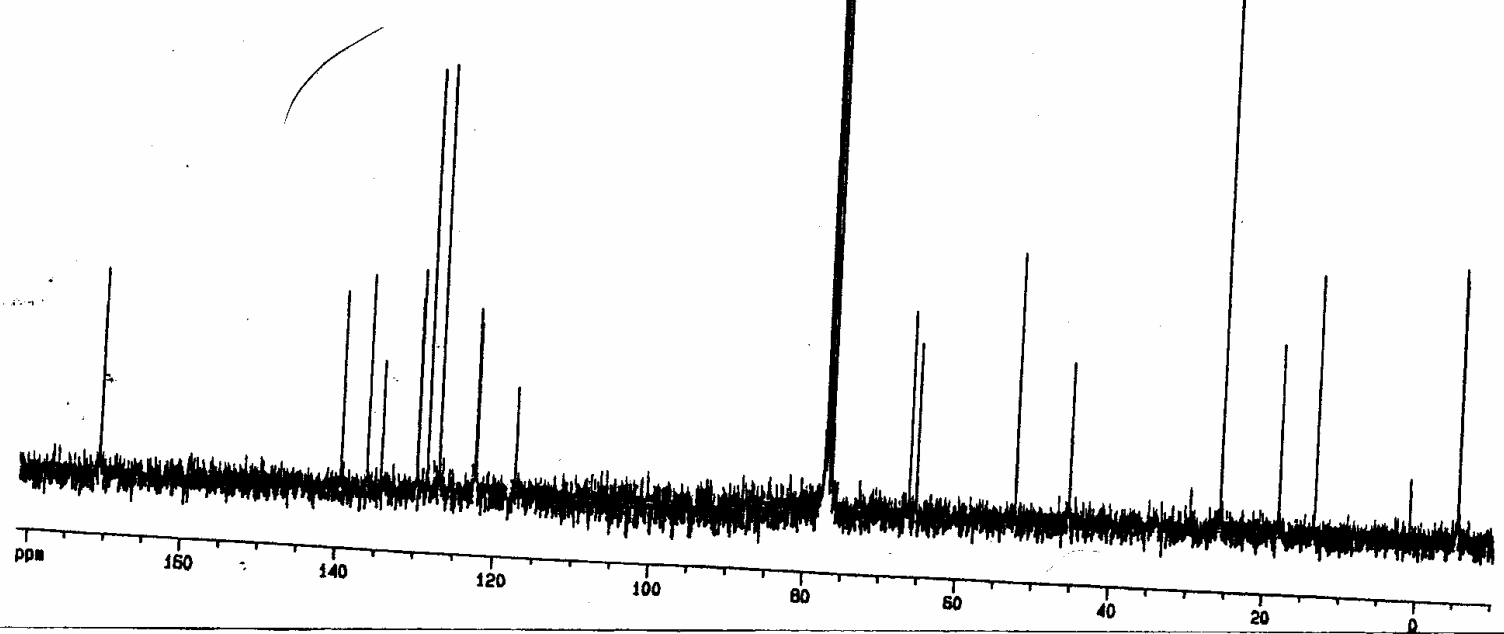



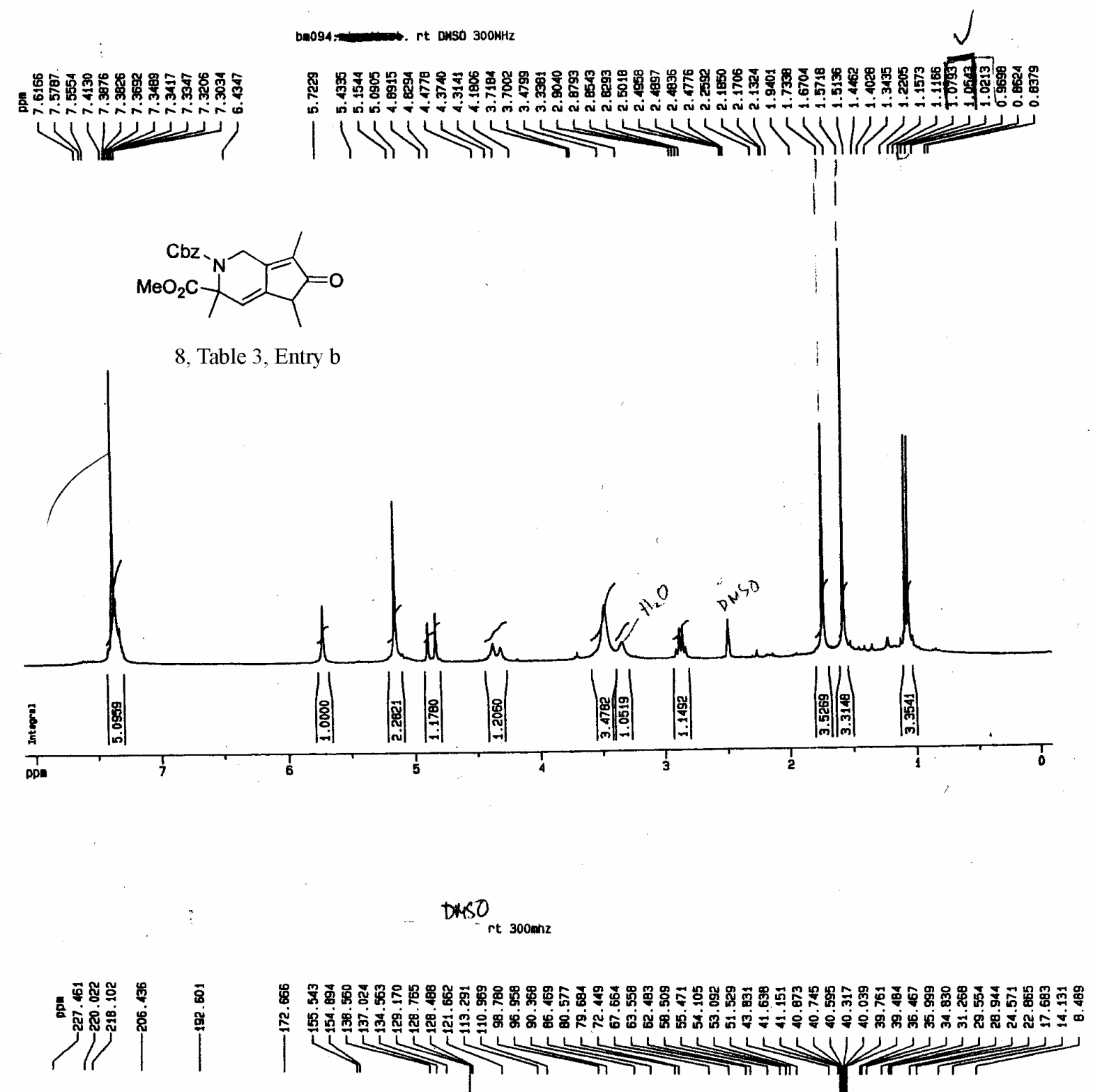<smiles>CC(=O)N1CC2=C(C)C(=O)C(C)C2=CC1(C)C(C)(C)OC(=O)c1ccccc1</smiles>

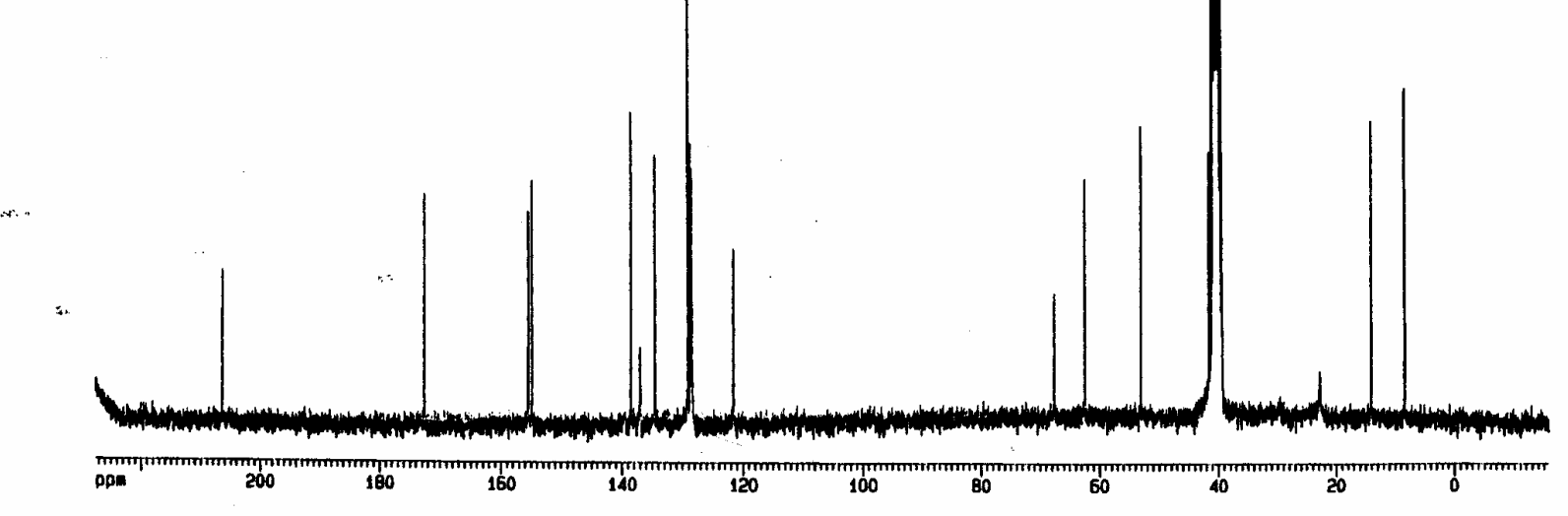



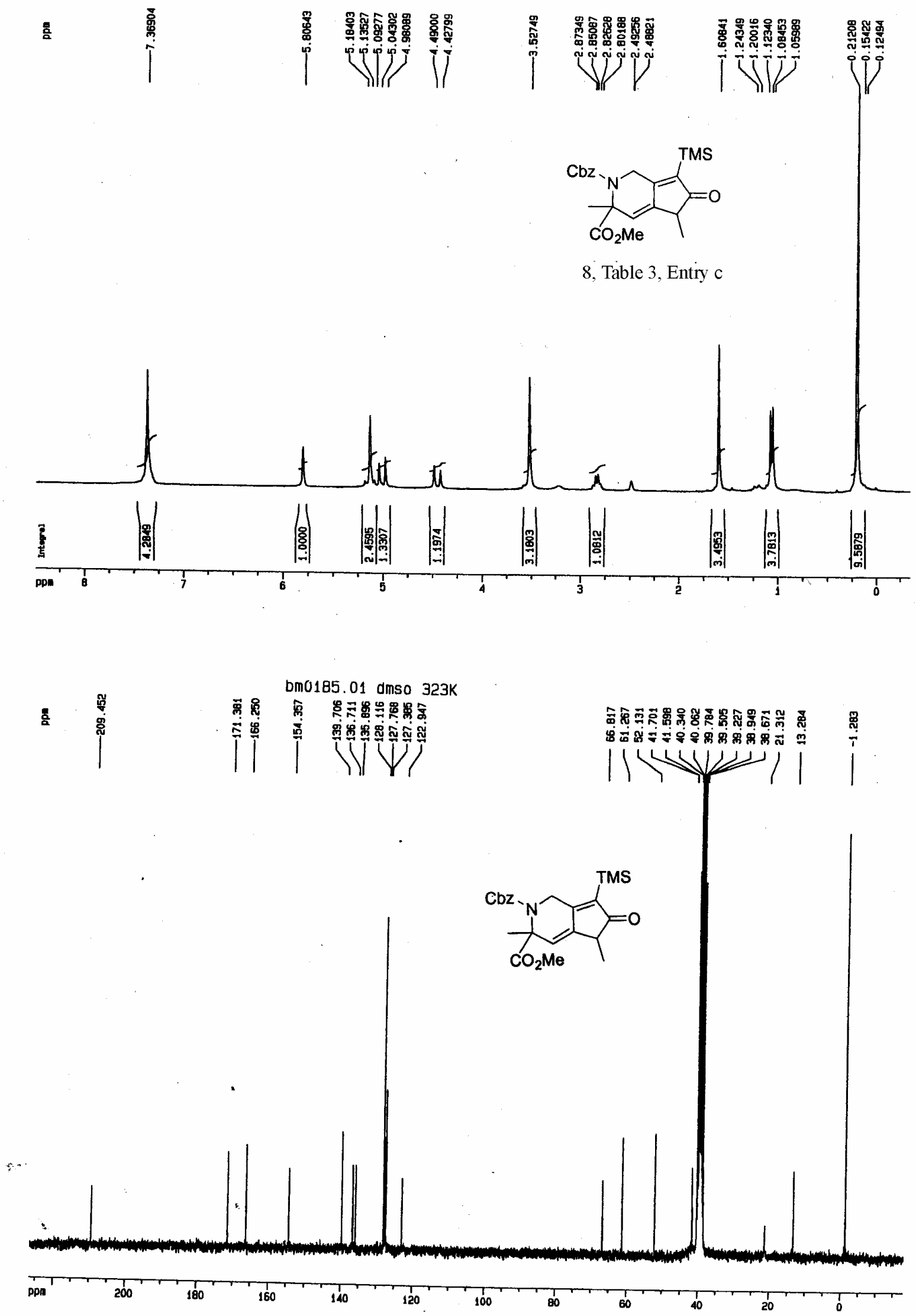
bm0184.01 dmso rt 300MHz

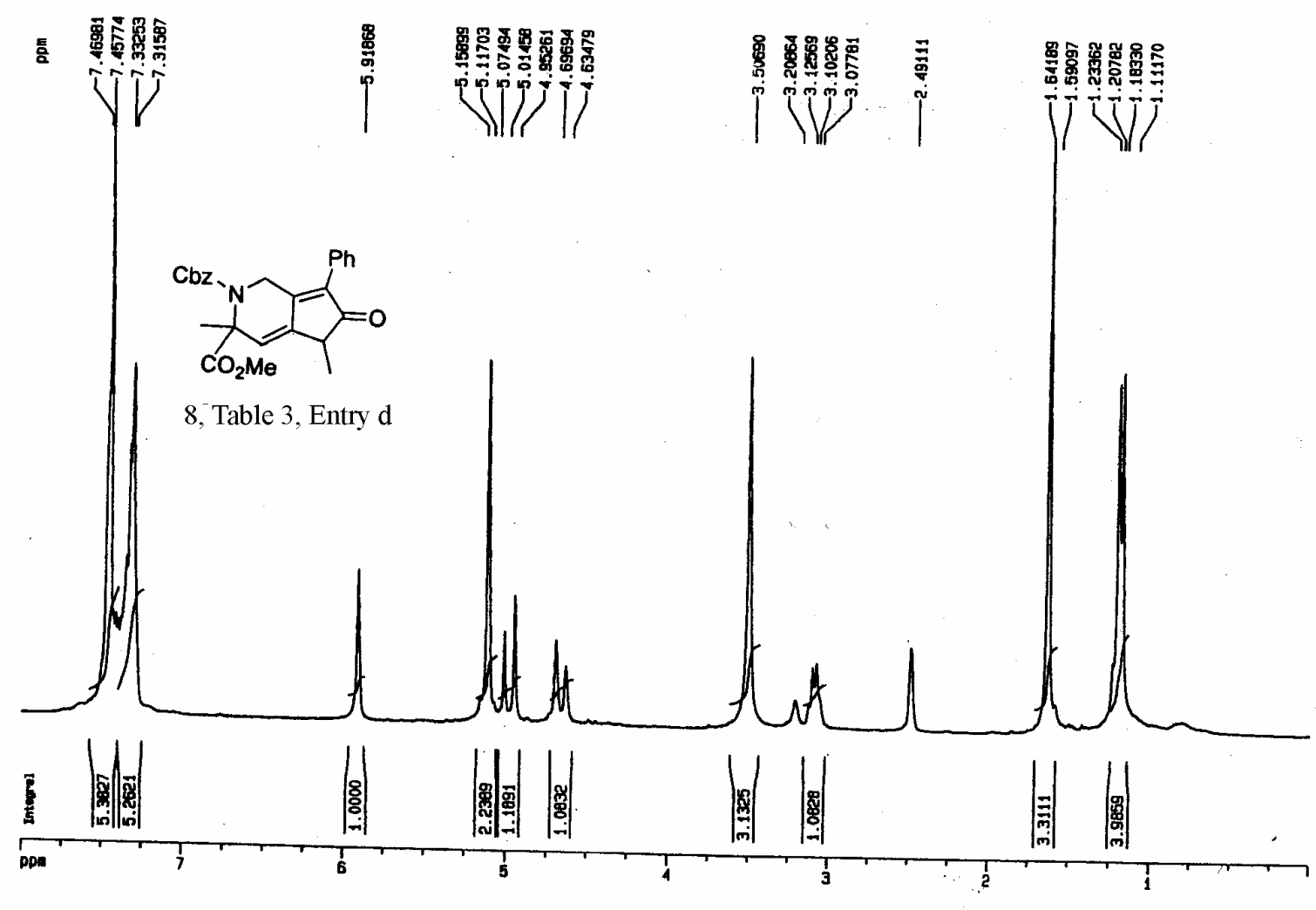

$-$

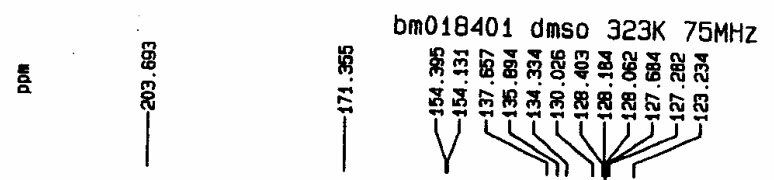

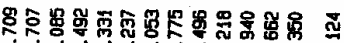

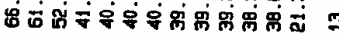

111

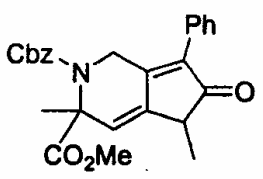

1

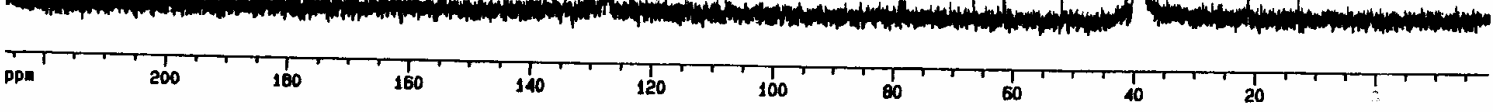


bm0520. pure coc13 320K 300MHz ,

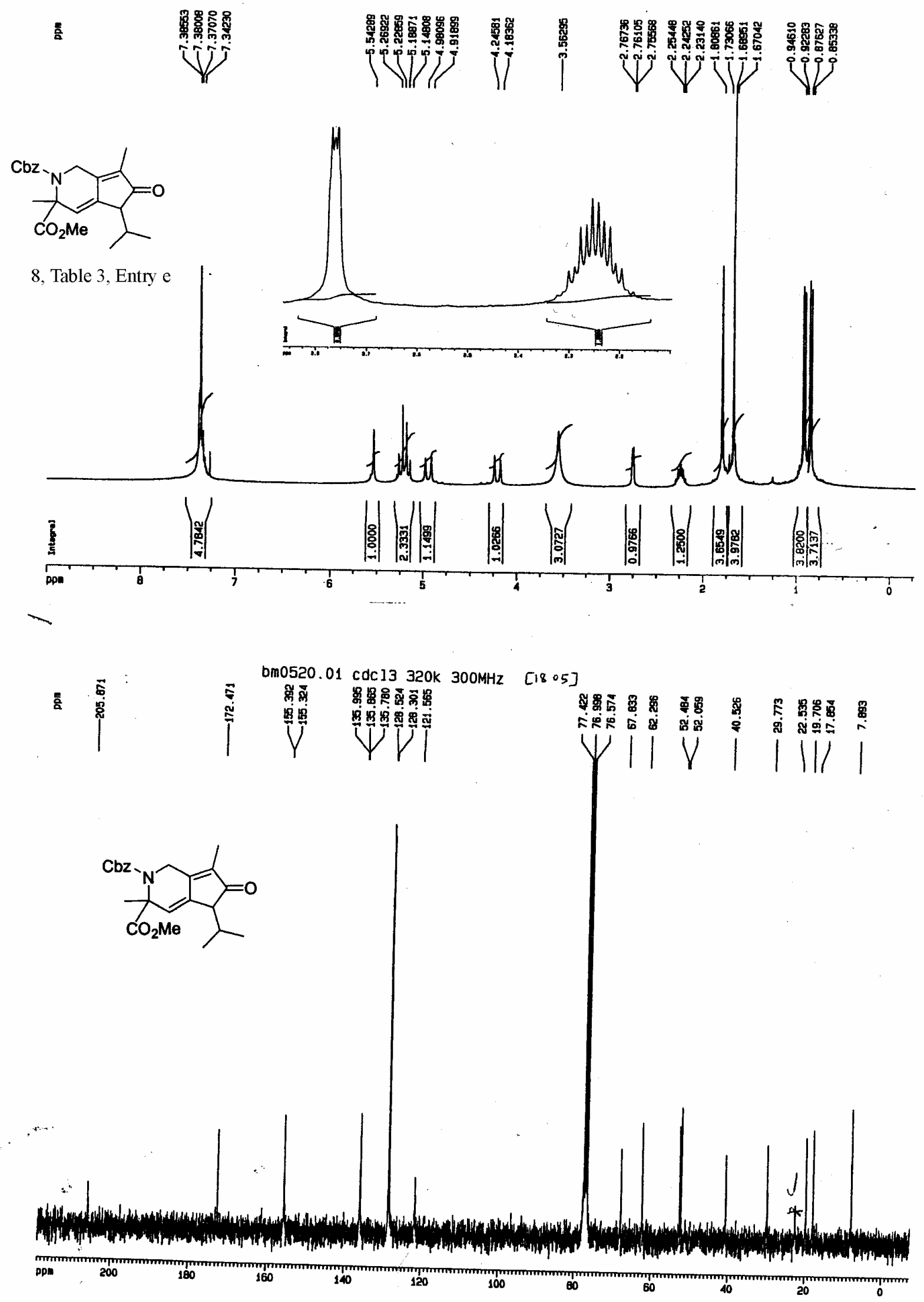




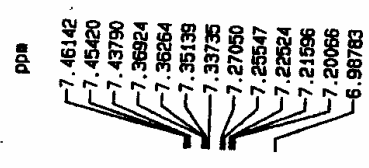

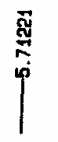
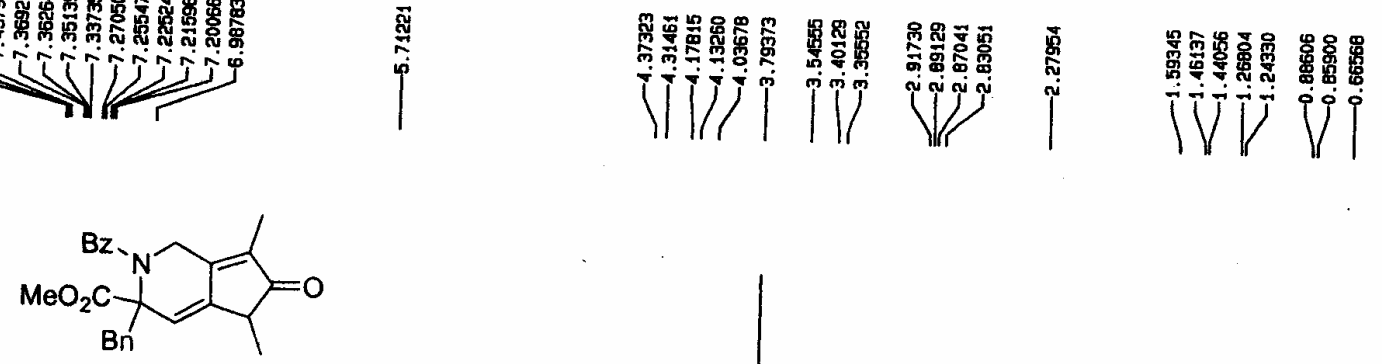

8, Table 3, Entry g
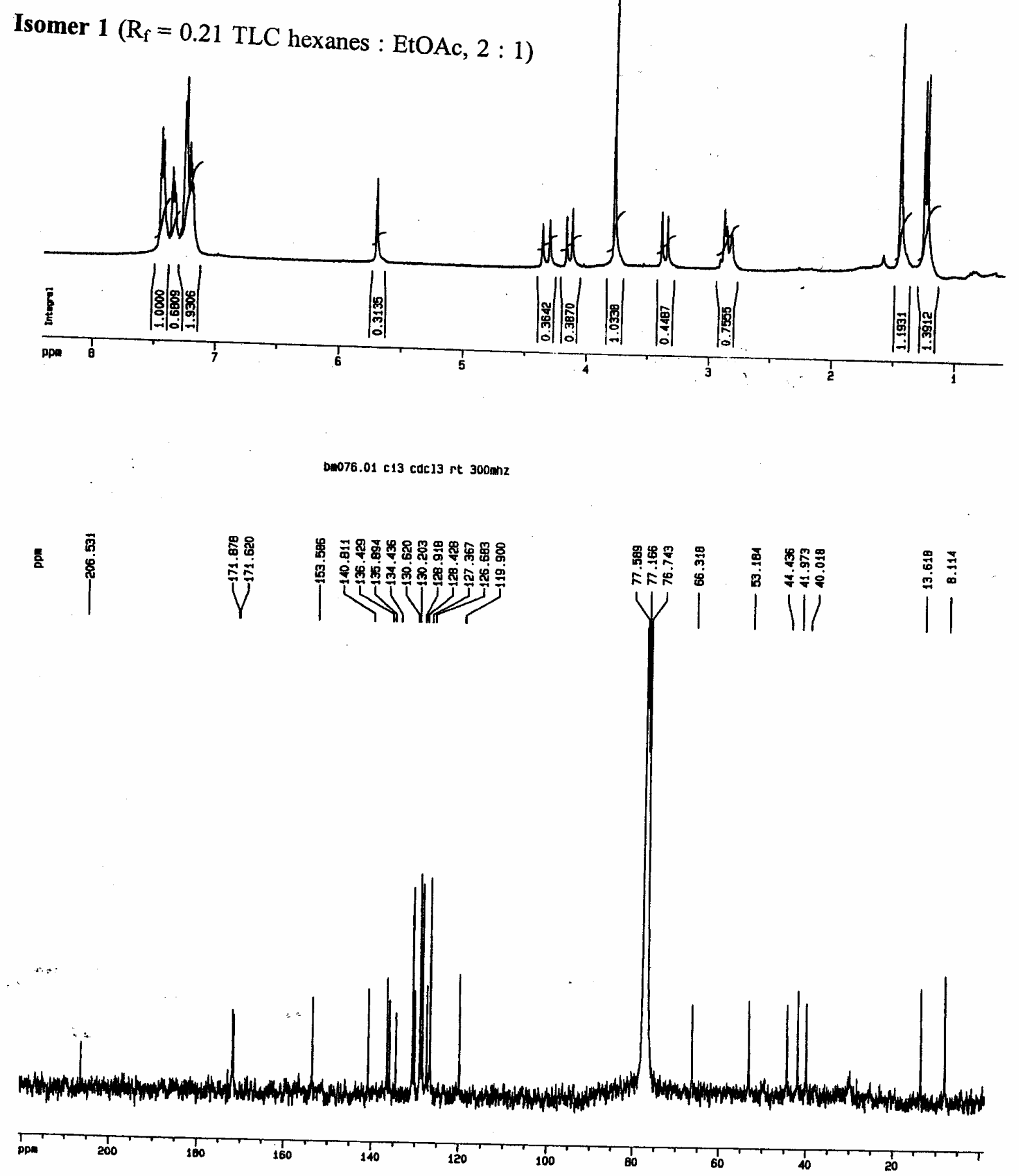


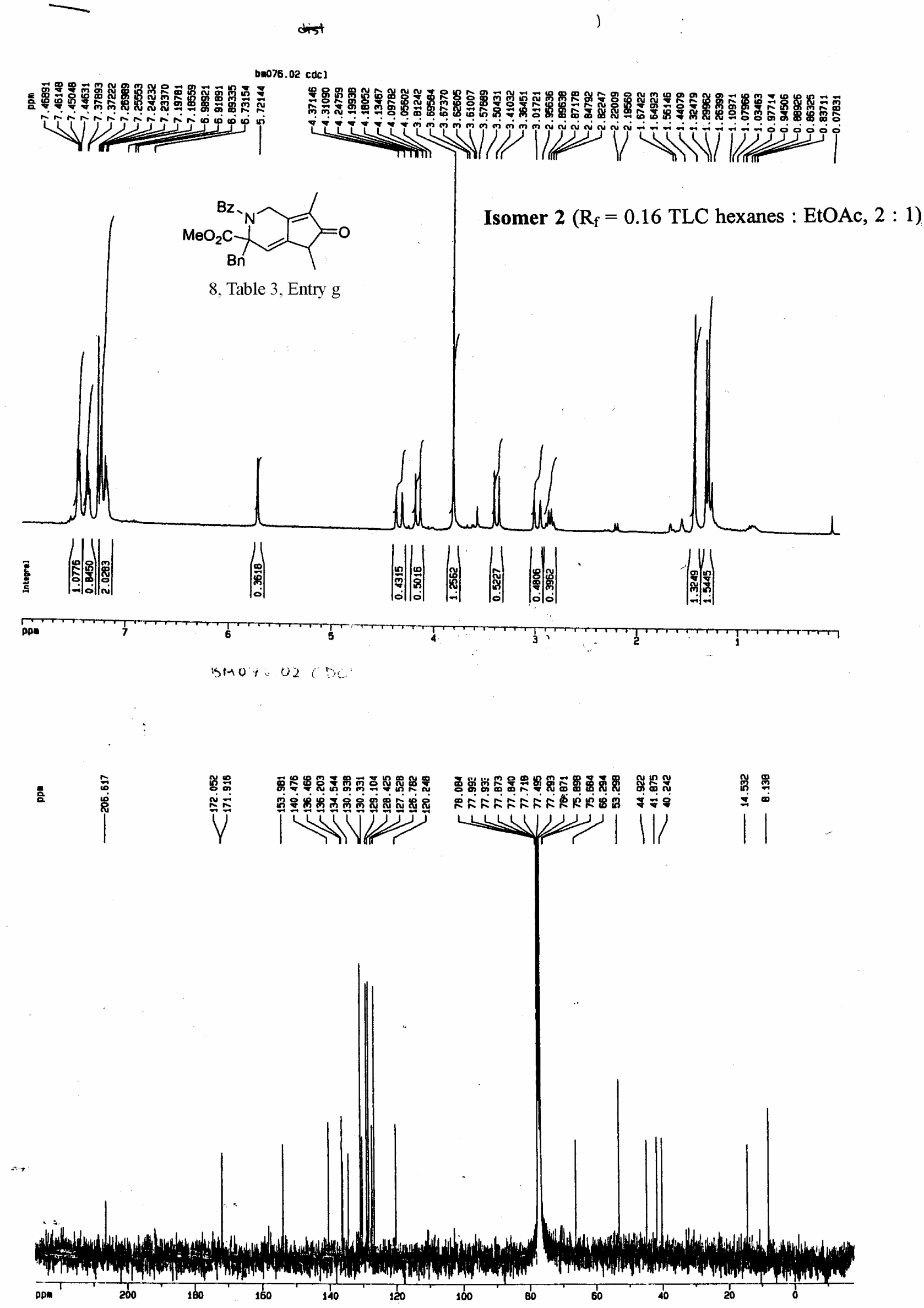



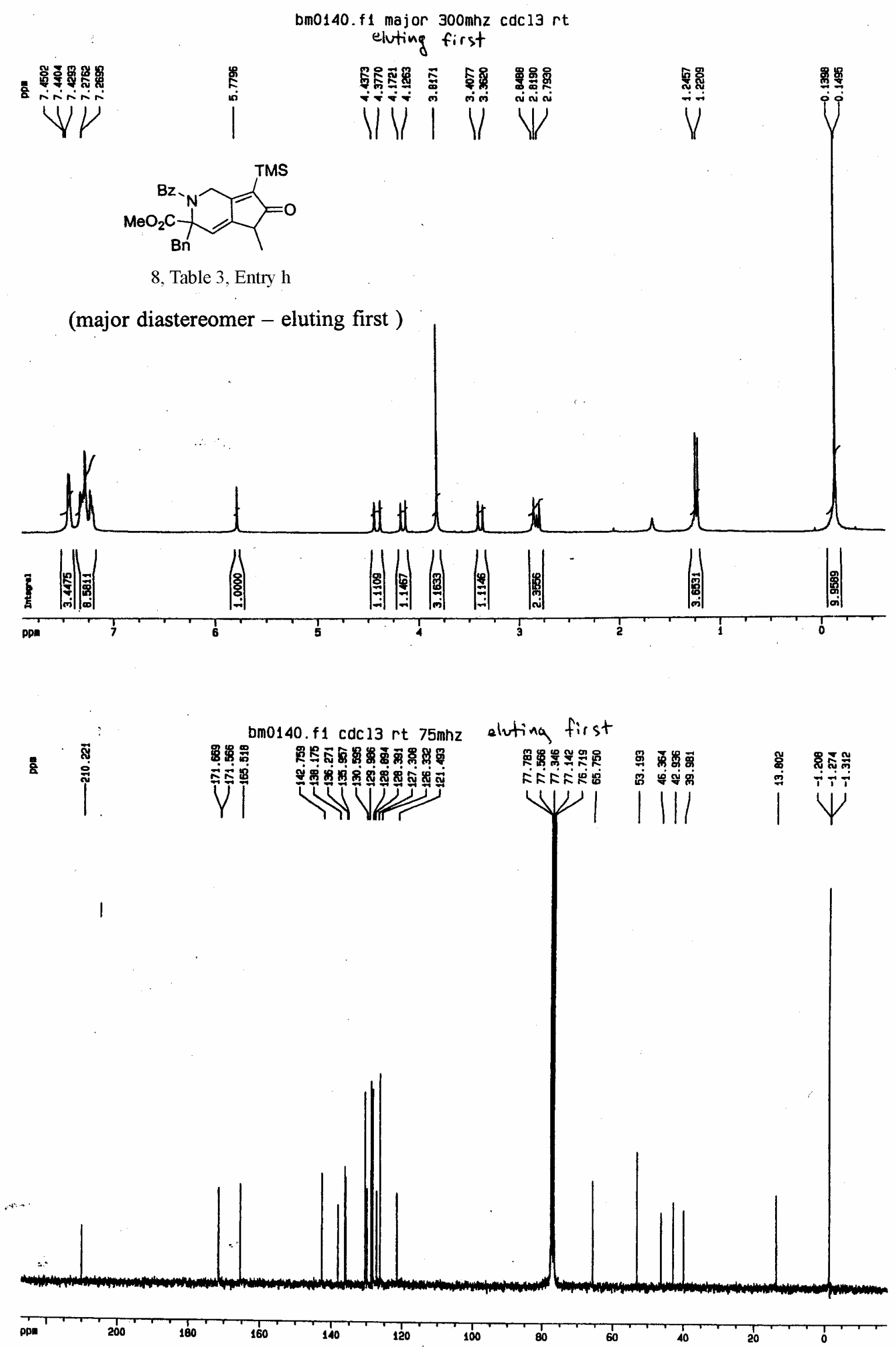

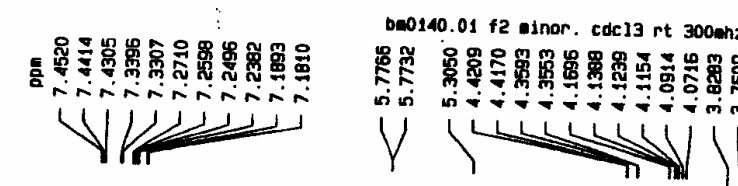

$\curlywedge$

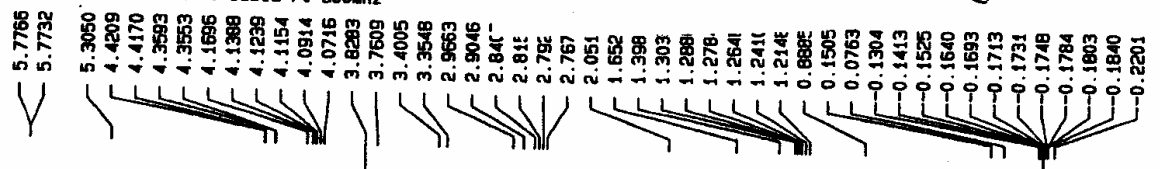<smiles>CC(=O)C1=C2CN(C(C)=O)C(Cc3ccccc3)(C(=O)c3ccccc3)C=C2C(C)C1=O</smiles>

8, Table 3, Entry h

(minor diastereomer - eluting second)
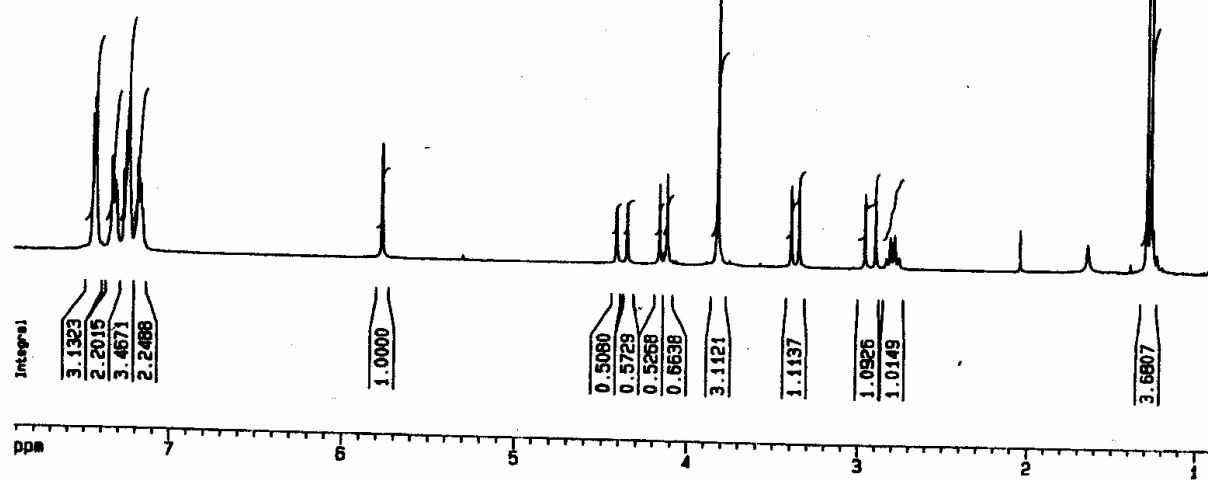

ad
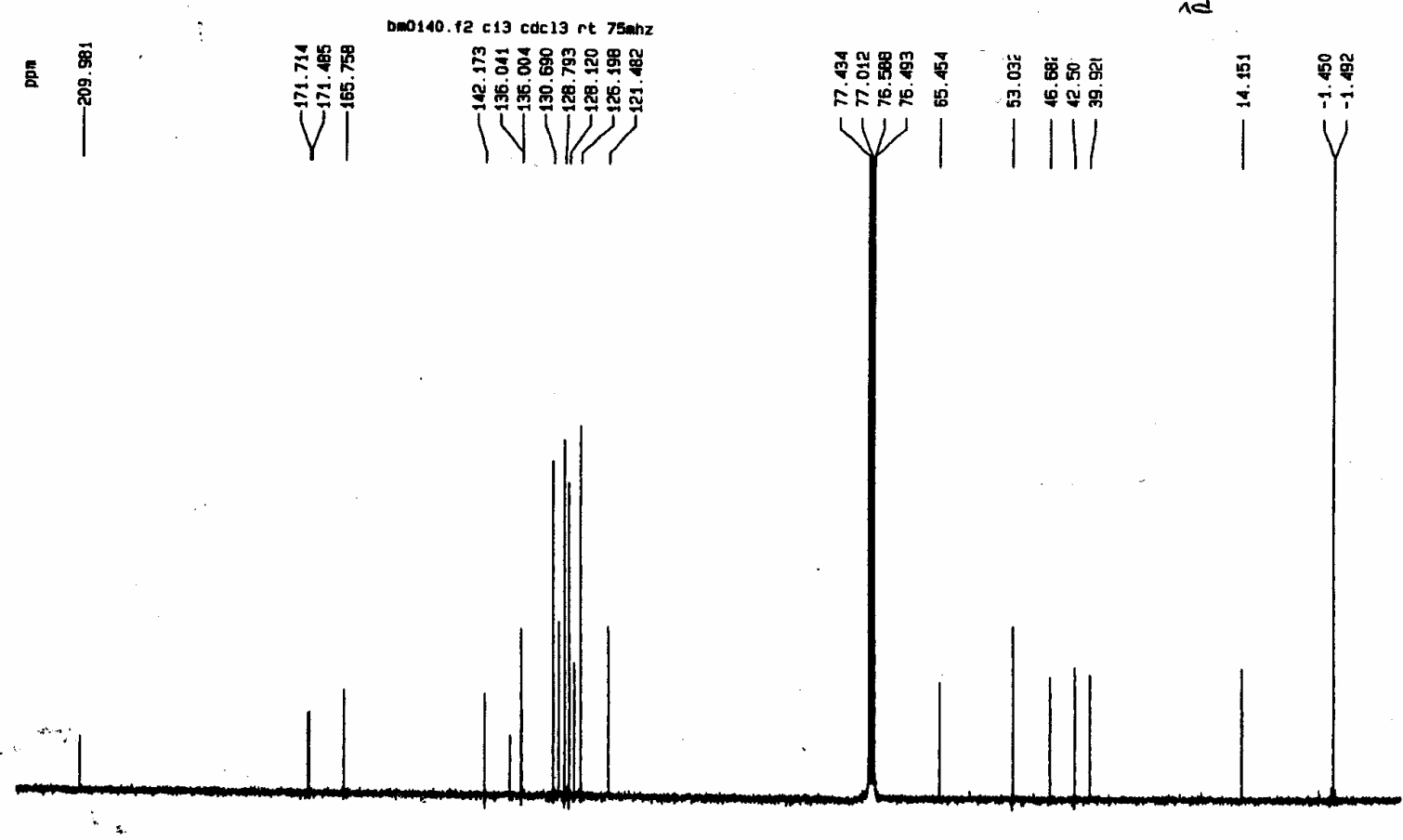

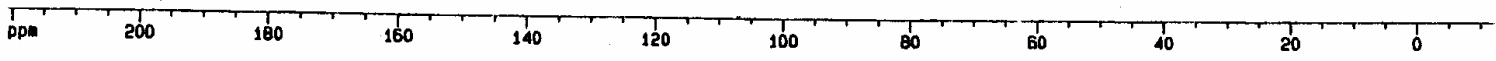


(major diastereomer $\mathrm{R}_{\mathrm{t}}=15$ min HPLC, hexanes : EtOAc $5: 1, \mathrm{v} / \mathrm{v}$ ):
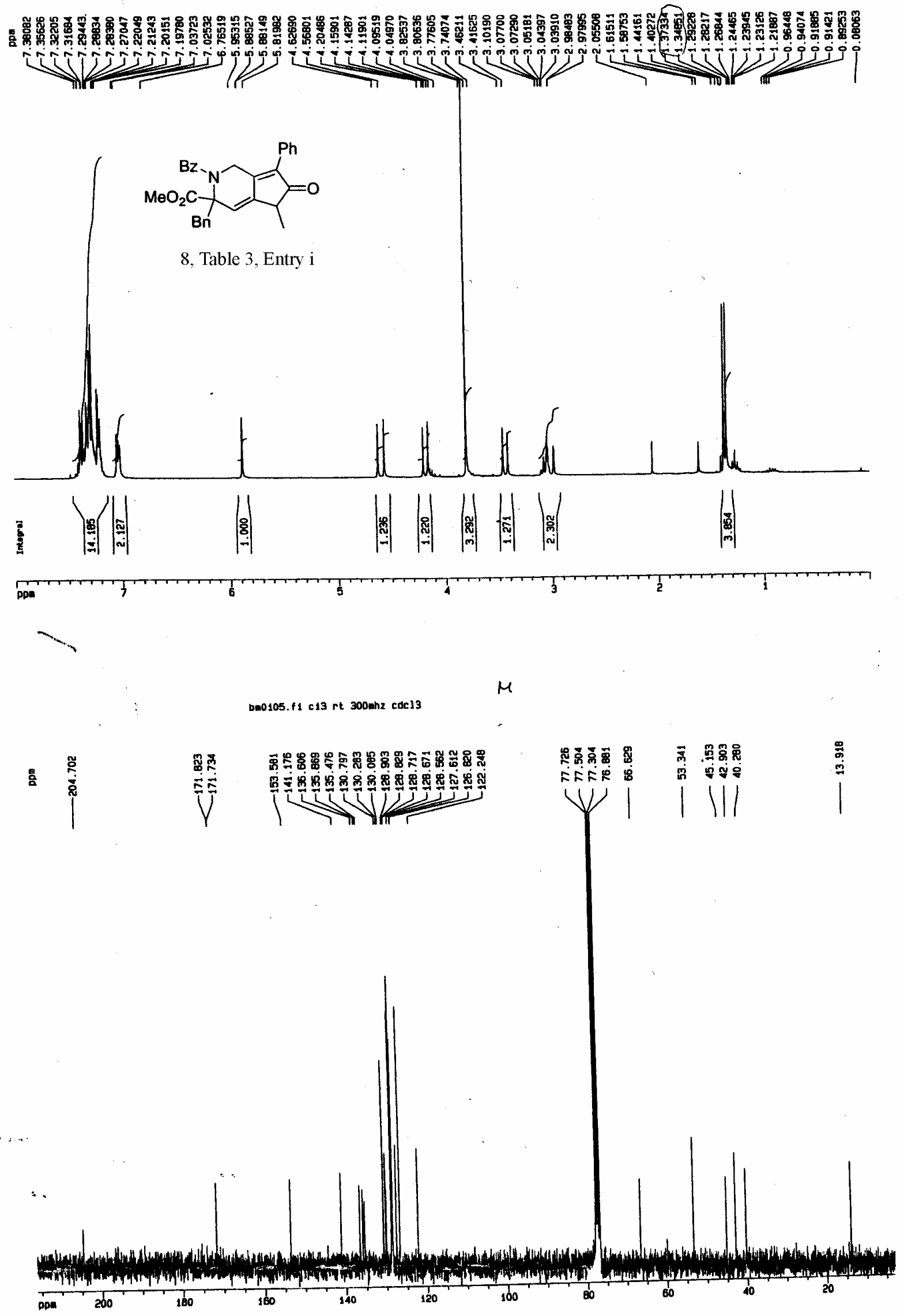
(minor diastereomer $\mathrm{R}_{\mathrm{t}}=18 \mathrm{~min}$ HPLC, hexanes : EtOAc $5: 1$ )

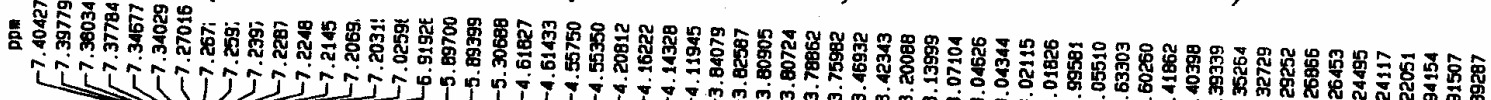

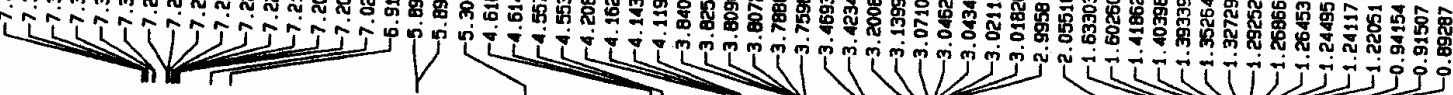

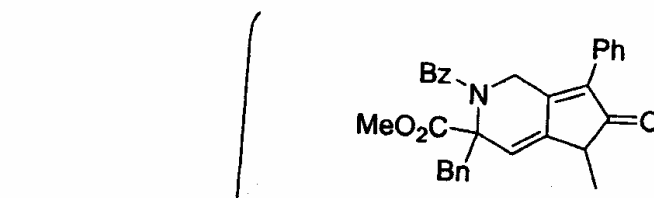

8, Table 3, Entry i
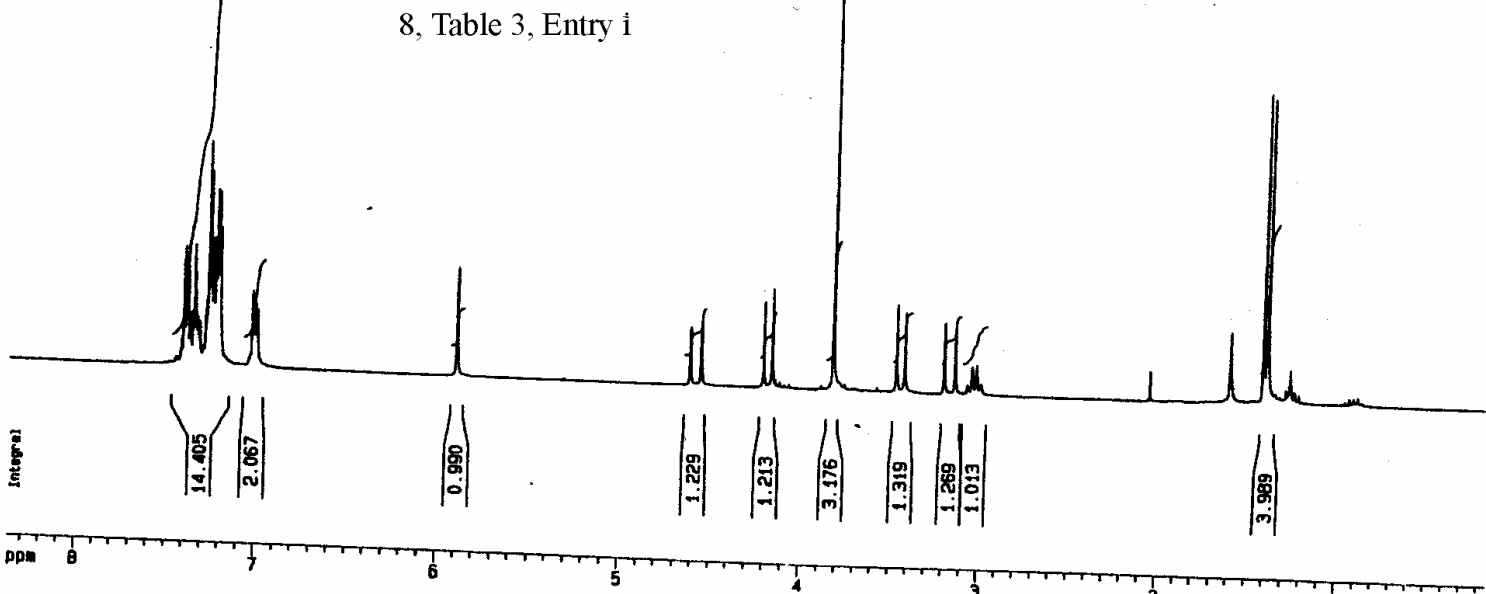

bmo105.01 f2 rt 300and cdc 13

.

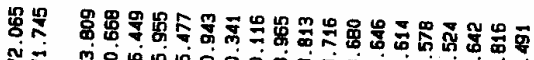

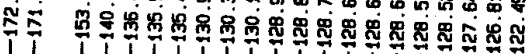
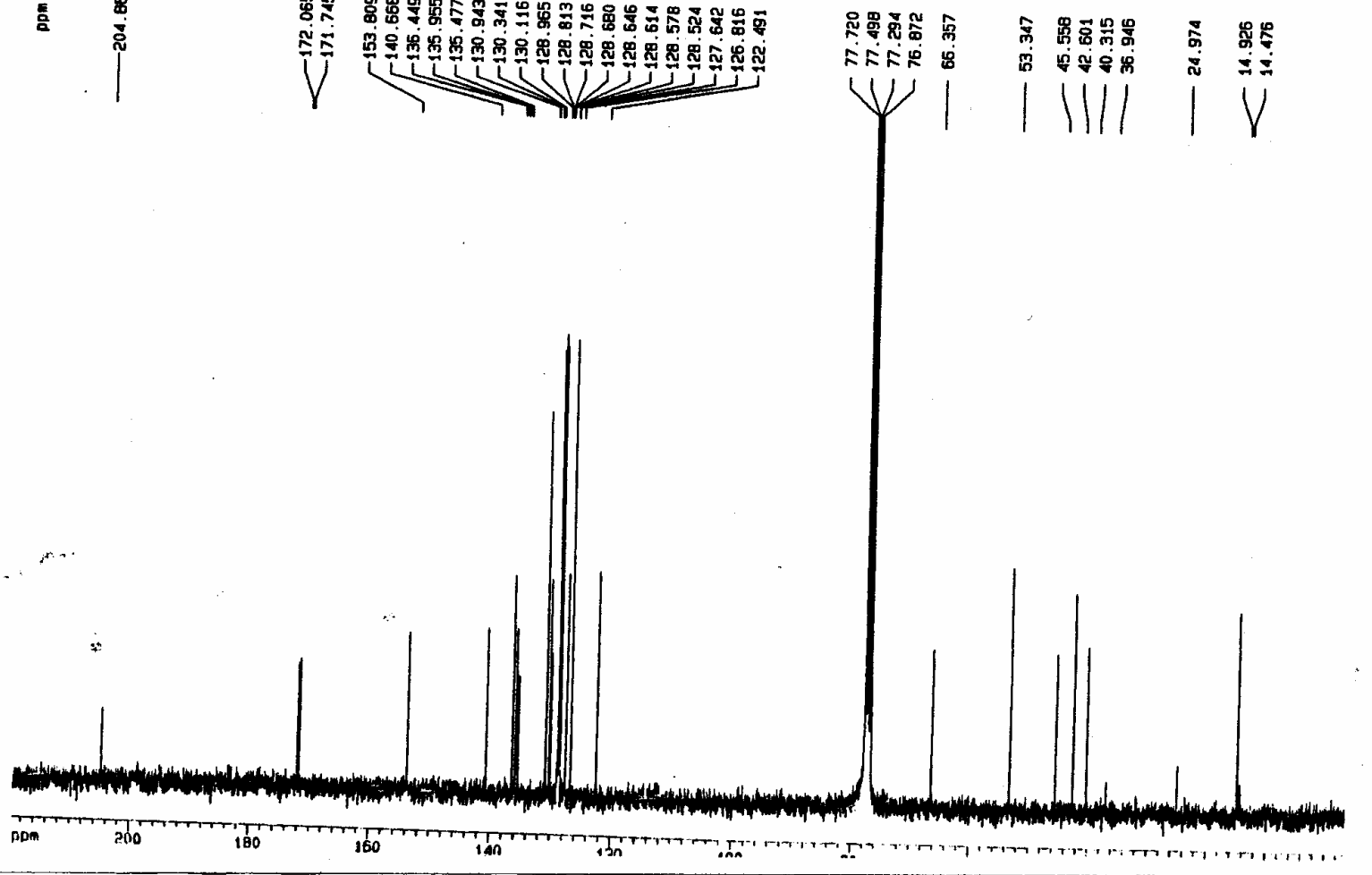


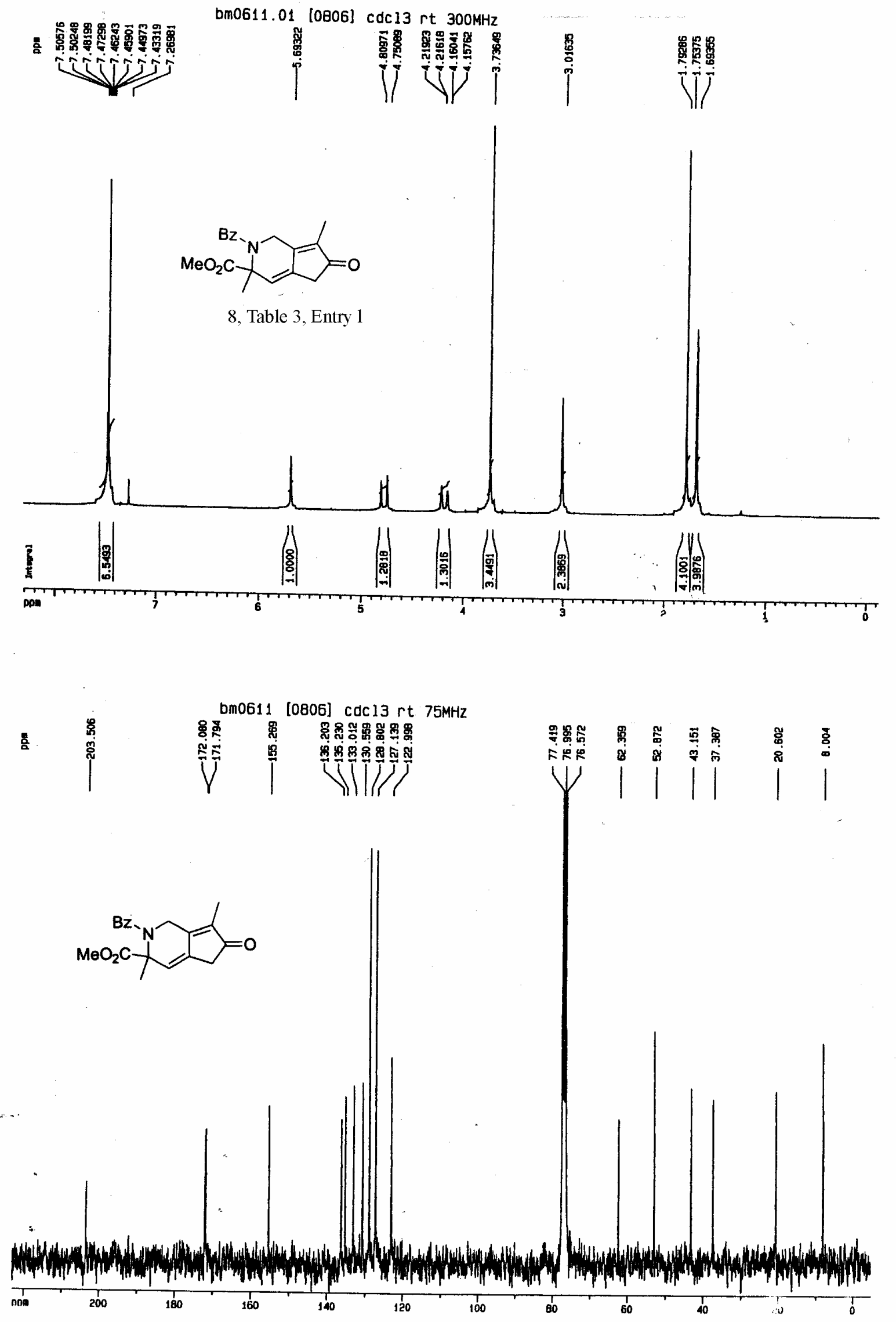



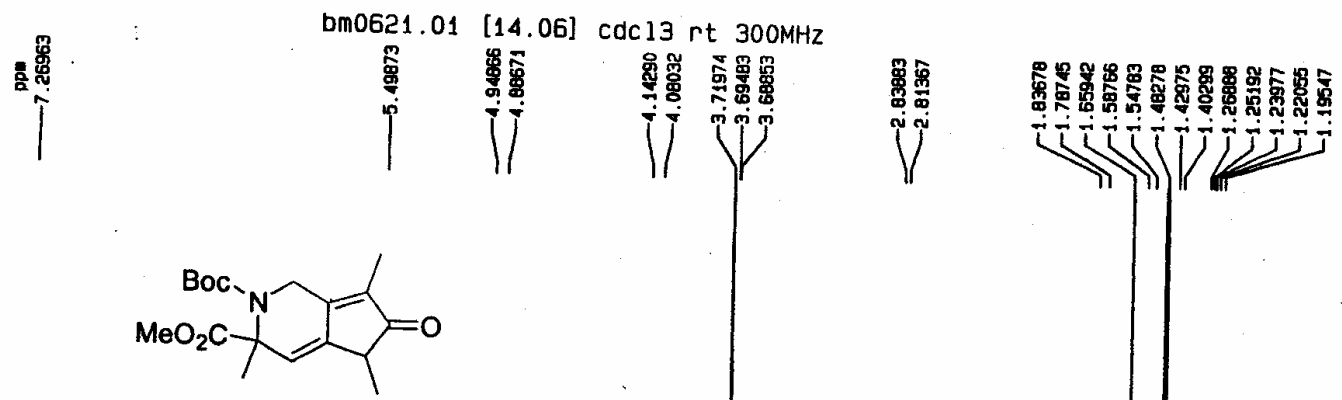

8, Table 3, Entry n

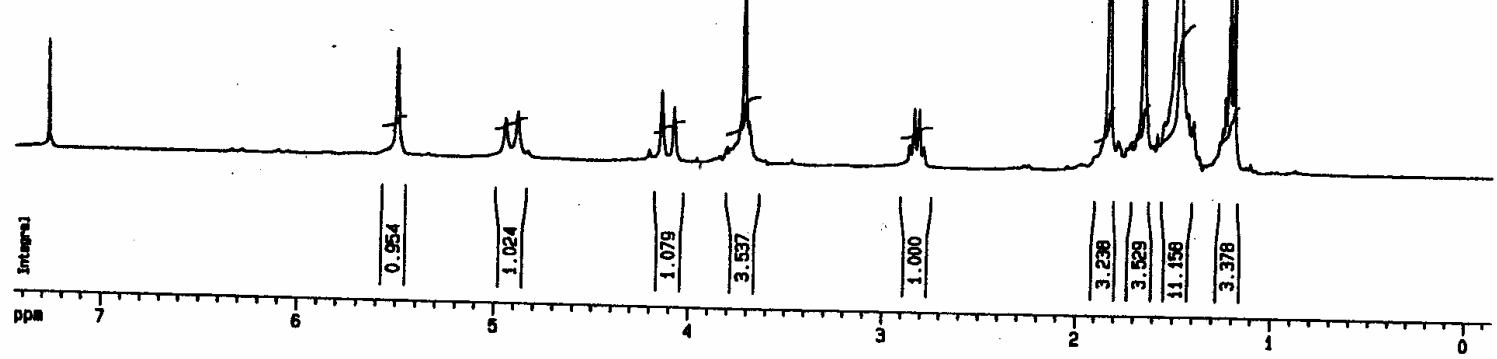

言
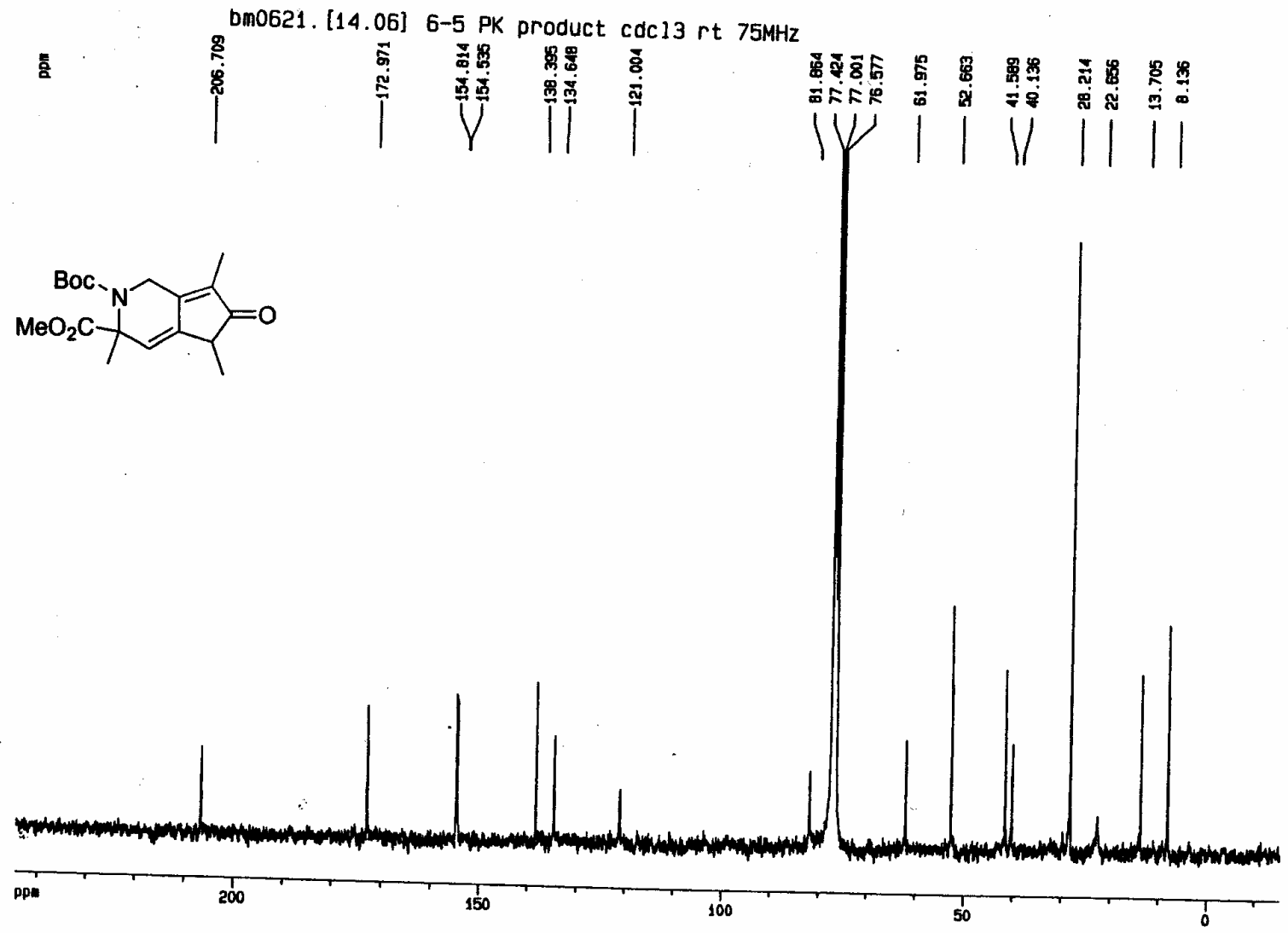

94 
(major diastereomer $\mathrm{R}_{\mathrm{t}}=17$ min HPLC, EtOAc : Hex $1: 6$ )

等

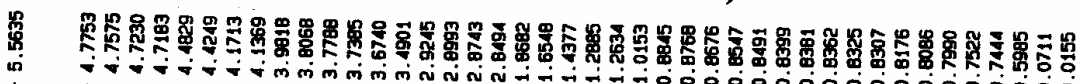

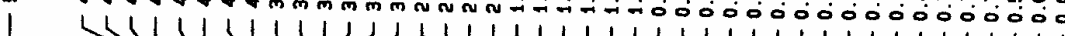

Y Y YIVIII W W

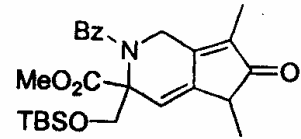

8, Table 3, Entry o

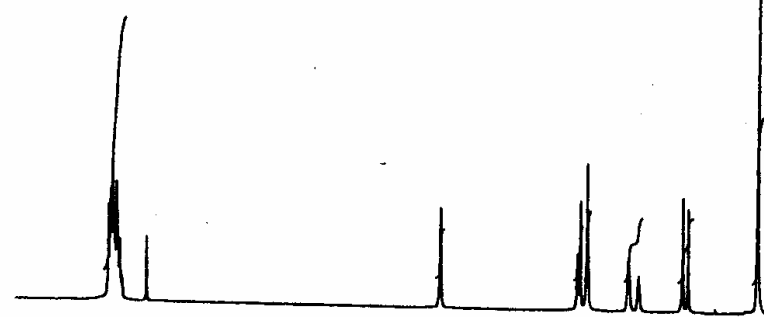

$\left|\begin{array}{l}\mid \\ \stackrel{0}{*} \\ \cdots\end{array}\right|$

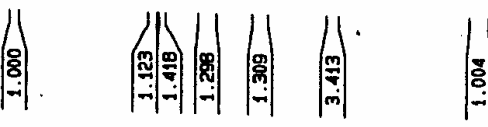

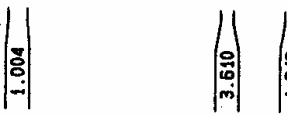

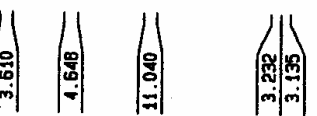

ppm
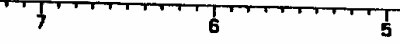

Throrth

FI maior.

$b$

咅 点

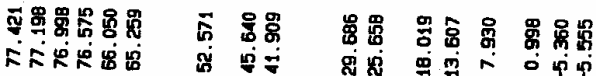

W

11111111

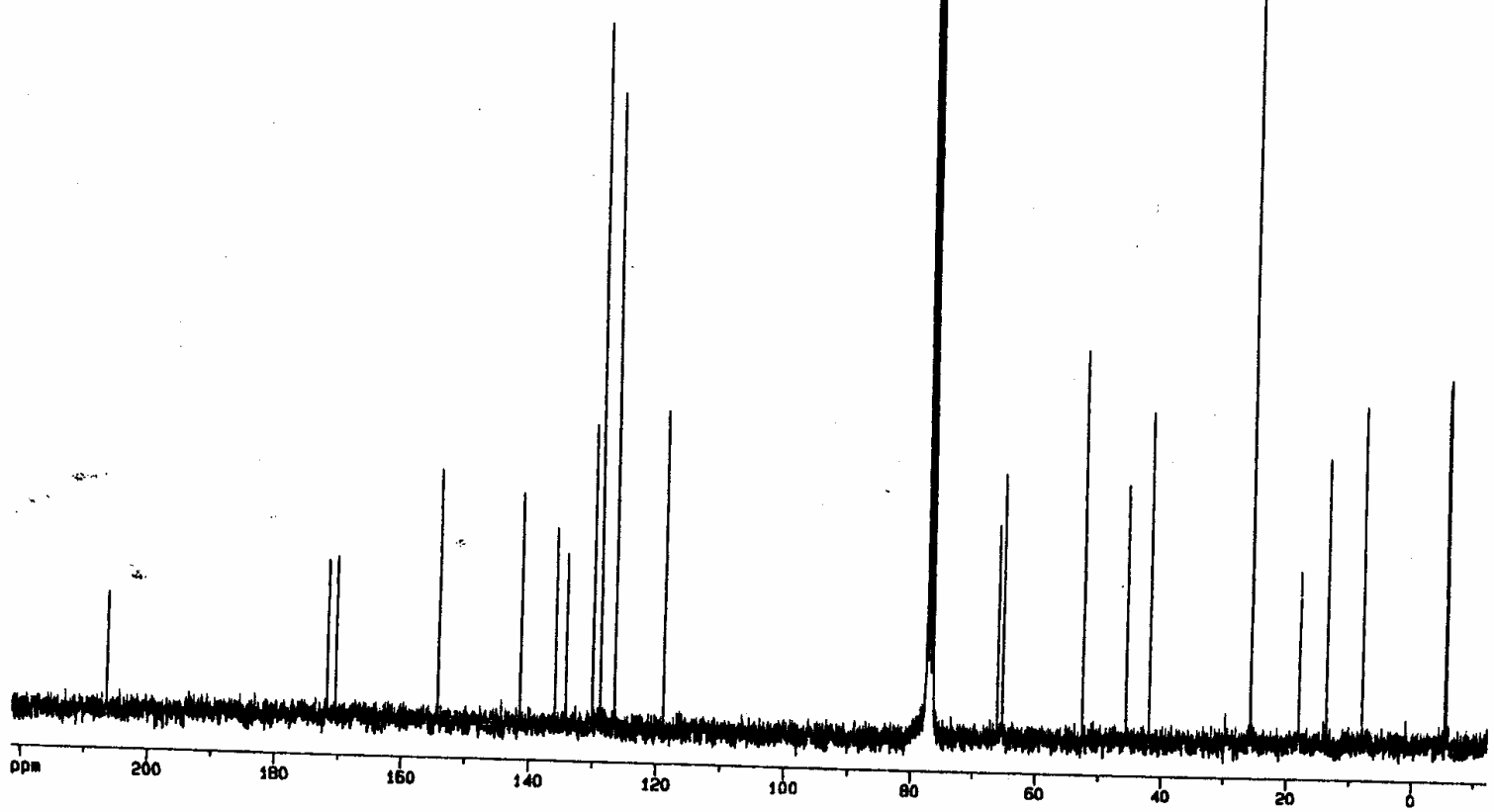


(minor diastereomer $\mathrm{R}_{\mathrm{t}}=26 \min$ HPLC, EtOAc $:$ Hex $1: 6$ )

:

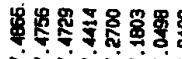
Wilii
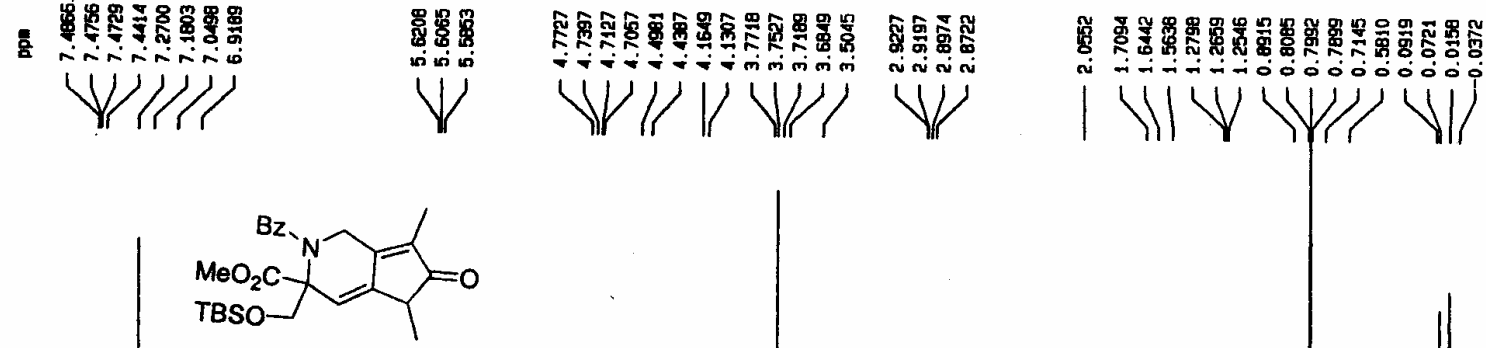

8, Table 3, Entry o
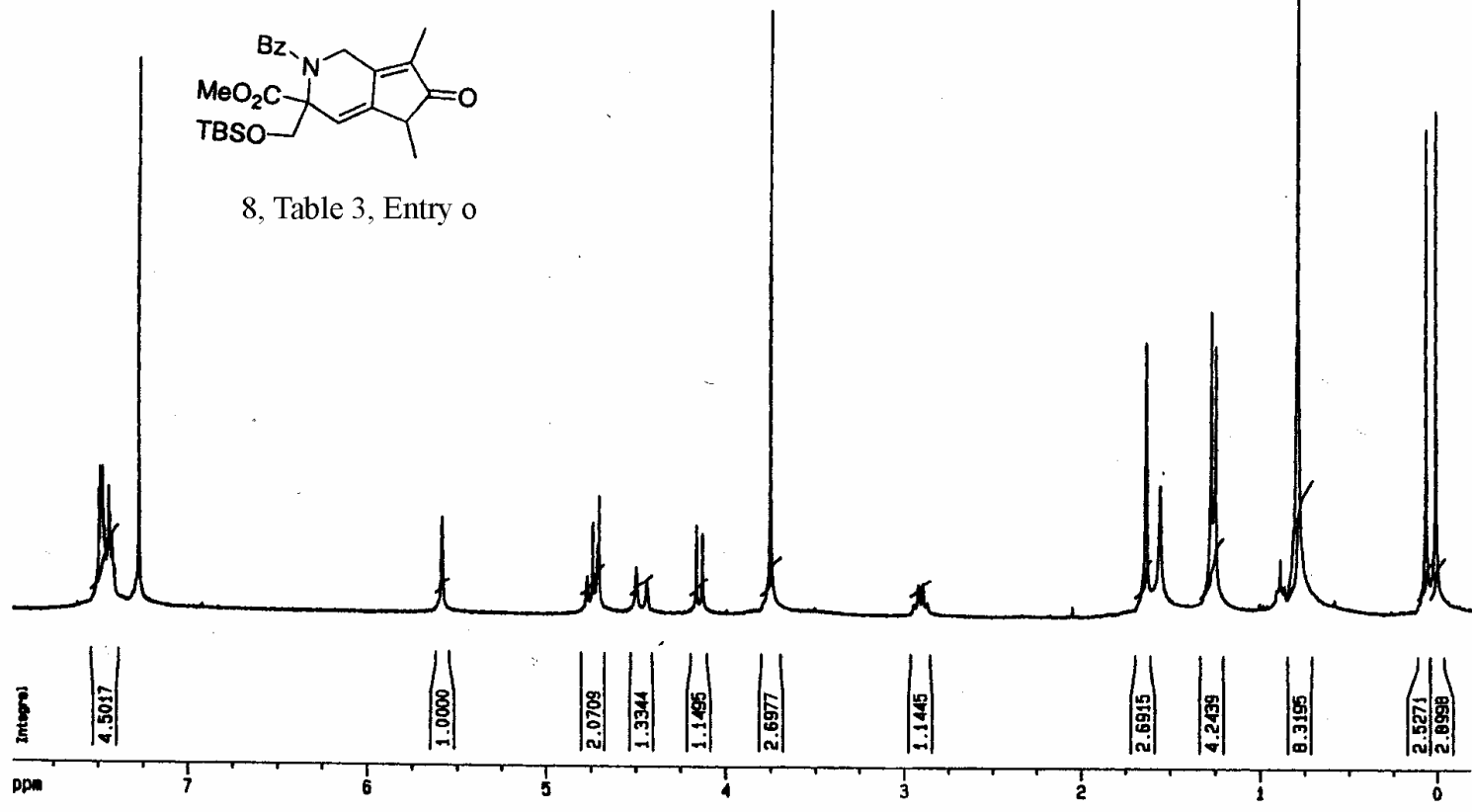

be0150.02 t2 minor coc13 rt $75 \mathrm{mhz}$

$$
\text { eluting second }
$$

|

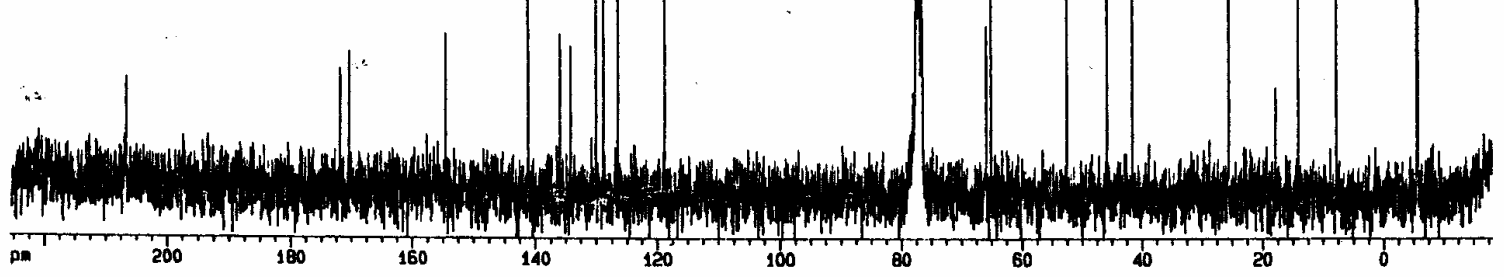


$\mathrm{BSI} \angle 0^{\circ} \mathrm{T}$
$98 \angle \angle 0^{\circ} \mathrm{T}$

26I0T'

EIBOT:-

$\checkmark \angle L G T^{\circ} \mathrm{C}$ $66181.2-$ EGEBD 2 $06687^{\circ} \mathrm{C}$ II96t"

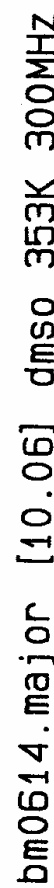
टS609 $E$

$66682 \cdot 9$ $76099^{\circ} E-$ $\angle 9699^{\circ} \mathrm{E}$ SLBG9 $E-$

$69600^{\circ} \vee$

DBBEÉ' $9 b 26 E^{\circ} b$ 9669 $\bullet$ OBLIS $\square-$

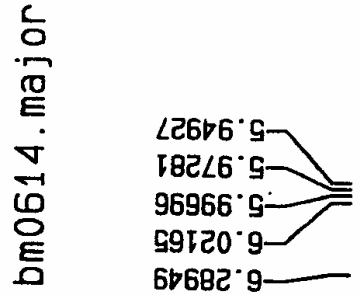

DZ6IE: $L$ E6VGE ' $L$

$9 S \square \angle E^{\circ} \angle$

Вट66E $\angle$

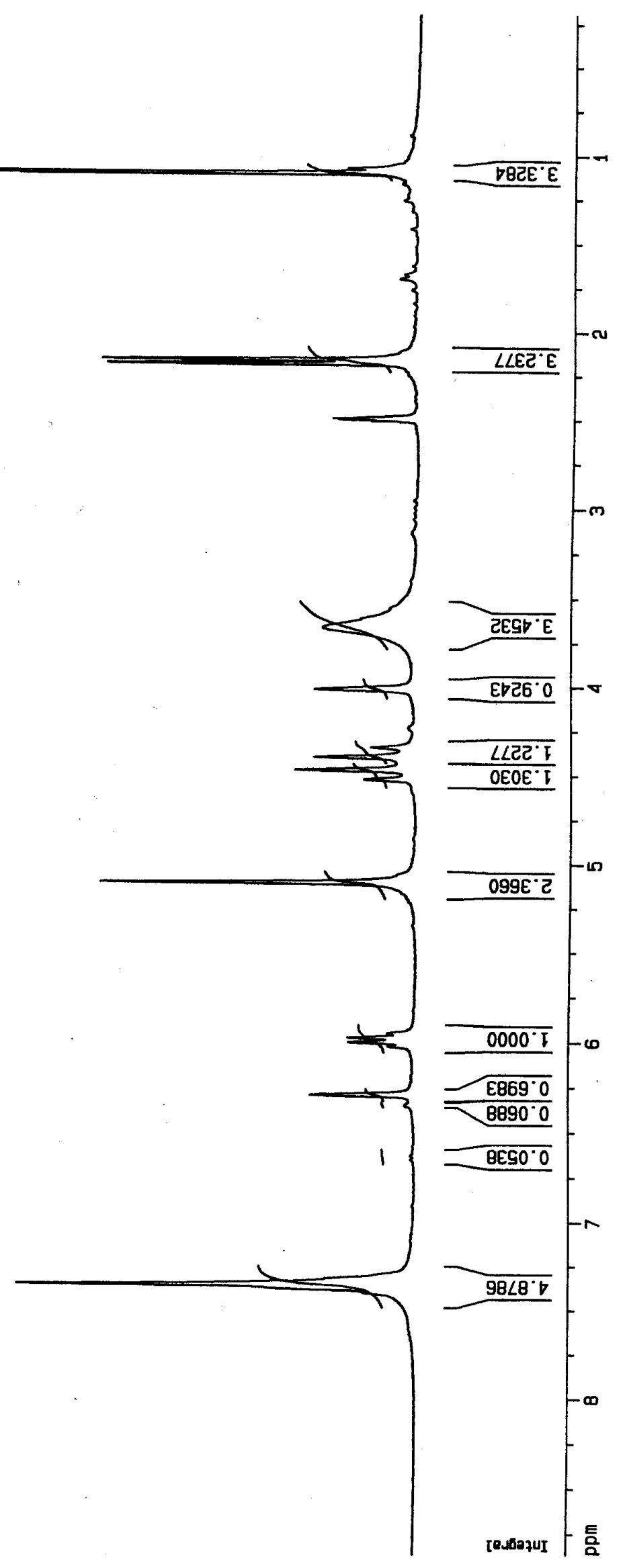

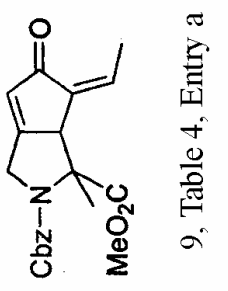

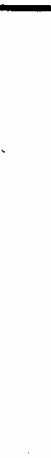


bm np 01 dmso $343 k$

立
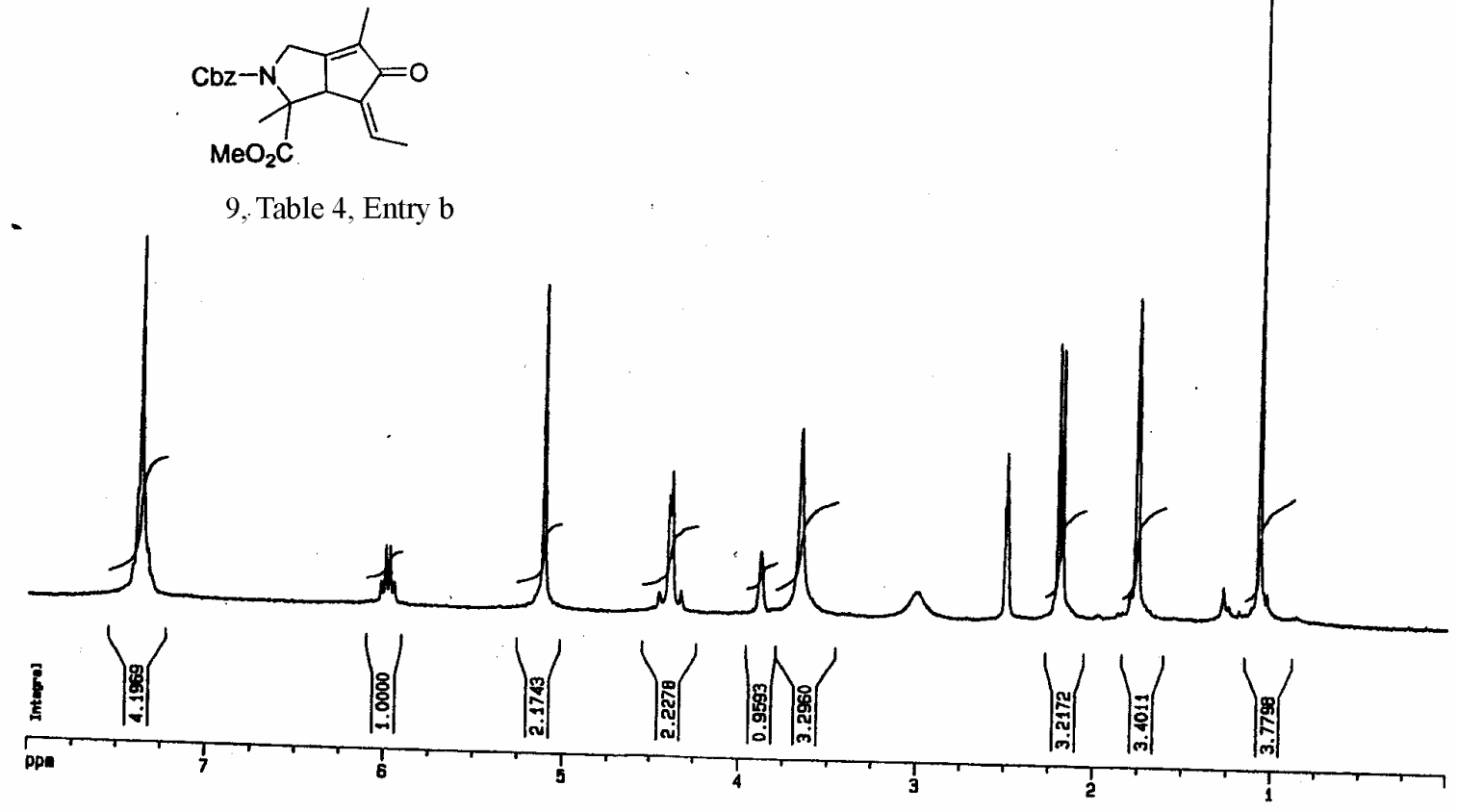

$\gamma$

2 bmohp1 dmso 353K $75 \mathrm{MHZ}$

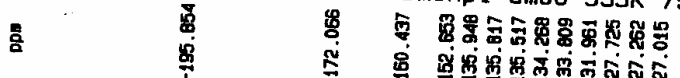

$\left.\left.\right|^{2}\right|^{2}$

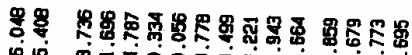

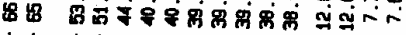

$V U V W V$

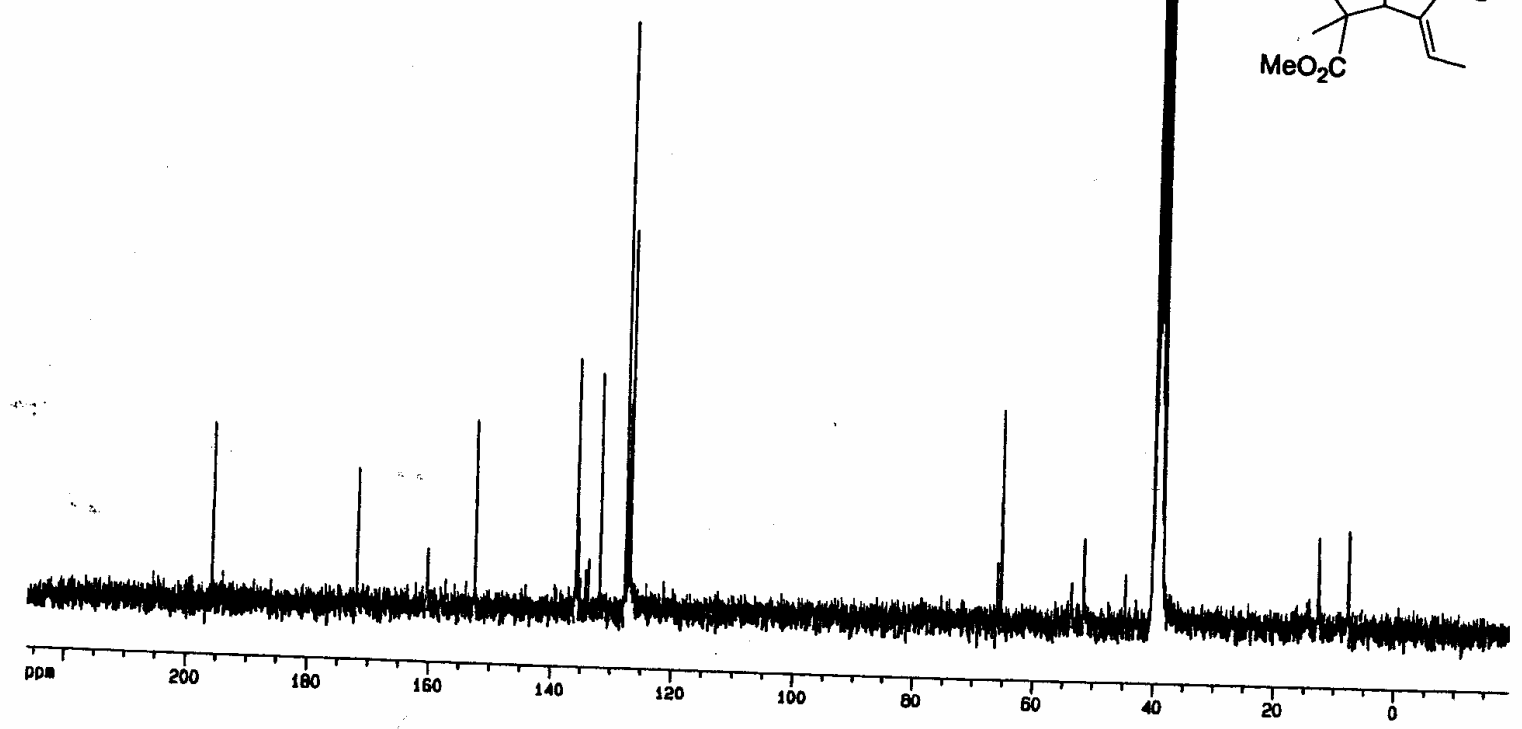




$$
\mathrm{Rf}=0.3(\mathrm{TLC} \text {, hexanes-EtOAc, } 3: 1 \mathrm{v} / \mathrm{v})[5,5] \text { major diastereomer }
$$
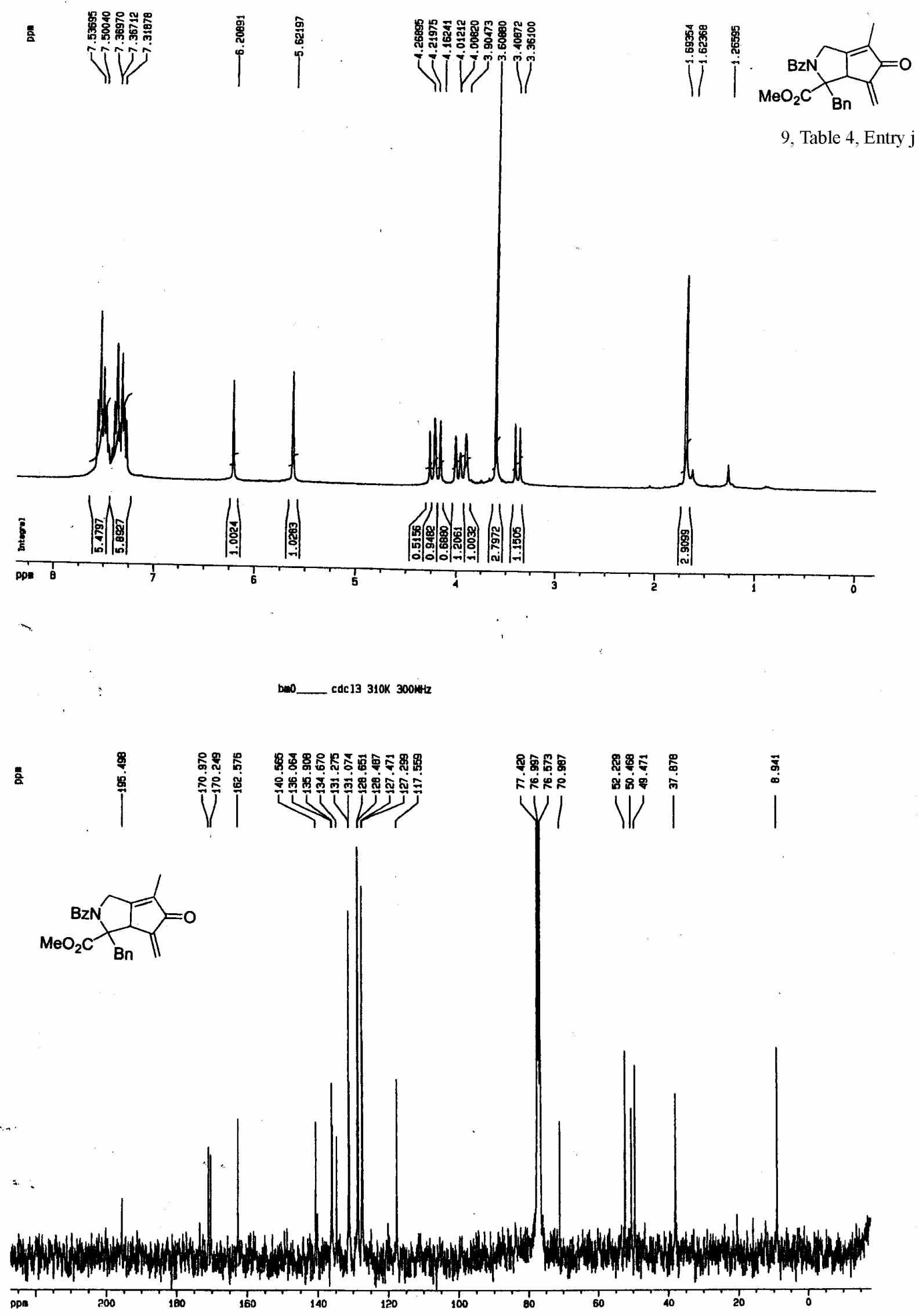

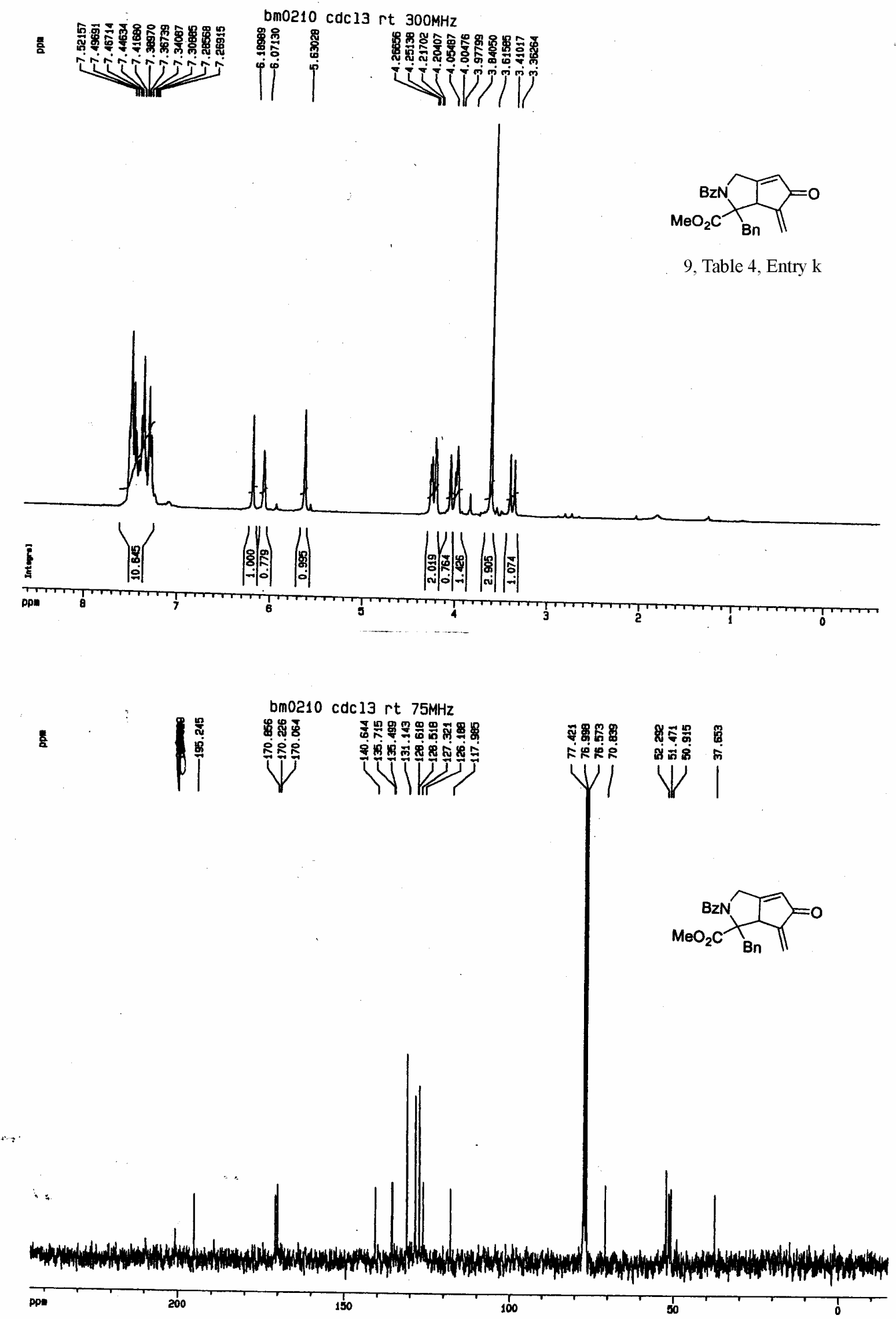

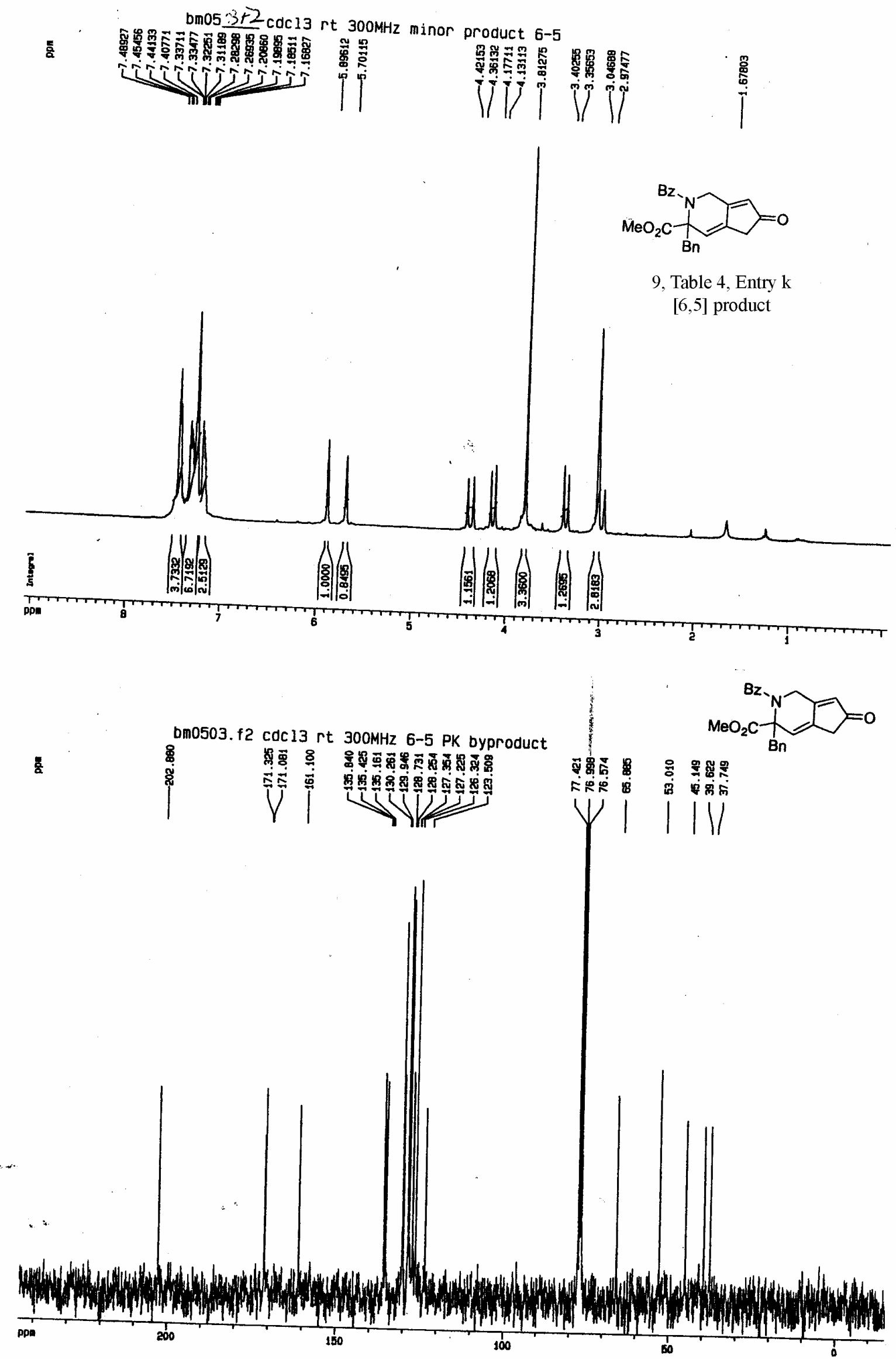


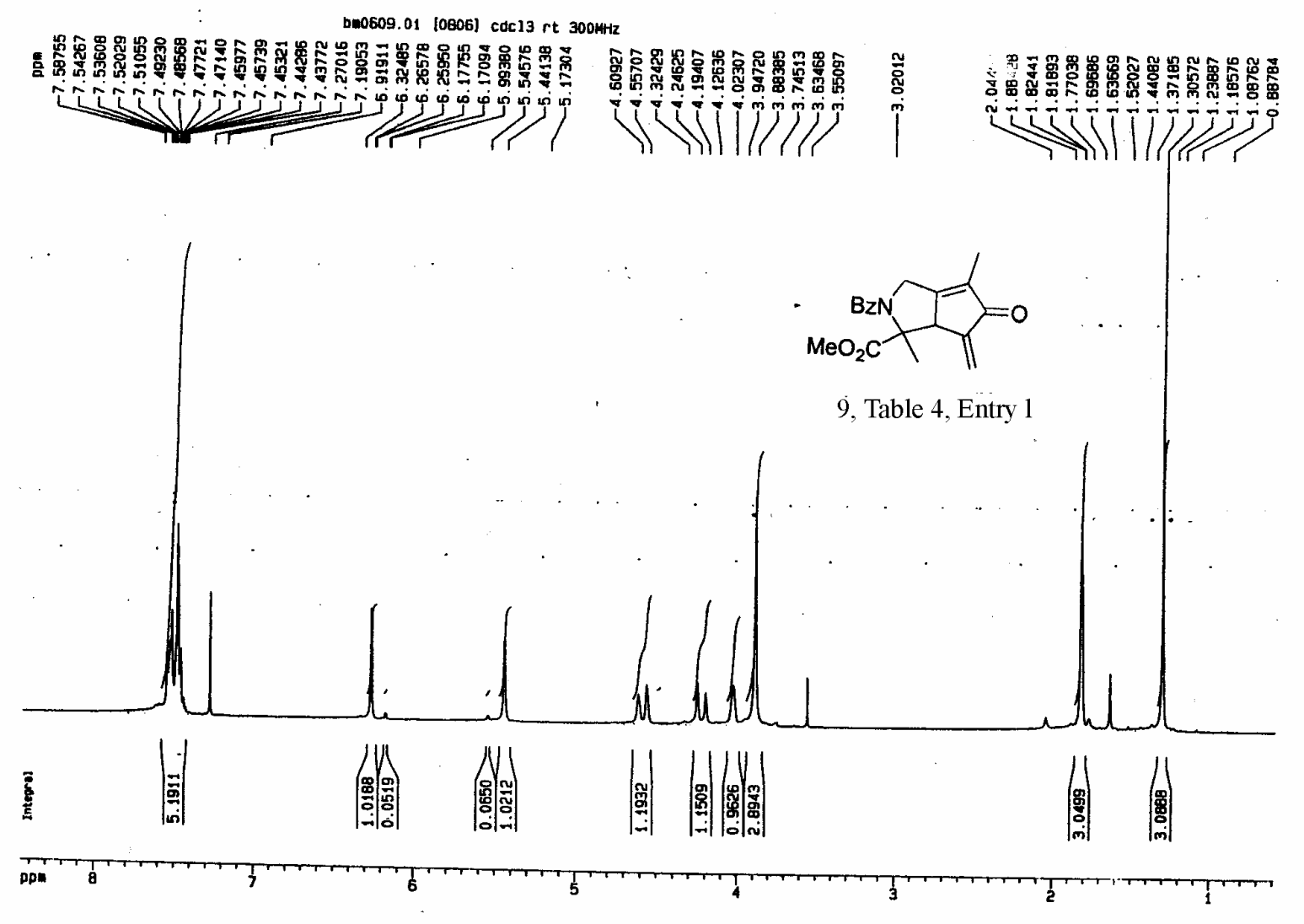

bm0609.01 (0706] cdc13 rt 75MHz

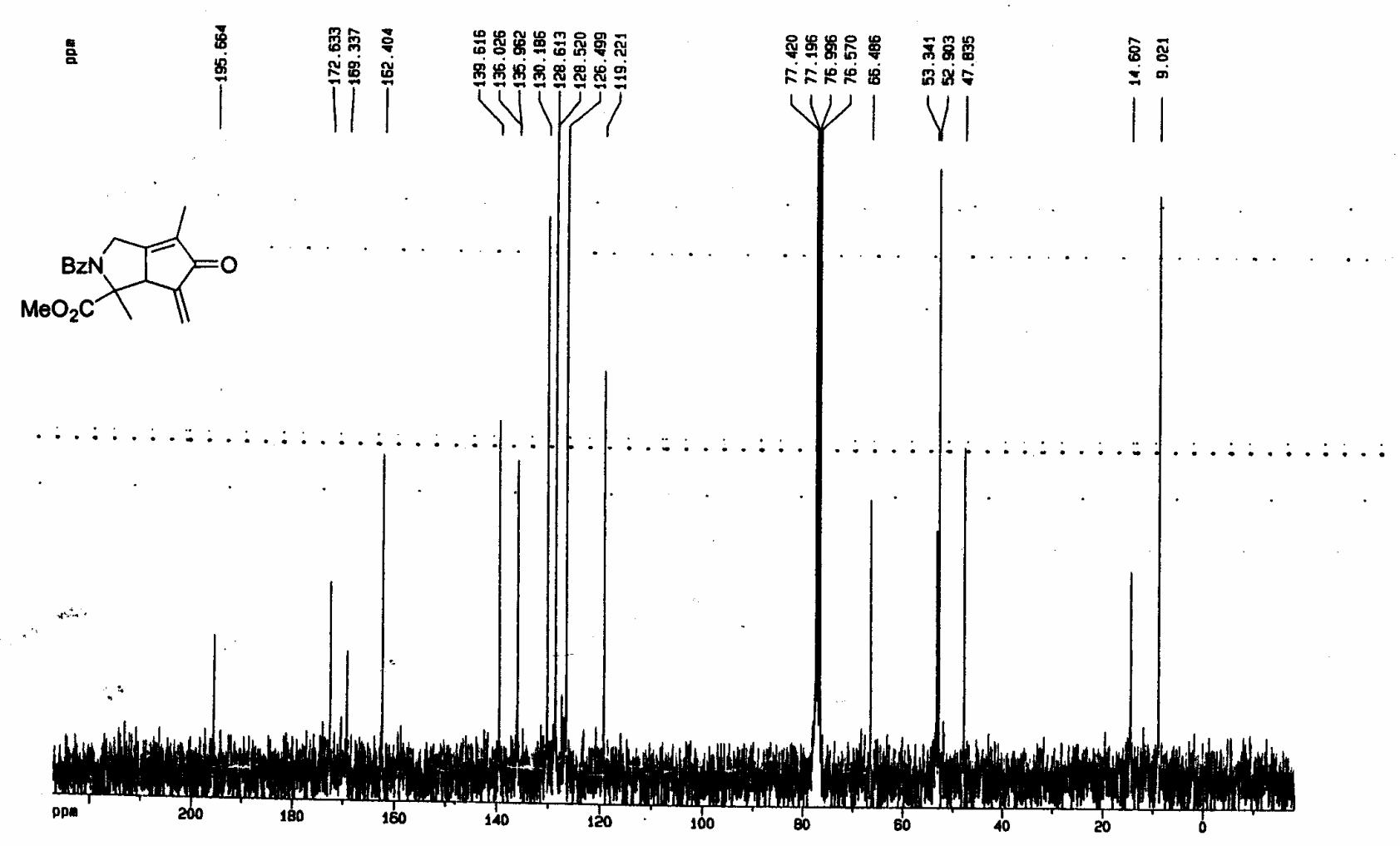




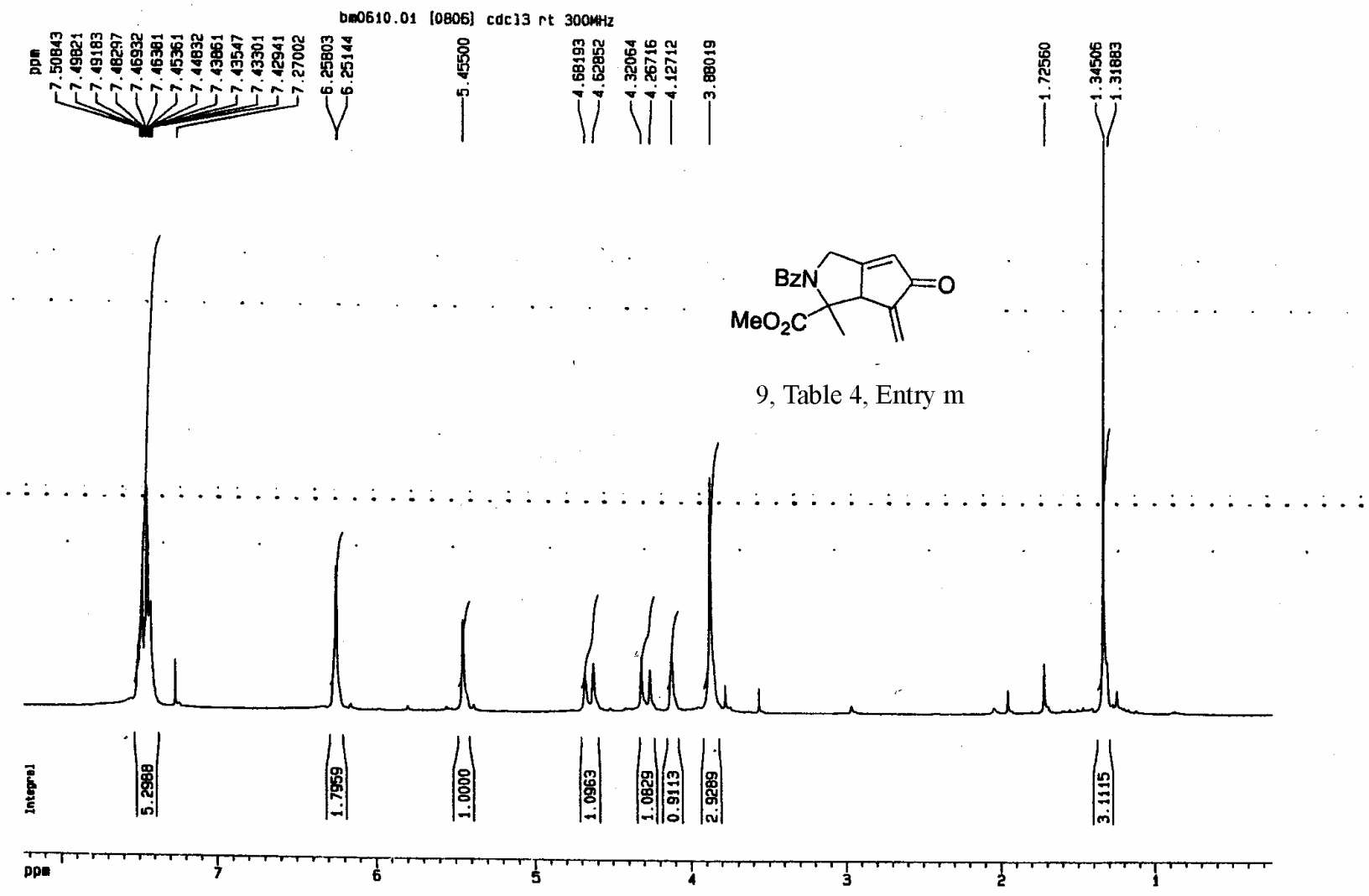

Dn0610.01 [0BO6] Cdc]3 rt 75NHz

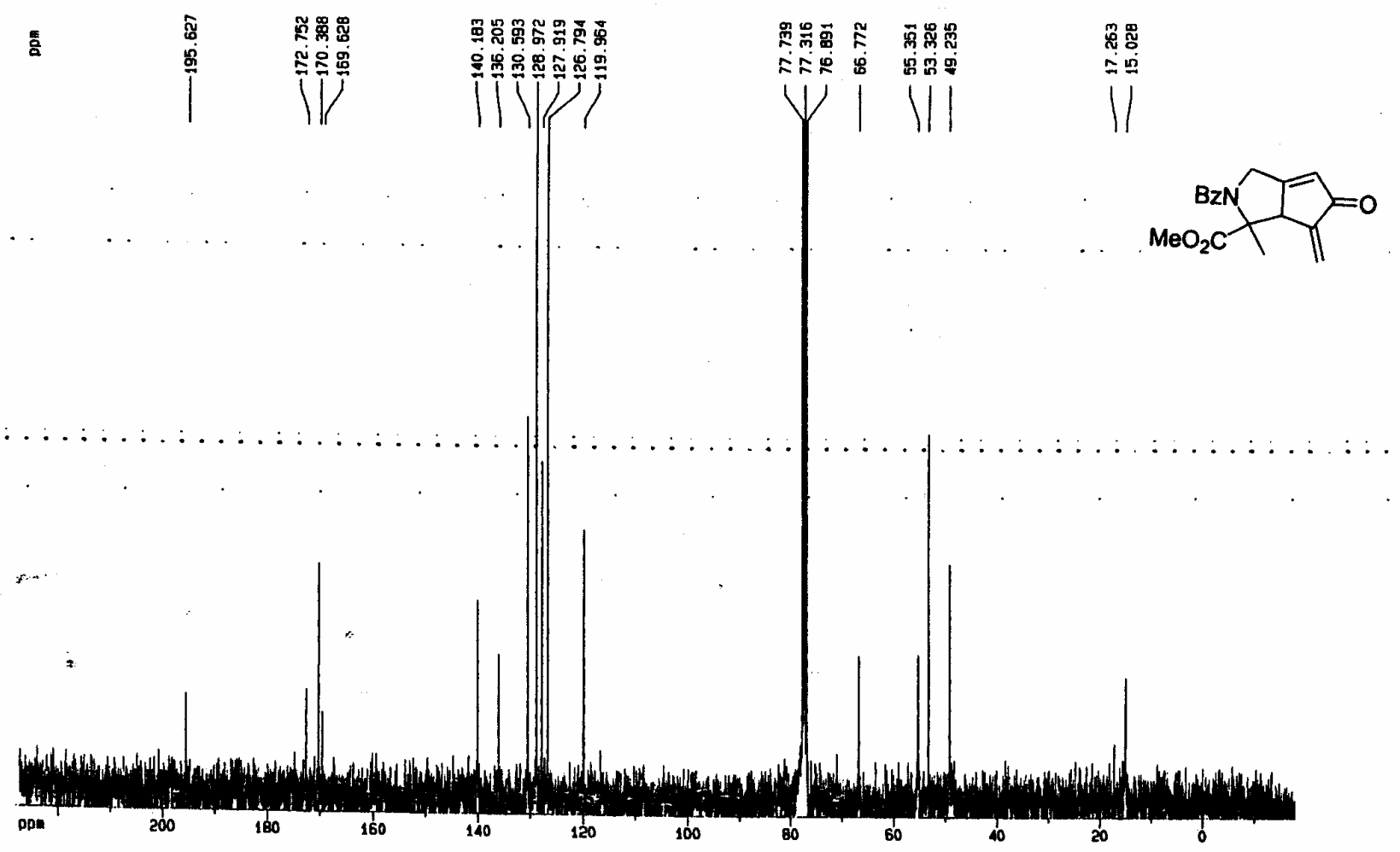


bm0610.01 major daso 363K 3001thz

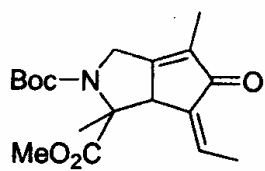

9, Table 4, Entry n

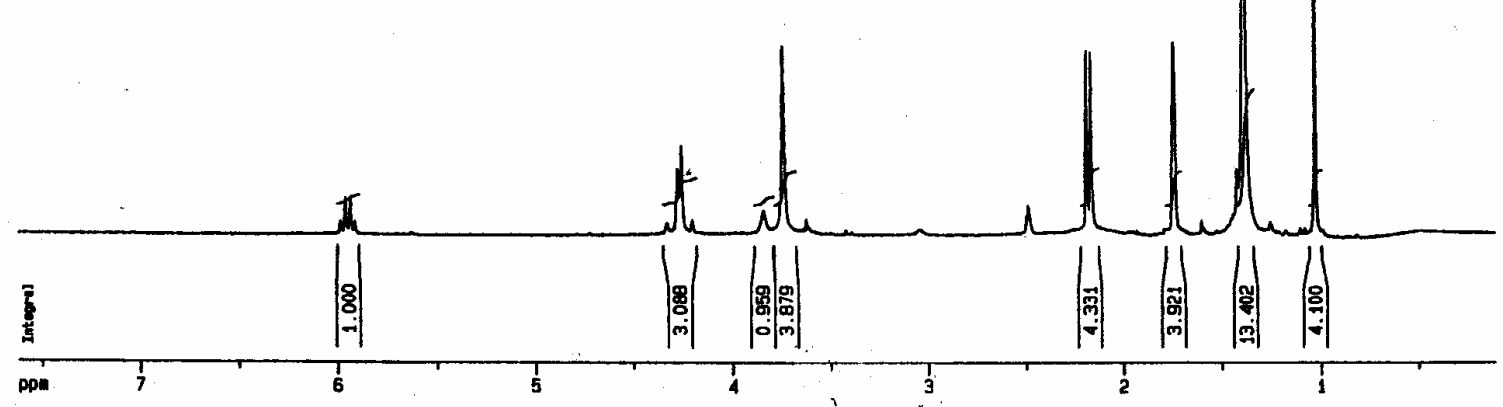

ban0619.major cdc13 rt 751412

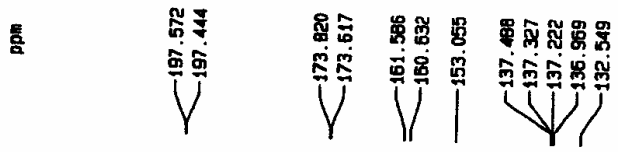

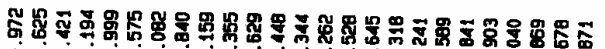

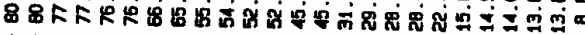

YY YWV IVIVH<smiles>C/C=C1\C(=O)C(C)=C2CN(C(C)=O)C(C)(C(C)=O)C21</smiles>

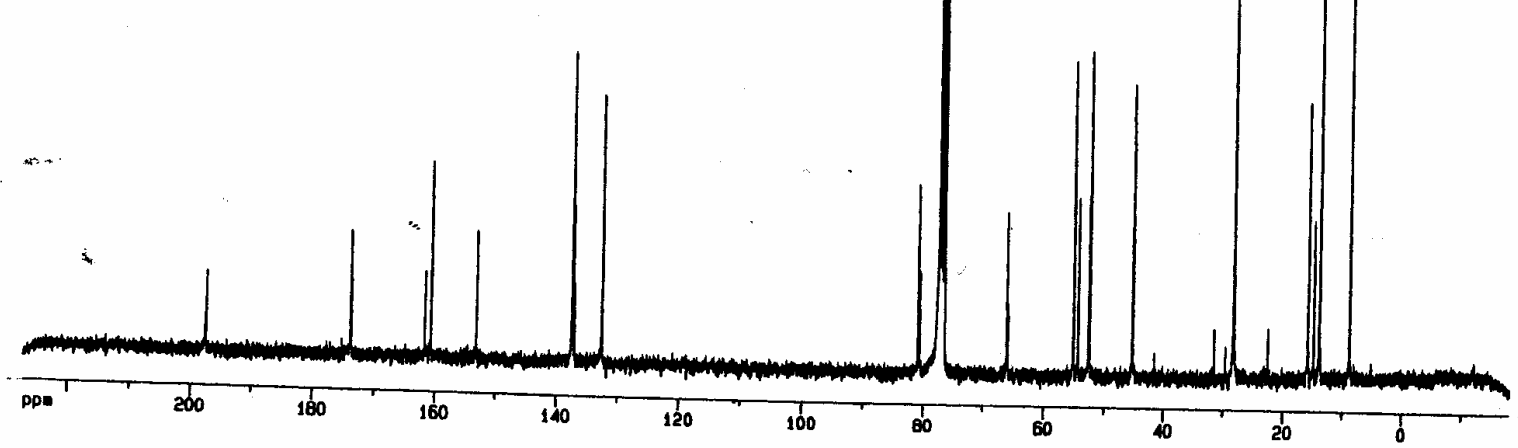

